UC-906

Issued: December 1990

LA- -12029

DE91 009227

Superconducting Super Collider

Silicon Tracking Subsystem

Research and Development

W. O. Miller

M. T. Gamble*

T. C. Thompson

H. J. Ziock

*Research Scienfist, Department of Materials Science and Engineering,

Massachussetts Institute of Technology, 77 Massachussetts Avenue, Cambridge, MA 02139.

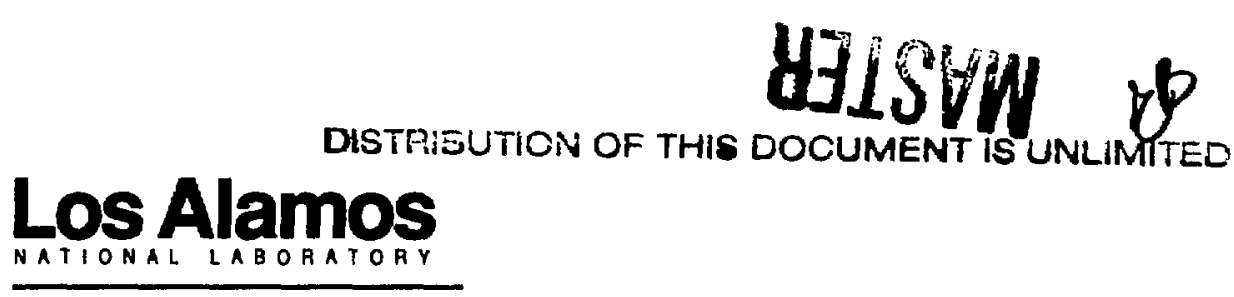

Los Namos, New Mexico 87545 


\section{Contents}

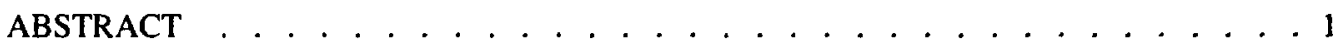

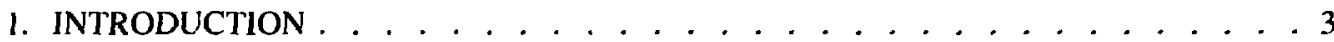

1.1. Scope . . . . . . . . . . . . . . . . . 3

1.2. Study Plan . . . . . . . . . . . . . . . . . . . . 3

1.2.1. Mechanical Design ................ . 3

1.2.2. Structural Analysis ... . . . . . . . . . . . . . 3

1.2.3. Cooling System Design . . . . . . . . . . . . . . . . . 6

1.3. Prototype Design, Fabrication, and Testing . . . . . . . . . . . . 6

2. EXECUTIVE SUMMARY .......................9

3. TECHNICAL DISCUSSION .................... I

3.1. Mechanical Design .. . . . . . . . . . . . . . . . . 11

3.1.1. Design Requirements .. . . . . . . . . . . . . . . . . . 11

3.1.2. Conceptual Design Approach . . . . . . . . . . . . . . . . . 11

3.1.2.1. Design Configuration . . . . . . . . . . . . . . 11

3.1.2.2. Materials Options . . . . . . . . . . . . . . . . . . 16

3.1.3. Design Activities . . . . . . . . . . . . . . . . . . . . . . 22

3.1.4. Detector Shape and Deformation Measurement . . . . . . . . . . . . 29

3.2. Radiation Length Considerations . . . . . . . . . . . . . . . . . . . . 33

3.2.1. Radiation Length Analytical Discussion . . . . . . . . . . . . . . . 33

3.2.1. Radiation Length Preliminary Results . . . . . . . . . . . . . . . 34

3.3. Structural Analysis and Materials Testing . . . . . . . . . . . . . . . . . 35

3.3.1. Development of Predictive Methods . . . . . . . . . . . . . . . . 35

3.3.1.1. Composite Sandwich Predictive Methods . . . . . . . . . . 36

3.3.1.2. Composite Tubing Predictive Methods . . . . . . . . . . . 36

3.3.2. Space Frame . . . . . . . . . . . . . . . . . . . . . . . . . . 37

3.3.3. Sandwich Panels . . . . . . . . . . . . . . . . . . . . . . . 42

3.3.3.1. Sandwich Panel Core Optimization . . . . . . . . . . . . 42

3.3.3.1. Beryllium Sandwich Panels . . . . . . . . . . . . . 48

3.3.4. Materials Testing . . . . . . . . . . . . . . . . . . 48

3.3.4.1. Physical Testing . . . . . . . . . . . . . . . . 48

3.3.4.2. Radiation Testing . . . . . . . . . . . . . . 48

3.4. Heat Pipe Cooling . . . . . . . . . . . . . . . . . 50

3.4.1. Working Fluid . . . . . . . . . . . . . . . . 51

3.4.2. Wafer Cooling . . . . . . . . . . . . . . . . 54

3.4.3. Wick Design . . . . . . . . . . . . . . . . . . . . . 55

3.4.4. Condenser Design . . . . . . . . . . . . . . . . . . . 59

3.4.4.1. Liquid Distribution Line Sizing . . . . . . . . . . 60

3.4.4.2. Liquid Line Connections . . . . . . . . . . . . . . . . . 61

3.4.4.3. Vapor Return Lines . . . . . . . . . . . . . . . . . . . 61

3.4.5. Startup, Thermal Control, and Shutdown . . . . . . . . . 65

3.4.5.1. Startup . . . . . . . . . . . . . . . . 65

3.4.5.2. Thermal Control System . . . . . . . . . . . 67

3.4.5.3. Shutdown . . . . . . . . . . . . 67

4. CONCLUSIONS AND FY 1991 PROGRAM PLAN . . . . . . . . . . . 69

ACKNOWLEDGMENTS . . . . . . . . . . . . . . . . . . 71

REFERENCES . . . . . . . . . . . . . . . . . . . . . 72 


\section{Figures}

1-1. Silicon tracking system task flow diagram for FY 1990 and FY 1991 . . . . . . . 4

I-2. Mechanical engineering program schedule for FY 1990 . . . . . . . . . . . . . 5

1-3. Estimated mechanical engineering program schedule for FY 1991 . . . . . . . . . 7

1-4. Silicon tracking system: full-scale, fully operational, and instrumented prototype . . . 8

3-1. Silicon tracking system silicon wafer arrangement . . . . . . . . . . . . 12

3-2. Baseline silicon tracking system arrangement layout . . . . . . . . . . . 13

3-3. Silicon sandwich sheli structure . . . . . . . . . . . . . . . . . . . . . . 14

3-4. Forward region typical planar silicon array . . . . . . . . . . . . . . . . 16

3-5. Permissible aggregate material thickness . . . . . . . . . . . . . . . . . . 17

3-6. Materials specific strength and tensile modulus comparison . . . . . . . . . . . 18

3-7. General relative radiation effects of magnet and other insulation materials . . . . 19

3-8. Unidirectional material properties . . . . . . . . . . . . . . . . . . . . . 20

3-9. Quasi-isotropic material properties . . . . . . . . . . . . . . . . . 21

3-10. CTE of various graphite composites as a function of volume fraction of graphite . . 23

3-11. Silicon tracking system concept evolution . . . . . . . . . . . . . . . . . . 24

3-12. FE and experimental deflections for silicon wafers . . . . . . . . . . . . 26

3-13. FE and experimental deflections for silicon sandwiches . . . . . . . . . . . . 27

3-14. Silicon wafer sandwich prototype . . . . . . . . . . . . . . . . 28

3-15. Metal matrix space frame . . . . . . . . . . . . . . . . . . . . . . 29

3-16. Detector prototype workfiow for measuring detector shape and deformations . . . 31

3-17. Conventional shape measurement concept . . . . . . . . . . . . . . . . . . 32

3-18. Speckle photography optical setup . . . . . . . . . . . . . . . . . . 32

3-19. Typical P100 graphite/aluminum 2-ply tube . . . . . . . . . . . . . . . . . 38

3-20. Space frame gravity-induced displacements . . . . . . . . . . . . . . . . 40

3-21. Metal matrix space frame (deformed configuration) . . . . . . . . . . . . 41

3-22. FE model of the full sandwich panel . . . . . . . . . . . . . . . . . . . . 43

3-23. Detailed FE model used to predict core shear modulus (pictorial and end views) . . 43

3-24. Four-point bend test schematic . . . . . . . . . . . . . . . . . . . . . . 44

3-25. Four-point bend test experimental setup . . . . . . . . . . . . . . . . . . 45

3-26. Numerical and experimental results of four-point bend test . . . . . . . . . . . 45

3-27. Shear molulus optimization expressed as a function of areal density . . . . . . . 46

3-28. Sandwich Panel geometry optimization expressed as a function of areal density . . 47

3-29. Sandwich Panel core optimization . . . . . . . . . . . . . . . . . . . . . 47

3-30. Permeability as a function of porosity for randomly packed $10 \mu$ m-radius spheres $\quad$. 57

3-3!. Minimum wick thickness as a function of pore radius for 3 vertical artery lengths . 58

3-32. Effect of porosity on minimum wick thickness . . . . . . . . . . . . . . 59

3-33. Shell and tube condenser design . . . . . . . . . . . . . . . . . . . 60

3-34. Primary liquid supply line pressure drop and volume as a function of line diameter . 62

3-35. Tee configuration for connecting the secondary liquid supply line to the artery . . . 62

3-36. Relationship bel. een vapor line diameter and length for a system . . . . . . . . 64

3-37. Pressure drop as a tunction of line diameter for a 25-m-long vapor return line . . . 64

3-38. Pressure drop as a funcision of diameter for two cooling rings . . . . . . . . . . 65

3-39. External fluid loop schemaic . . . . . . . . . . . . . . . . . . 66

4-1. Estimated mechanical engine ring program schedule for FY 1991 . . . . . . . . 70 


\section{Tables}

3-1. Baseline Design Requirements . . . . . . . . . . . . . . . . . . . 13

3-2. Selected Material Properties . . . . . . . . . . . . . . . . . . . . . . . 17

3-3. Graphite/Epoxy Composite Material Systems . . . . . . . . . . . . . . . . 19

3-4. Silicon Tracking System Materials Study . . . . . . . . . . . . . . . . . . 23

3-5. Radiation Length Calculations . . . . . . . . . . . . . . . . . . . . . . 35

3-6. Space Frame Structural Member Dimensions and Resulting Structural Mass . . . . 40

3-7. Graphite/Epoxy Tension Test Results, Before and After Hydrocarbon Soak . . . 49

3-8. Graphite/Epoxy Modulii and Poisson Ratio Analytical and Tension Test Results . . 49

3-9. List of Candidate Working Fluids, with Normal Boiling Points Near $0^{\circ} \mathrm{C}$. . . . . 52

3-10. Working Fluid Cost Comparison . . . . . . . . . . . . . . . . . . 53

3-11. Comparison of Candidate Working Fluids . . . . . . . . . . . . . . . . 53

3-12. List of Candidate Working Fluids . . . . . . . . . . . . . . . . . . . . . 53

3-13. Summary of Preliminary Shell and Tube Condenser Design . . . . . . . . . . 61 


\title{
Superconducting Super Collider Silicon Tracking Subsystem Research and Development
}

\author{
by \\ W. O. Miller, M. T. Gamble, T. C. Thompson, and H. J. Ziock
}

\begin{abstract}
The Los Alamos National Laboratory Mechanical Engineering and Electronics Division has been investigating silicon-based elementary particle tracking device technology as part of the Superconducting Super Collider-sponsored silicon subsystem collaboration. Struciural, materials, and thermal issues have been addressed. This paper explores detector structural integrity and stability, including detailed finite element models of the silicon wafer support and predictive methods used in designing with advanced composite materials. The current design comprises a magnesium metal matrix composite (MMC) truss space frame to provide a sparse support structure for the complex array of silicon detectors. This design satisfies the $25-\mu \mathrm{m}$ structural stability requirement in a 10-Mrad radiation environment. This stability is achieved without exceeding the stringent particle interaction constraints set at $2.5 \%$ of a radiation length. Materials studies have considered thermal expansion, elastic modulus, resistance to radiation and chemicals, and manufacturability of numerous candidate materials. Based on optimization of these parameters, the MMC space frame will possess a coefficient of thermal expansion (CTE) near zero to avoid thermally induced distortions, whereas the cooling rings, which support the silicon detectors and heat pipe network, will probably be constructed of a graphite/epoxy composite whose CTE is engineered to match that of silicon. Results from radiation, chemical, and static loading tests are compared with analytical predictions and discussed. Electronic thermal loading and its efficient dissipation using heat pipe cooling technology are discussed. Calculations and preliminary designs for a sprayed-on graphite wick structure are presented. A hydrocarbon such as butane appears to be a superior choice of heat pipe working fluid based on cooling, handling, and safety criteria. All of these aspects of the system are explored in detail.
\end{abstract}




\section{INTRODUCTION}

\subsection{SCOPE}

This report describes work accomplished during Fiscal Year (FY) 1990 and work planned for FY 1991 on the silicon tracking subsystem (STS), Fig. 1-1. The overall program goals are to prove the mechanical and cooling feasibility and to demonstrate a viable design, by means of analysis and prototype testing, for a silicon-based elementary particle tracking device. ${ }^{1-3}$ Particular attention is paid to the highly stable mechanical structure needed to support and cool all detector elements and related electronics. The design exploits the inherent physics advantages of silicon microstrip detectors by accommodating silicon wafer placement of extreme accuracy and stability.

\subsection{FISCAL YEAR 1990 ACCOMPLISHMENTS}

The accomplishments of FY 1990 included the resolution of five critical issues.

1. Completed an analysis and conceptual design of a low-mass support frame for the silicon detectors. Achieved 5- $\mu \mathrm{m}$-wafer positional stability with a completely passive system that requires no periodic adjustments.

2. Completed a space frame design and satisfied the maximum average radiation length restriction of $2.5 \%$. However, most of the detector is well below this limit, including the structure and the associated service connections.

3. Completed initial design, calculations, and specifications of a heat pipe cooling system for managing wafer electronics waste heat.

4. Tested material tensile and sandwich panel specimens for compatibility with radiation and chemical environments. Resolved manufacturability and alignment processes for these materials.

5. Perfected and applied methods for predicting material properties and mechanical stability.

The mechanical engineering program for FY 1990 focused on the following three areas of investigation, which are explored in detail: mechanical design, structural analysis, and cooling system development (Fig. 1-2).

\subsubsection{Mechanical Design}

The mechanical design study is separated into two tasks: conceptual design and preliminary design. In the conceptual design, various arrangements of the mechanical support structure were studied to minimize the mass in the particle path. A maximum $2.5 \%$ radiation length restriction, with most of the detector being well below this limit, has been imposed as a design goal for the subsystem materials, excluding the silicon wafer material. This requirement seriously restricts the choice of materials, basic structural arrangement, cooling system, electrical cabling, connections, etc. Most of our study emphasis has been on resolving these issues and providing a definition of the conceptual design approach.

The preliminary design phase addressed issues associated with strain-free mounting of the silicon, alignment of the various substructures, manufacturability, and material stability. Also, the structural loads used in our preliminary design calculations were updated and analyses were revised as these parameters were better defined.

\subsubsection{Structural Analysis}

The final mechanical support structure design for the silicon tracker may be composed of several different composite materials or, possibly, beryllium. In many instances, physical material data for proposed composite candidates are meager. Consequently. our structural analysis activities included provisions for predicting materials property data, the behavior of high-stiffness/weight 


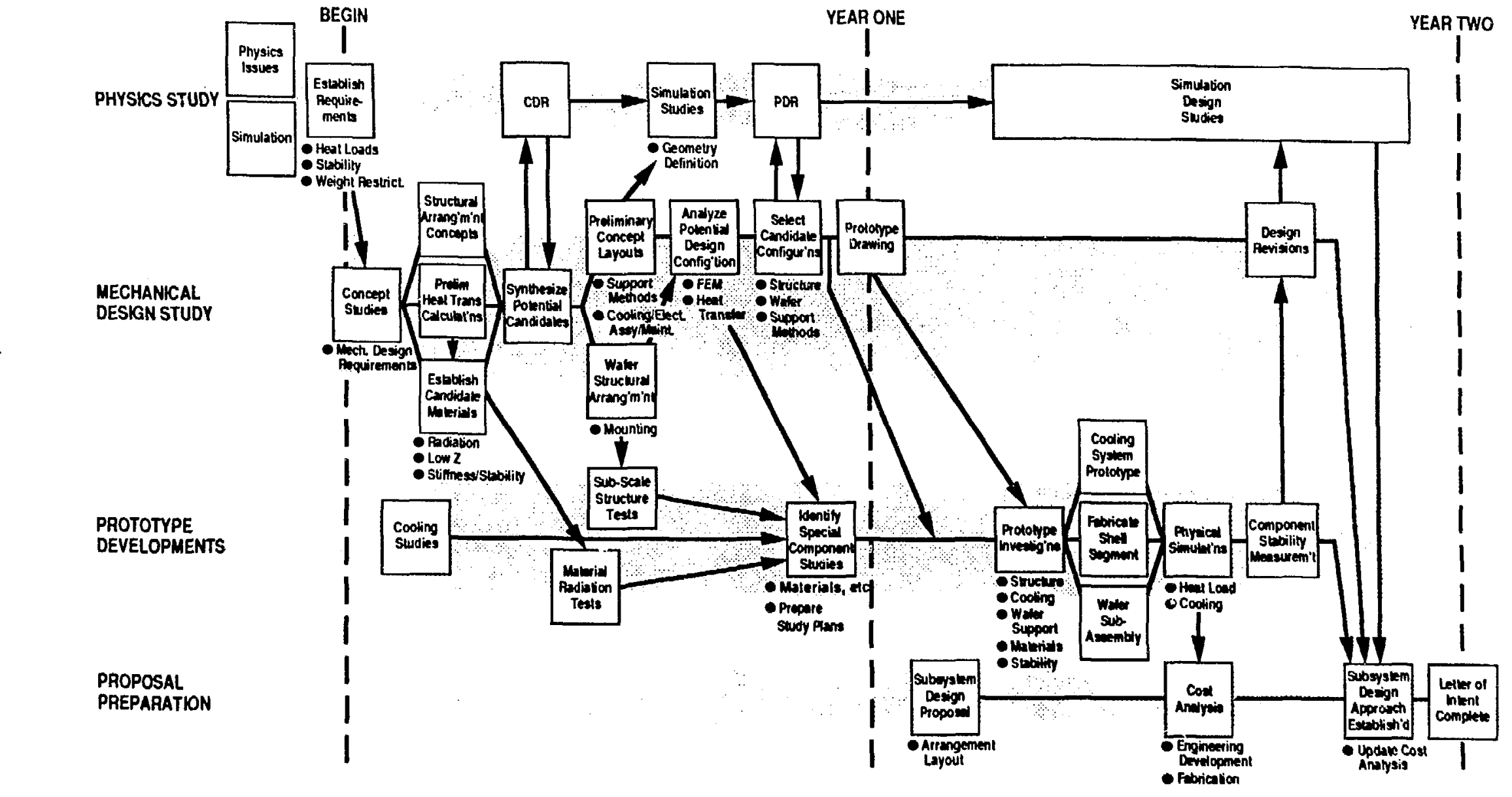

Figure 1-1. Silicon tracking system task flow diagram for FY 1990 and FY 1991. 


\section{Mechanical Design}

Initiate configuration studies

Subsystem conceptual design

Candidate STS selection complete

Conceptual design review complete

Initiate preliminary design study

Design layout complete

Preliminary design review

cuinitiplete

Phase I of project complete

\section{Structural Analysis}

Initiate radiation length study

Initiate structural analysis

Structural analysis complete

\section{Cooling System Development}

Initiate cooling system study

Preliminary thermal analysis complete

Initiate heat pipe system integration

System thermal performance prediction complete

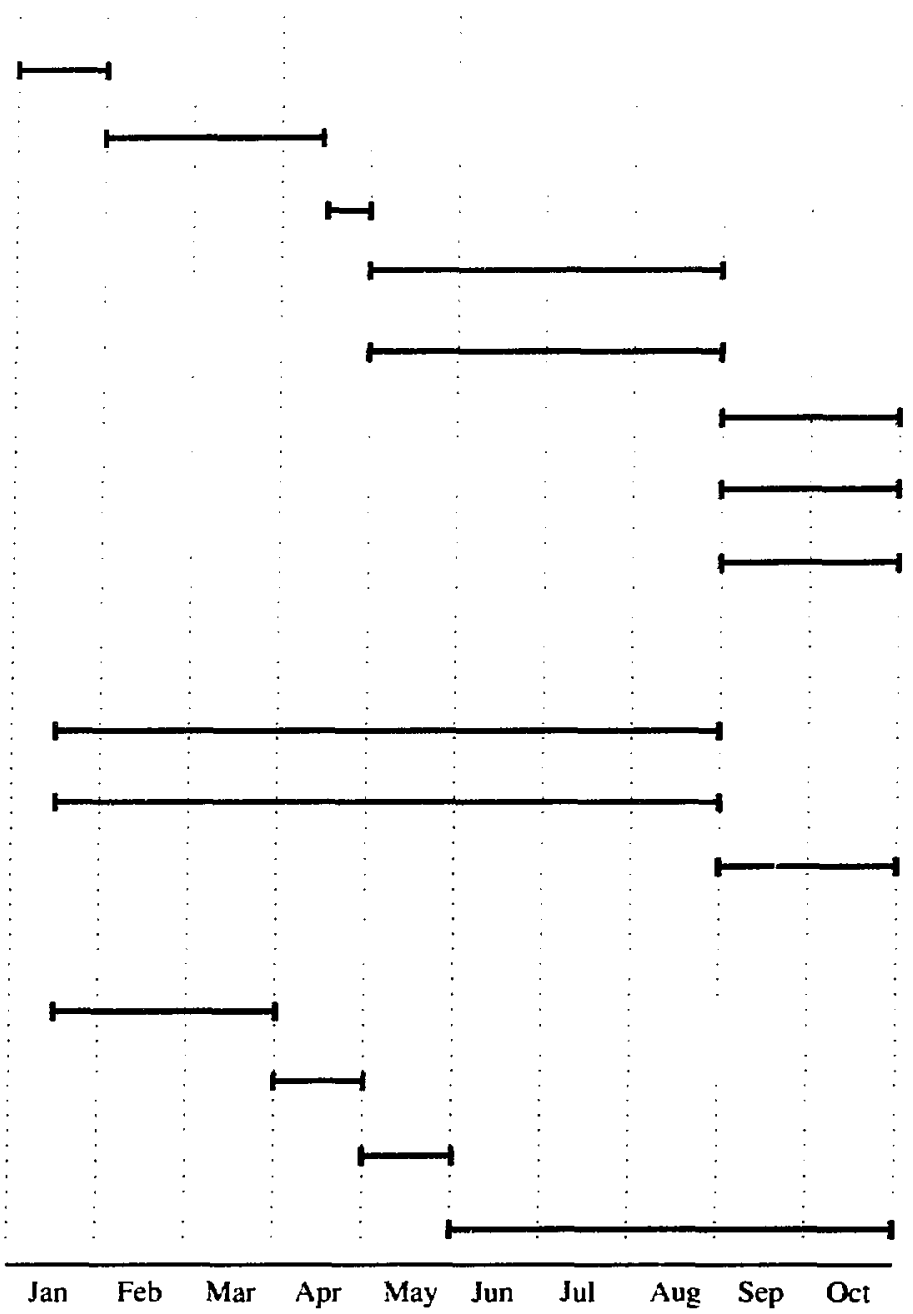

Figure 1-2. Mechanical engineering program schedule for FY 1990.

sandwich structures made from these materials, and, finally, the properties of complex constructions made from sandwich assemblies. These predictive techniques will be validated by conducting material and structural tests.

Construction materials that were chosen to satisfy the radiation length requirement have been reviewed, and available engineering property data have been assimilated. Materials of current interest are

- aluminum or magnesium metal matrix composite,

- graphite/epoxy composite, and

- beryllium.

Each material offers certain distinct advantages, such as ease of fabrication, a desirable coefficient of thermal expansion, or a large effective radiation length. As the design study progressed, each candidate material's performance was evaluated to achieve the best combination of overall attributes. 


\subsubsection{Cooling System Design}

Early studies demonstrated that air convective cooling would be insufficient to maintain the system at the design operating temperature, in the presence of the anticipated heal flux, without introducing undesirable thermal gradients. Therefore, an evaporative heat pipe cooling system concept was initiated.

The heat pipe concept underwent a conceptual definition, and several possible working fluid candidates were selected. Wick materials that are consistent with the materials chosen for the structures are being investigated experimentally. During the conceptual design phase. the analysis tasks included wick sizing, facets of wafer cooling, heat pipe condenser design. and system operation.

\subsection{PROTOTYPE DESIGN, FABRICATION, AND TESTING DURING FY 1991}

The mechanical engineering program for FY 1991 (Fig. 1-3) will focus on producing prototypes with the intent to prove the feasibility and viability of material selections, cooling schemes, and structural designs developed during FY 1990. Accomplishing these goals will require the fabrication of a full-scale subsection of the barrel region of the detector, as shown in Fig. 1-4. This 54-cm-diam replica is composed of approximately 1200 silicon wafers arranged as two superlayers and connected by polymeric matrix composite material cooling rings with associated heat pipe cooling. The two silicon superlayers will be supported by a low coefficient of thermal expansion (CTE) graphite/epoxy sandwich shell structure and a zero CTE metal matrix space frame. This combination will provide an opportunity to investigate all of the mechanical and structural effects anticipated in a full-scale silicon tracking system. It will be fully equipped with electronics-equivalent resistive heat loading to simulate thermal conditions of the operating silicon detector system. An interferometric measurement system will detect minute motions of the silicon detectors. The performance of the metal matrix composite space frame and fully operational heat pipe cooling system can be inferred from such measurements.

Critical issues that will be resolved by these tests include

- cooling ring construction and wick development and their optimization,

- materials characteristics and stability,

- selectively enhanced polymeric and metal matrix composite engineering properties, such as CTE and elastic modulus,

- silicon module stability under electrical load simulation, and

- material and component radiation and chemical exposure compatibility.

Design and analysis activities will be performed as needed to support these tests. 
Task

Prototype Module

Design/Analysis

STS system layout/updates

Prototype cooling ring/ wick test setup

System analysis

Module protoype drawings

Optical instrument alignment verifification study

Space frame design drawings

\section{Fabrication}

Silicon wafers

Prototype cooling rings

Optical instrumentation

Prototype module

Central region space frame

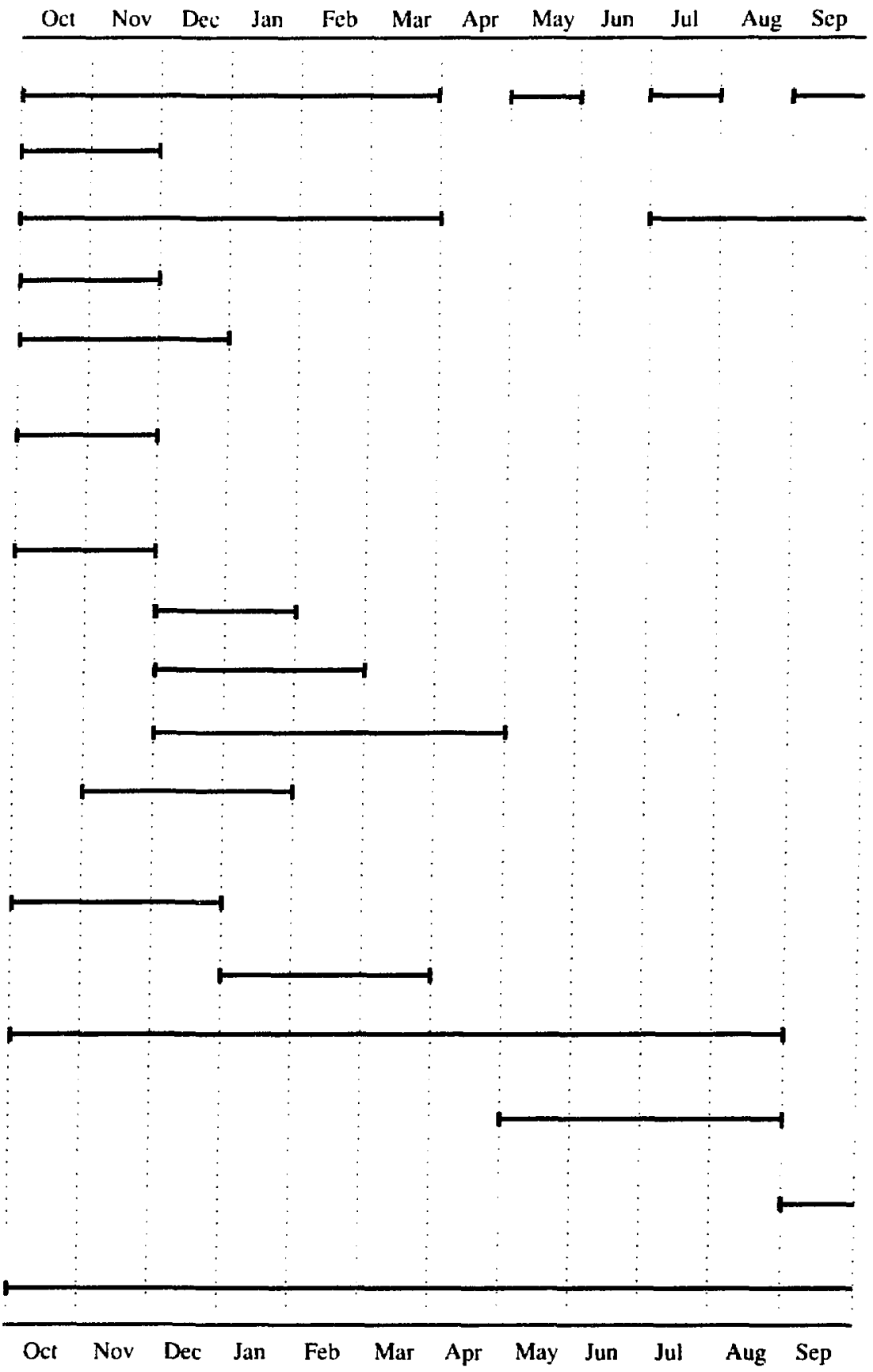

Project Support

\section{Testing}

Wick development

Cooling ring/ wick integration

Material stability and component radiation

Module stability

Test evaluation and repon preparation

and




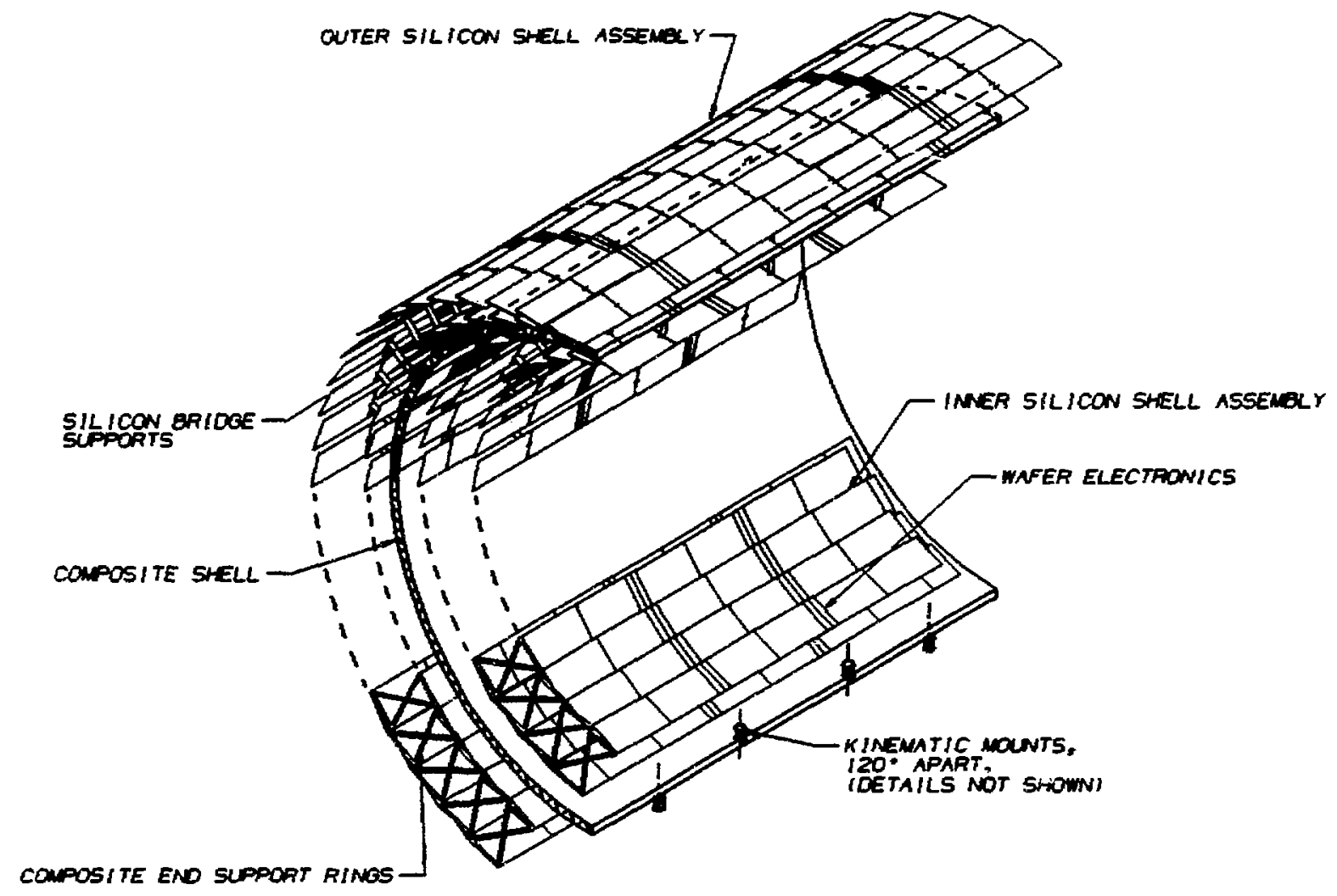

Figure 1-4. Silicon tracking system: full-scale, fully operational, and instrumented prototype (cutaway view). 


\section{EXECUTIVE SUMMARY}

The silicon tracking system resoarch and development effort addresses the many mechanical engineering issues facing the successful deployment of a precision silicon-based elementary particle tracking device. At this interim stage of the mechanical design study, the central issues that have been addressed are the

- conceptual system design approach,

- radiation length calculations,

- material candidates selection,

- material specimen testing initiation,

- critical systems structural analysis,

- alignment concepts for verifying wafer position,

- cabling concepts for data transmission and electronic circuit power, and

- cooling system design for the individual wafer electronic circuits.

The significant progress in these areas has made possible extensive prototype testing that wi $i_{1}$ culminate in the verification of the feasibility of a silicon tracking device and a viable design for such a system during FY 1991.

The current design comprises a metal matrix truss space frame that serves as a very sparse support structure for the complex array of silicon super layers, while effectively satisfying the structural integrity requirements in a 10-Mrad radiation environment without exceeding the stringent radiation length limits. The framework draws upon material technologies being developed for the National Aerospace Plane (NASP) and Strategic Defense Initiative (SDI) programs. The silicon superlayers are formed into silicon sandwich-like constructions which are combined in cylindrical silicon shell configurations for the central region and flat panel arrays for the forward region. The cooling rings supporting the silicon also serve as an effective means of incorporating a heat pipe network. The use of heat pipe technology is another innovative use of advanced technology for achieving the stringent stability requirements demanded of the silicon tracking system. Major advances in the following areas are expected to occur when these requirements are met:

- application of metal matrix composites,

- sucessful development of silicon sandwich, shell structures, and silicon planar array,

- implementation of heat pipe cooling technology for isothermal stabilization of the structure and silicon, and

- innovative use of fiber optics for rapid data transmission.

Considerable progress has been made during FY 1990. The development of a full-scale prototype, as discussed in the introduction, will ensure that all materials and structural and heat pipe cooling issues are resolved by the end of FY 1991. Failure to construct and test a prototype sufficiently representative of the operational silicon tracker during, FY 1991, would result in an unproven design for this critical subsystem. A potentially faulty design would jeopardize our ability to achieve the position and momentum measurement accuracies of which the detector is inherently capable.

The construction and resting of the planned prototype during FY 1991, as summarized in Sec. 4, will ensure that this research and development effort demonstrates the feasibility of a silicon-based tracking device and solidifies a design, based upon proven concepts, for such a system. 


\section{TECHNICAL DISCUSSION}

\subsection{MECHANICAL DESIGN}

\subsubsection{Design Requirements}

The silicon tracking subsystem is composed of an array of silicon wafers arranged both in a cylindrical and a flat panel array about the particle beam interaction point. The cylindrical array is referred to as the central region and the flat panel arrays, which are normal to the beam axis, are referred to as the forward regions. Figure 3-1 depicts the location of the individual layers of silicon without any structural support. The method being considered for supporting the individual silicon layers combines adjacent layers into superlayers. Two such layers can be supported separately or as a pair. This provision offers the potential for minimizing the structural material and, hence, for maximizing the effective radiation length.

Simulation studies have lead to a general definition of a typical geometry and to a number of individual silicon layers in the forward and central regions. The basic features of the silicon tracking support system chosen for this study are sufficiently generic to span the anticipated engineering problems existent in a central tracker. The present effort is based on the general specifications outlined herein.

In the central region, it is possible to support adjacent superlayers with a common structure because the number of layers in each region is even and the distance separating the individual layers is about $3 \mathrm{~cm}$. This feature is not always possible in the forward region because the separation between silicon layers increases significantly.

It is important to realize that the design approach for a silicon tracking subsystem structure and the integrated cooling system may depend on the ultimate silicon wafer electronics technology chosen. Conventional long-strip silicon technology requires fast electronics that drive up the power dissipation requirements and the heat fux. In contrast, short-strip silicon technology distributes the electronics heat loading and eliminates the need for double-sided strips. Furthermore, $\mathbf{t}_{\mathrm{e}}$ overall heat load for short-strip technology could be lowered to approximately $2 \mathrm{~kW}$, as opposed to $40 \mathrm{~kW}$ for long-strip technology. Consequently, various aspects of the design may be intimately tied to wafer technology, i.e., long strips, vs shor strips, or, alternatively, to monolithic integre' $:$ on of the electronics with the silicon. Monolithic integration eliminates wire bonding and offers the potential for simplification of the overall packaging. It is not currently possible to develop and discuss individual design concepts that satisfy this full spectrum of wafer technology. As a starting point, specific design criteria were chosen for the silicon tracking subsystem generic study. These criteria are listed in Table 3-1. The long-strip technology was selected for this study. Advances in silicon-wafer technology might afford opportunities to improve on the silicon tracking subsystem design. We hope to identify potential improvements as our study progresses.

\subsubsection{Conceptual Design Approach}

The STS baseline design is shown in Fig. 3-2. The overall length is $6.2 \mathrm{~m}$, and the outer diameter, including the shell enclosure, is approximately $1.4 \mathrm{~m}$, yet our design requirements are comparable to the stringent constraints currently placed upon much smaller vertex detectors. ${ }^{4-6}$ The silicon wafers are edge-bonded into long strips. Strip length will be optimized to yield a maximum number of similar individual wafers.

3.1.2.1 Design Configuration. For the present study, we have selected $36 \mathrm{~cm}$ as the maximum design strip length. Electronics for powering the strips are mounted at each end of the edge-bonded strips. Two 36-cm-long bonded silicon layers are joined together to form a sandwichlike structure, as shown in Fig. 3-3. A maximum active strip length of $18 \mathrm{~cm}$ is expected. The silicon layer is supported at discrete points between the end supports to preclude excessive sag. As shown. both ends of silicon layers are bonded to rings. The rings, in addition to providing 

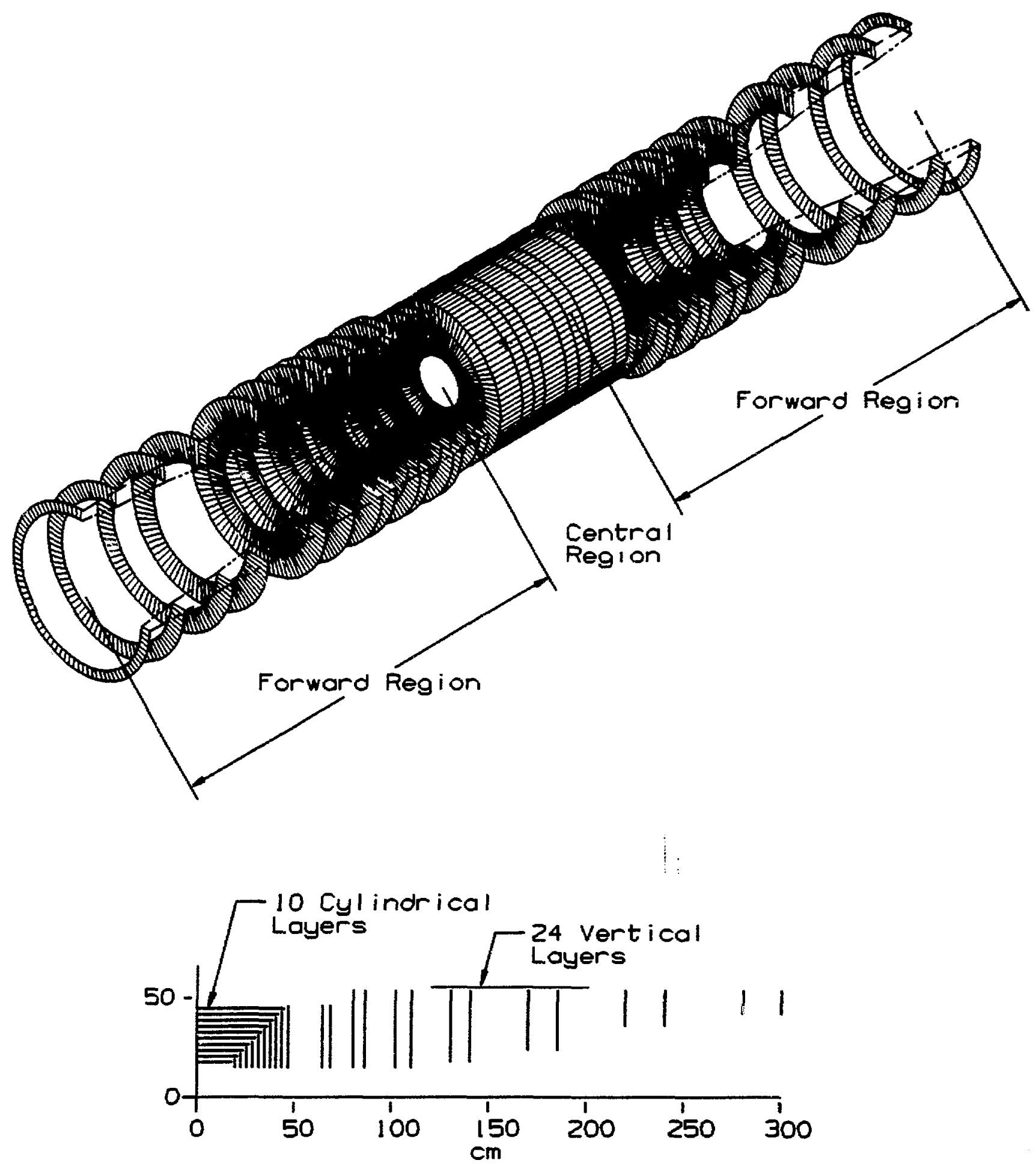

(1/4 Section)

Figure 3-1. Silicon tracking system wafer arrangement. 
TABLE 3-1. Baseline Design Requirements

Detector characteristics

Detector assembly

Detector heat load

Radiation exposure

Material radiation length budget
Silicon, long-strip technology 50- $\mu \mathrm{m}$ pitch, double-sided

Electronics surface area, $3.52 \times 0.6 \mathrm{~cm}^{2}$

Maximum length, $3 \times 36 \mathrm{~cm}$ (six wafers, edge-bonded)

Mounting precision

$\mathrm{R}, \varphi, \mathbf{Z}-25 \mu \mathrm{m}$

Angular, 1 milliradian

Positional stability

$\mathrm{R}, \phi, \mathrm{Z}-5 \mu \mathrm{m}$

Angular, 0.2 milliradian

Detector cant angle, $11^{\circ}$

Operational temperature, $0^{\circ} \mathrm{C}$

Heat flux, $1.8 \mathrm{~W} / \mathrm{cm}^{2}$

40-kW total

10 Mrad over 10-year service life

No measureable stability effects $>5 \mu \mathrm{m}$

Structure and related service connections

$2.5 \%$ (except in limited regions e.g., transition from centrai to forward)

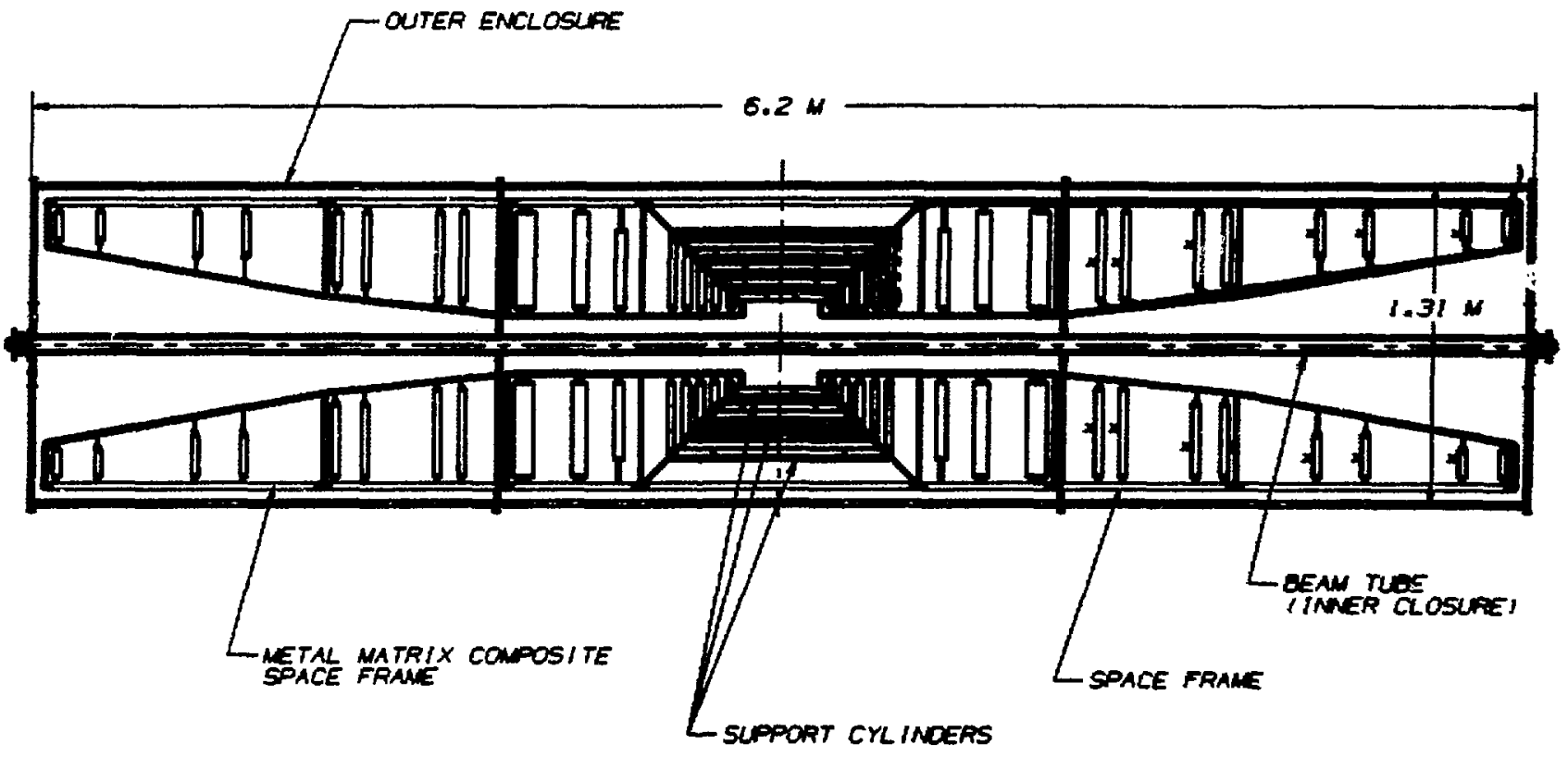

Figure 3-2. Baseline silicon tracking system arrangement layout. 


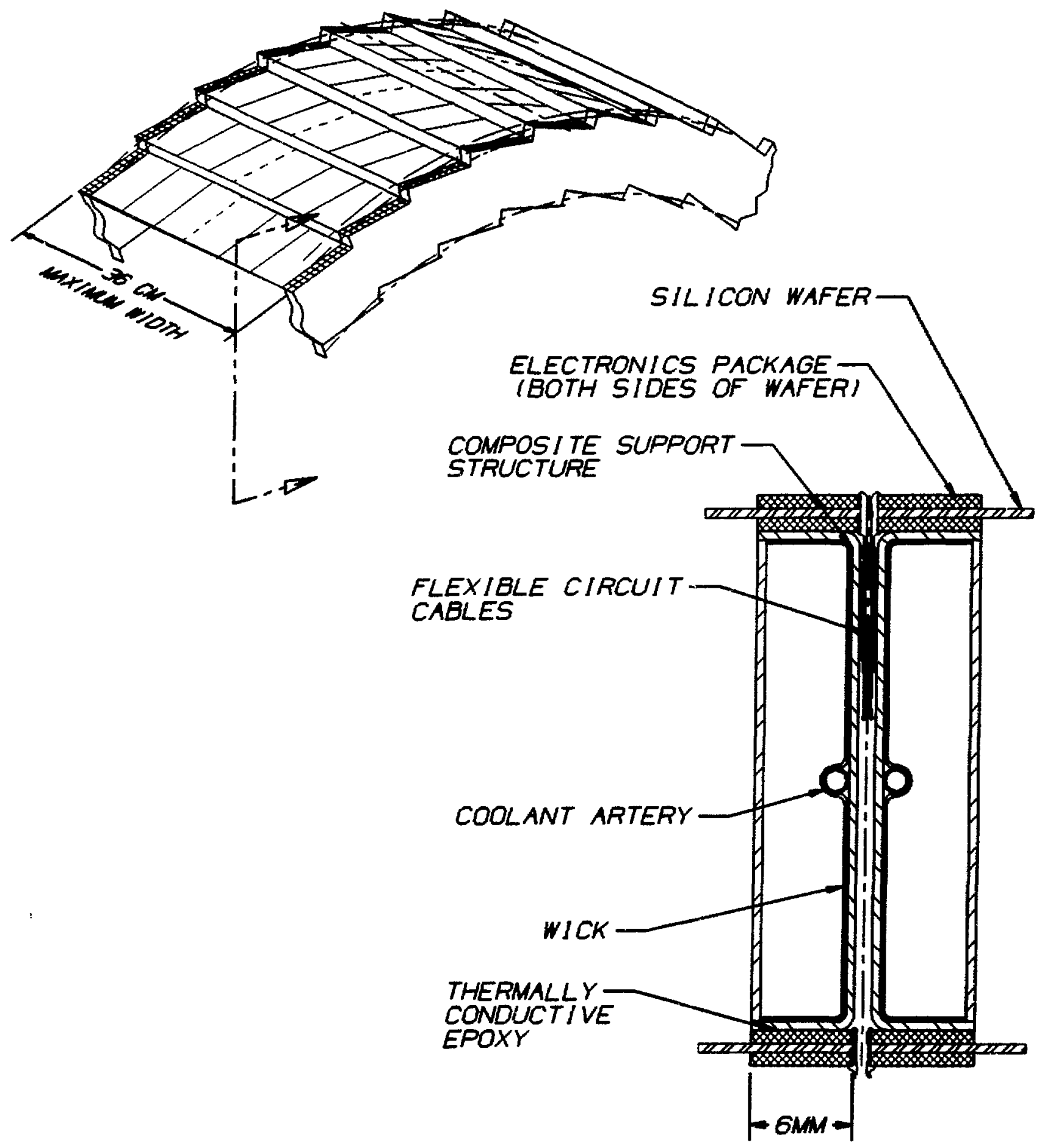

Figure 3-3. Silicon sandwich shell structure. 
structural support, provide a passage for an internal heat pipe artery. Working fluid is wicied to an area directly beneath the electronics package, as shown in Fig. 3-3. Heat flows through this thin-walled area and evaporates the cooling medium, as described in Sec. 3.4. This technique greatly siniplifies the process of cooling the enormous number of individual wafers. The 1.8 $\mathrm{W} / \mathrm{cm}^{2}$ heat flux associated with the wafer electronics package can be handled effectively with a minimum temperature gradient by minimizing the conductive path. Distortions in the silicon-shel] substructure are avoided by minimizing the thermal gradient and by choosing the appropriate material for the cooling ring. Because the silicon subassembly will be operated at temperatures well below room temperature, coefficients of thermal expansion (CTE) for materials composing this assembiy must be carefully selected and tailored to match that of silicon. This will eliminate undesirable distortion.

The long-strip wafer technology imposes a significant design heat load; a maximum value of $40 \mathrm{~kW}$ has been chosen as this design value. The heat load is highly localized. Helium cooling, which was considered as an alternative, is simple in concept but cannot equilibrate the silicon tracking subsystem adequately to avoid excessive thermal gradients and, hence, physical distortions. As stated above, our design goal is to optimize the placement of heat pipes, and thereafter, minimize the pressure drop in the vapor return path to the condenser. As long as the vapor space around the various detector elements is at a constant pressure and the pressure loss in individual vapor return lines for all silicon modules are equal, the structure will thermally equilibrate. Our design goal for structural temperature uniformity is $0.25^{\circ} \mathrm{C}$.

The silicon modules are mounted onto the support structure of the silicon detector central region. These modules are supported on kinematic supports to avoid introducing distortions. Consideration is being given to using a shell support structure material, such as graphite/epoxy or a metal matrix composite that can be engineered to exhibit a zero CTE. Factors that enter into the final selection process are discussed in Sec. 3.1.2.2.

Silicon-layer sandwich substructures are also proposed for the forward detector regions. In this instance, the structures are pie-shaped to fit as individual arc sectors. Figure 3-4 shows these pie segments. The technique envisioned for cooling the silicon-wafer module electronics would be as previously discussed. Cooling rings, which support pie-shaped silicon layers, must track the contraction of silicon, or they will introduce the possibility of distortion. Calculations show that in the central region, the CTE of the cooling ring must also match the CTE of silicon to avoid wafer distortion. Options for achieving the desired CTE equality include tailoring the expansivity of a graphite/metal matrix composite or using a graphite/epoxy composite to match that of silicon. Prototypes of the envisioned ring construction techniques are being produced in this study phase.

The central and forward detector regions mus! be supported by a frame network that is highly dimensionally stable throughout the life of the detector. Problems that must be considered are thermal distortion, physical property changes caused by radiation effects and/or chemical attack from the heat pipe working fluid, and creep. In addition, radiation length restrictions must be considered in formulating the design approach. In the initial concept, an open, lightweight space-frame structure was chosen for a baseline design. This was done specifically to maximize the effective radiation length. The space-frame network would be assembled in subsections, to provide a natural jigging fixture, when assembling the silicon modules. The present plan would be to assemble the central detector region first, then add the adjacent forward regions. The central unit would compose roughly half of the detector length. It would be possible to support this assembly inside the external shell structure on the support points that will later become the nominal quarter points for the entire assembly. The outboard forward regions would be cantilevered off the first assembly. The actual support locations will be set after determining the distribution of mass in the longitudinal direction for the entire assembly.

The entire silicon tracking subsystem must be enclosed in a pressure vessel capable of withstanding up to two atmospheres of differential pressure. Kinematic supports will be used to mechanically isolate the silicon tracking subsystem from the shell external pressure load. Overly constraining, nonkinematic, rigid supports between the shell and the uitralightweight silicon detector support structure would cause severe localized distortions and unpredictable movement. 


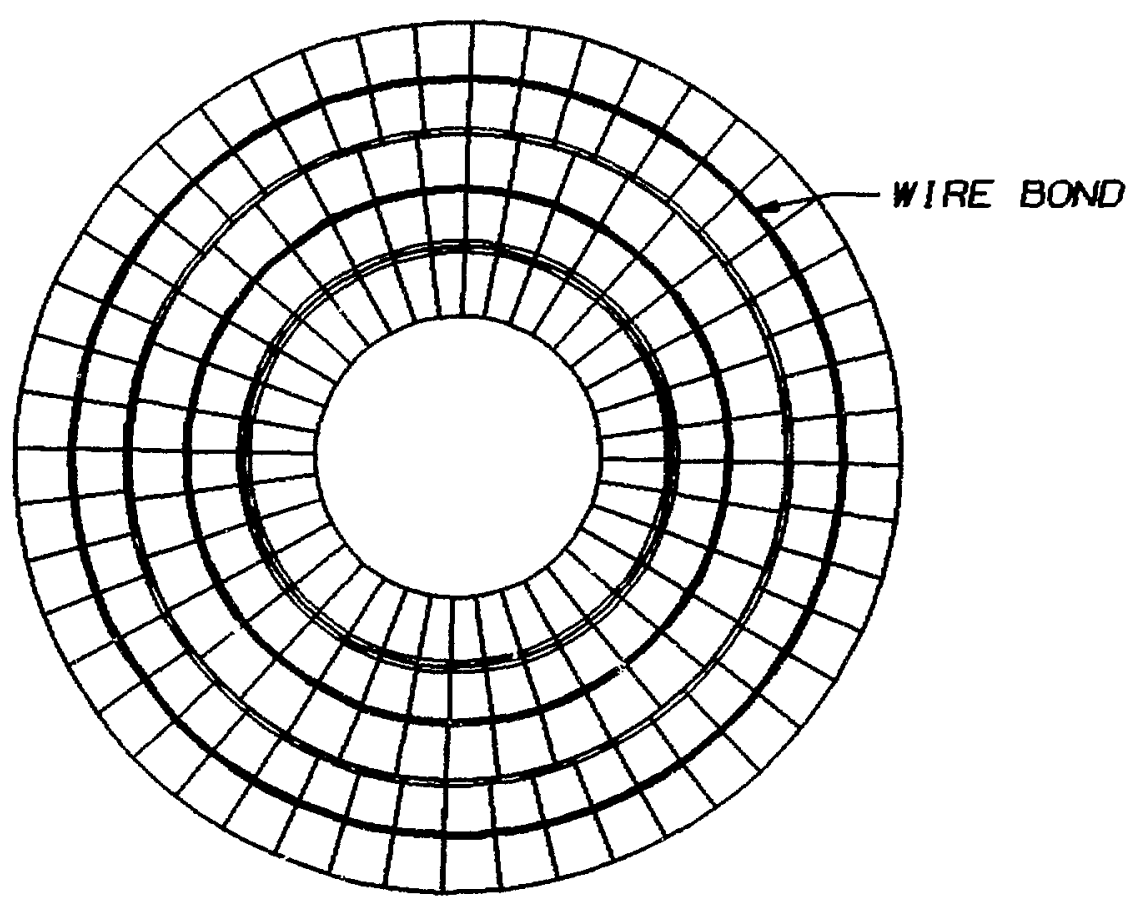

Figure 3-4. Forward region typical planar silicon array.

To ensure $5-\mu \mathrm{m}$ stability, these external loads must be isolated. The internal operating pressure of this enclosure will track the vapor pressure of the heat pipe working fluid. When the final design for heat pipe working fluid and cooling system has been established, uncertainties in the design pressure will be eliminated. The baseline design approach for the external enclosure is a sandwich graphite composite that is very lightweight. Beryllium is an alternate material choice for this enclosure.

The condenser for the integrated heat pipe system will be part of a heat pump system with sensitive temperature control. The heat pump maybe required to reject up to $40 \mathrm{~kW}$ and must be capable of stabilizing the condenser sink temperature against cyclic thermal drifts greater than $0.1^{\circ} \mathrm{C}$

3.1.2.2 Materials Options. In most design applications many factors are considered in material selection. However, the material selection for the superconducting super collider (SSC) silicon tracking subsystem is driven by three primary factors:

1. 5- $\mu \mathrm{m}$ material stability,

2. $2.0 \%$ radiation length for the structure, and

3. radiation resistance in the presence of hydrocarbon fluids.

Our preliminary studies have shown that achieving these goals will require the application of state-of-the-art material composites and high stiffness-to-weight ratio construction techniques.

Table 3-2 summarizes pertinent data for candidate materials for the structures under investigation. If material specific stiffness were a singular important attribute, then boron carbide would be an ideal candidate. It is rad hard and shows no evidence of creep under load. However, the material is brittle and exceedingly hard. Its hardness is surpassed only by diamond. Attainment of precise geometric shapes would be difficult and expensive. Another factor that detracts from its choice for this application is the modest effective radiation length. Beryllium's effective radiation length is nominally 1.78 times that of boron carbide; see Sec. 3.2 for more detail. Because effective radiation length is a primary factor in selecting a suitable material, Fig. 3-5 illustrates the permissible aggregate material intercepted by a particle. Beryllium clearly stands out as the best choice in this regard. Graphite/epoxy composites offer the next best alternative for achiev- 
TABLE 3-2. Selected Material Properties

\begin{tabular}{|c|c|c|c|c|c|c|c|}
\hline Material & $\begin{array}{c}\text { Elastic } \\
\text { Modulus } \\
E \\
(\mathrm{GPa})\end{array}$ & $\begin{array}{c}\text { Density } \\
\rho \\
\left(\mathrm{g} / \mathrm{cm}^{3}\right)\end{array}$ & $\begin{array}{c}\text { Specific } \\
\text { Stiffness } \\
E / \rho \\
\left(10^{8} \mathrm{~cm}\right)\end{array}$ & $\begin{array}{c}\text { CTE } \\
\alpha \\
(\mathrm{ppm} / K)\end{array}$ & $\begin{array}{c}\text { Thermal } \\
\text { Conductivity } \\
k \\
(\mathrm{~W} / \mathrm{m}-K)\end{array}$ & $\begin{array}{c}\text { Specific } \\
\text { Heat } \\
C_{p} \\
(J / g-K)\end{array}$ & $\begin{array}{c}\text { Radiation } \\
\text { Length (eff.) } \\
L_{R e} \\
(\mathrm{~cm})\end{array}$ \\
\hline \multicolumn{8}{|c|}{ Material Candidates } \\
\hline Beryllium & 290.0 & 1.84 & 16.08 & 11.60 & 146.0 & 1.88 & 35.43 \\
\hline Boron Carbide & 448.2 & 2.52 & 18.15 & 4.73 & 43.0 & 0.90 & 19.90 \\
\hline Carbon/Carbon $^{a}$ & 152.0 & 1.90 & 8.16 & 0.10 & 246.0 & 1.00 & 18.80 \\
\hline Graphite/Epoxy ${ }^{b}$ & 311.7 & 1.68 & 20.00 & -1.13 & 46.2 & 0.92 & 25.00 \\
\hline $\mathrm{Mg}-\mathrm{MMC}^{\mathrm{c}}$ & 190.3 & 2.03 & 9.56 & -0.35 & 412.0 & 1.00 & 16.80 \\
\hline Al-MMC & 196.5 & 2.39 & 8.39 & 0 & 409.0 & 1.02 & 13.22 \\
\hline \multicolumn{8}{|c|}{ Reference Materials } \\
\hline Silicon & 131.0 & 2.33 & 5.74 & 2.60 & 129.0 & 0.70 & 9.37 \\
\hline Aluminum & 68.9 & 2.70 & 2.59 & 23.58 & 168.0 & 0.90 & 8.89 \\
\hline Bo on & 344.7 & 2.34 & 15.03 & 8.30 & 1.0 & 1.29 & 22.52 \\
\hline Fus d Silica & 73.0 & 2.20 & 3.39 & 0.50 & 1.0 & 0.92 & 12.30 \\
\hline Copper & 117.2 & 8.91 & 1.34 & 16.90 & 400.0 & 0.39 & 1.44 \\
\hline $\mathrm{SiC}$ & 325.0 & 3.00 & 11.05 & 2.30 & 200.0 & 0.89 & 8.52 \\
\hline
\end{tabular}

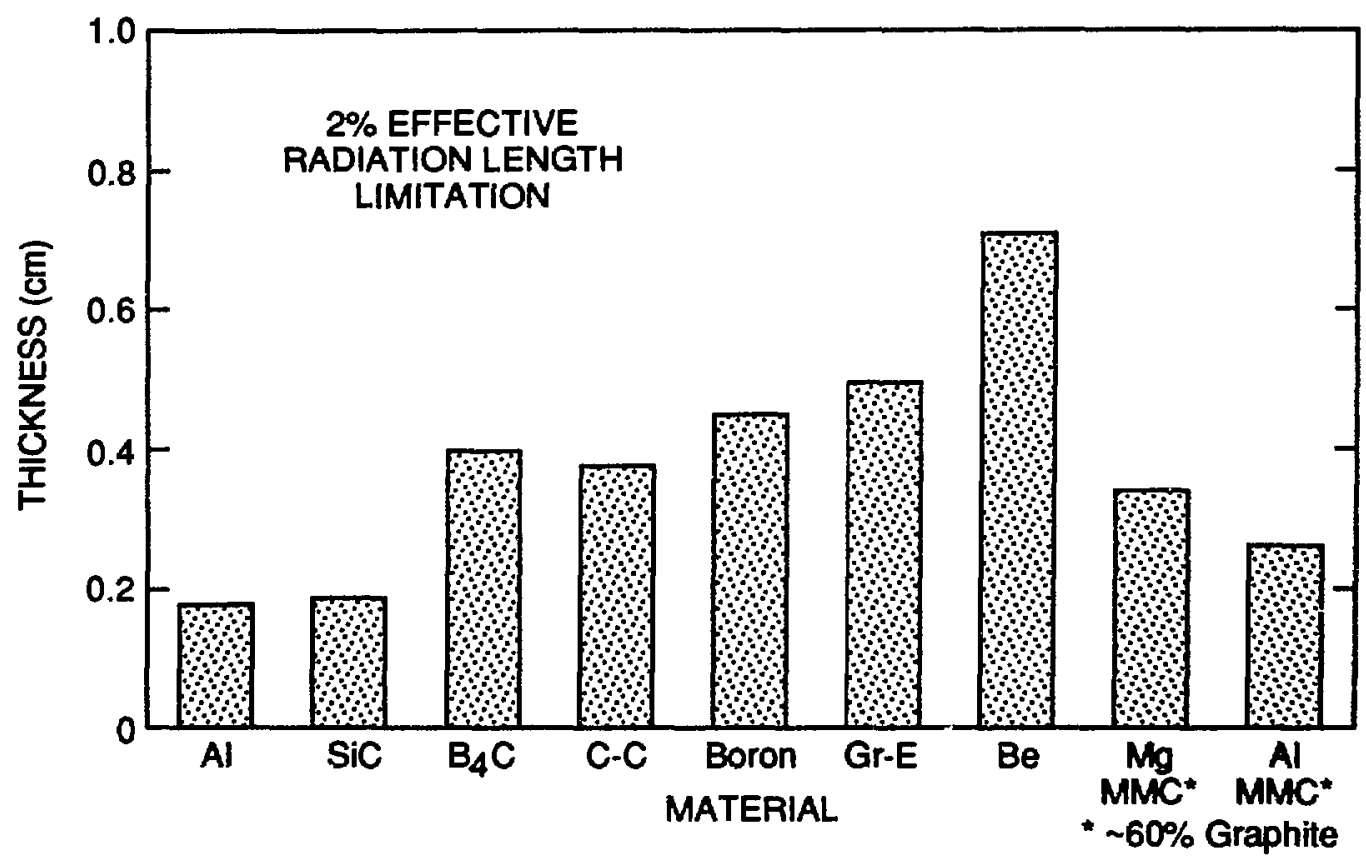

Figure 3-5. Permissible aggregate material thickness. 


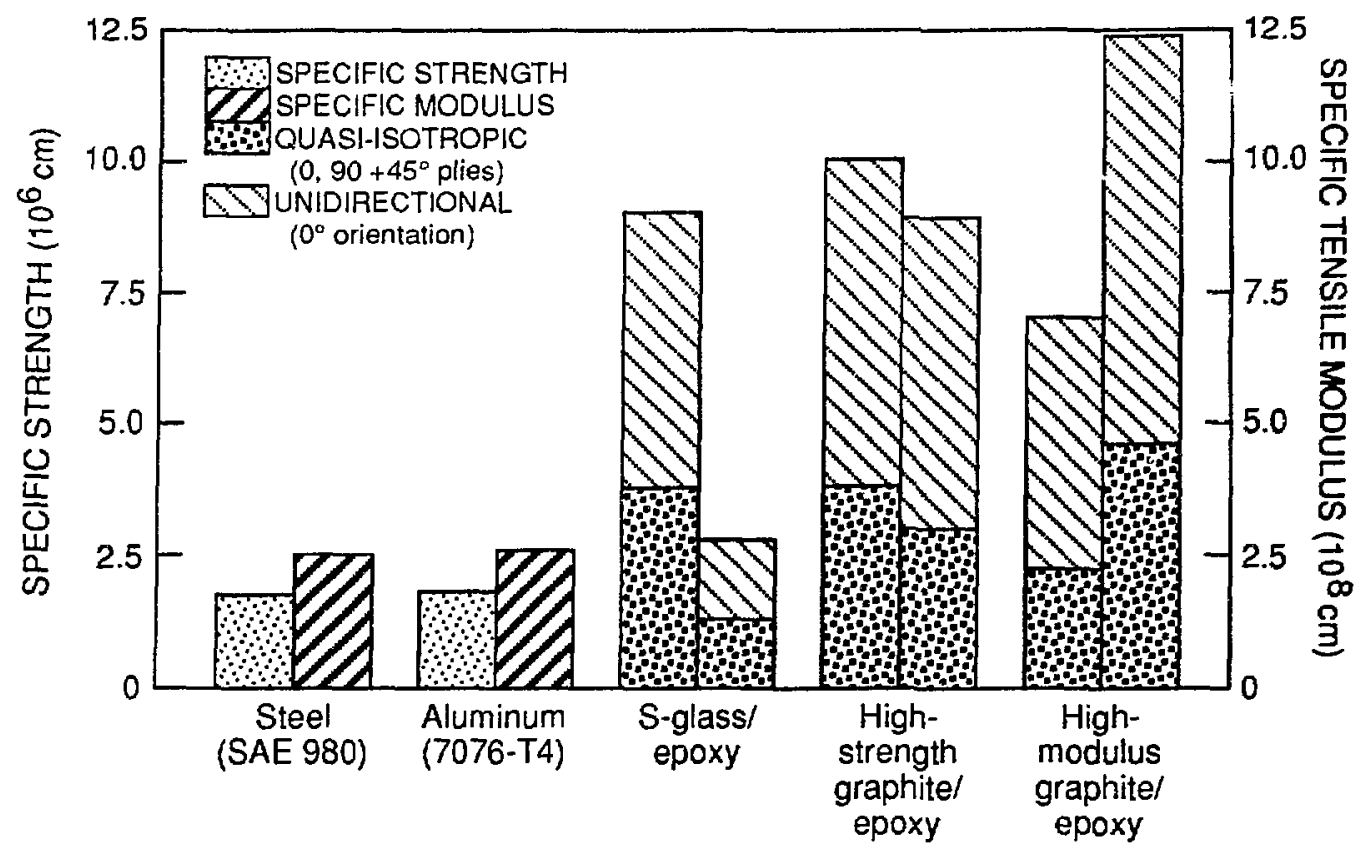

Figure 3-6. Materials specific strength and tensile modulus comparison.

ing the radiation length design goal. Silicon carbide is used extensively in highly stable mirror applications. It can be reaction sintered to complex shapes, but only a limited amount of material can be used in configuring a structural design. Silicon carbide has a very low effective radiation length, that is, it is not a very low- $Z$ material by comparison. However, silicon carbide does have a coefficient of thermal expansion that closely matches that of silicon, and this is a very desirable characteristic as a structure for mounting silicon.

Returning to Table 3-2, graphite/epoxy composites have specific stiftnesses slightly higher than beryllium. However, the value quoted is for unidirectional properties. Structural panels composed of individual graphite/epoxy plies with fiber orientations arranged to achieve quasiisotropic properties, have noticeably lower stiffness properties. Figure 3-6 depicts the general reduction in stiffness and strength for quasi-isotropic structures. The STS can effectively use both composite property classes, that is, unidirectional and quasi-isotropic. The internal truss space frame is an example of the use of a unidirectional laminate. However, a zero CTE in the dirction of the truss member is desired. Achieving this requirement requires a tradeoff in fiber properties and fiber-to-epoxy matrix volume fraction.

Table 3-3 illustrates the candidates being considered for shell and ring structures for which a quasi-isotropic CTE is needed or where a particular CTE value is to be matched; for example, IM6/3501-6 (2.9 ppm/ $\left.{ }^{\circ} \mathrm{C}\right)$ compares favorably with silicon $\left(2.6 \mathrm{ppm} /{ }^{\circ} \mathrm{C}\right)$.

Graphite/epoxy composites have been tested in a radiation environment and data exist on the aromatic amines (3501-6) and aromatic isocyanates (1939-3), which show that structural degradation after exposure to $10 \mathrm{Mrads}$ is not a problem, as demonstrated in Fig. 3-7. However, none of the existing data on graphite/epoxy composites is useful in understanding how dimensionally stable the material will be after exposure to a radiation environment in the presence of a hydrocarbon. Creep may become a serious problem. We are conducting radiation and plyysical property tests to qualify the material. Because of the limited test scope this fiscal year, we will be unable to make any determination on whether significant creep will exist under our design loads. Our tests will be directed toward establishing whether residual stresses in panel fabrication are relieved through an annealing process that results in micron-level distortions. Uncertainty in material lonr-term dimensional stability will remain a major concern. An additional concem is 
Table 3-3. Graphite/Epoxy Composite Material Systems Quasi-isotropic Laminate Engineered Parameters

\begin{tabular}{lcccccc}
\hline & $\begin{array}{c}\text { Elastic } \\
\text { Modulus } \\
E(\mathrm{GPa})\end{array}$ & $\begin{array}{c}\text { Density } \\
\rho\left(\mathrm{g} / \mathrm{cm}^{3}\right)\end{array}$ & $\begin{array}{c}\text { Specific } \\
\text { Stiffness } \\
E / \rho\left(10^{\circ} \mathrm{cm}\right)\end{array}$ & $\begin{array}{c}\mathrm{CTE} \\
\left(\mathrm{ppm} /{ }^{\circ} \mathrm{C}\right)\end{array}$ & $\begin{array}{c}\text { Poisson } \\
\text { Ratio }\end{array}$ & $\begin{array}{c}\text { Shear } \\
\text { Modulus } \\
G(\mathrm{GPa})\end{array}$ \\
\hline P75/1939-3 & 109.2 & 1.68 & 6.6 & -1.43 & 0.321 & 41.3 \\
P75/3501-6 & 107.8 & 1.68 & 6.5 & -0.5 & 0.321 & 40.8 \\
GY70/3501-6 & 98.9 & 1.66 & 6.1 & -0.016 & 0.318 & 37.5 \\
UHM3501-6 & 95.8 & 1.60 & 6.1 & 0.18 & 0.314 & 36.4 \\
IM6/3501-6 & 78.3 & 1.56 & 5.1 & 2.9 & 0.296 & 30.2 \\
AS4/3501-6 & 55.9 & 1.56 & 3.7 & 1.96 & 0.30 & 21.5 \\
AS1/3501-6 & 51.7 & 1.56 & 3.4 & 2.32 & 0.298 & 19.9 \\
\hline \hline
\end{tabular}

EPOXY RESIN, UNFILLED AROMATKC TYPE CURING

EPOXY GLASS LAMNATE

PHENOLIC RESIN, UNFILLED

PHENOLIC RESIN, GLASS LAMINATE

POLYURETHANE RESIN

POLYESTER RESIN, LNFILLED

POLYESTER RESW, GLASS FILLED

POLYPHENYLENE SULFIDE (AYTON)

POLY-M-PHENLENE AMIDE (NOMEX)

POLYAMIDE (NYLON)

POLYCARBONATE (MAKROLON)

Gy
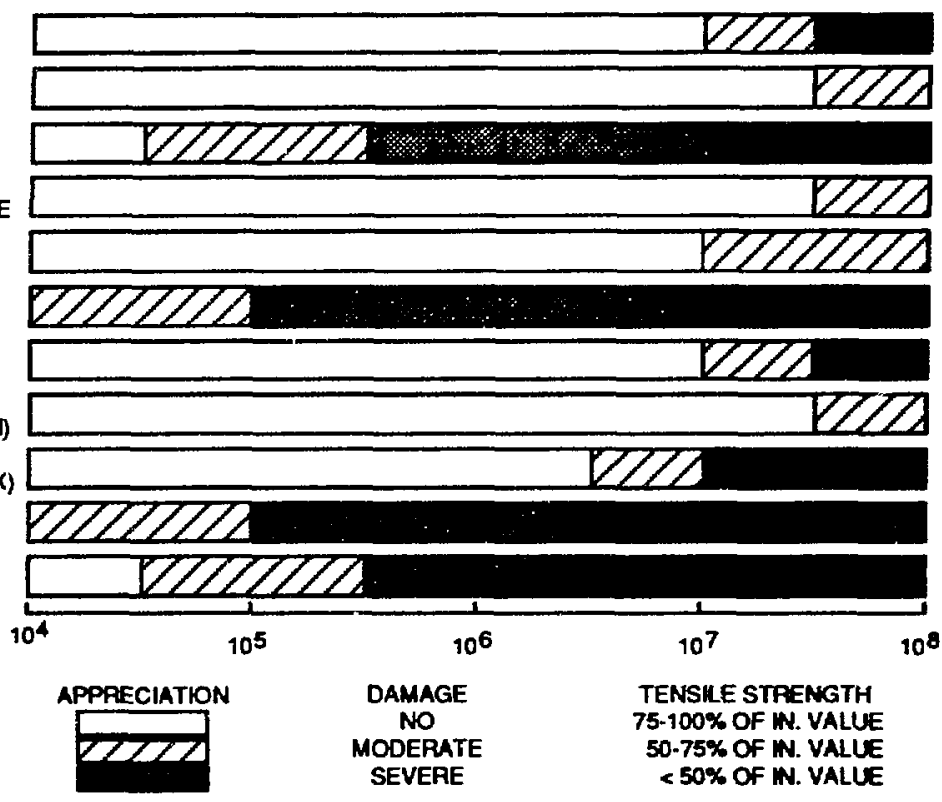

TENSHE STRENGTH

75-100\% OF W. VALUE

$50-75 \%$ OF N. VALUE

ENVIRONMENT: AR + AMBIENT TEMPERATURE

NOTE: The Appreciation can serve only as a general guideline. Atmosphere and other environmental conditione may influence the results. References: CERN 79-08, CERN 82-10, CERN 85-02

Figure 3-7. General relative radiation effects of magnet and other insulation materials.

the dimensional change that occurs after exposure to the vapor that will exist in a completely open heat pipe working fluid system. Material swelling caused by the working fluid vapor space will stabilize, so dimensional changes will not occur randomly from this source: but the change must be factored in when establishing the final location of all silicon wafers to the $25 \mathrm{~mm}$ placement accuracy.

Metal matrix composites (MMCs) offer the potential for resolving many of the urcertainties that exist in graphite/epoxy. One option is to use the metal matrix to replace the epoxy matrix: this is an area of specific concern. Another option is to tailor the CTE as shown in Figs. 38 and 3-9. Because graphite is a low-Z material when compared with the two metal matrices under consideration, the effective radiation length improves as the volume fraction of the graphite increases. We would like to achieve a volume fraction of 60 to $65 \%$. whereas present industry 


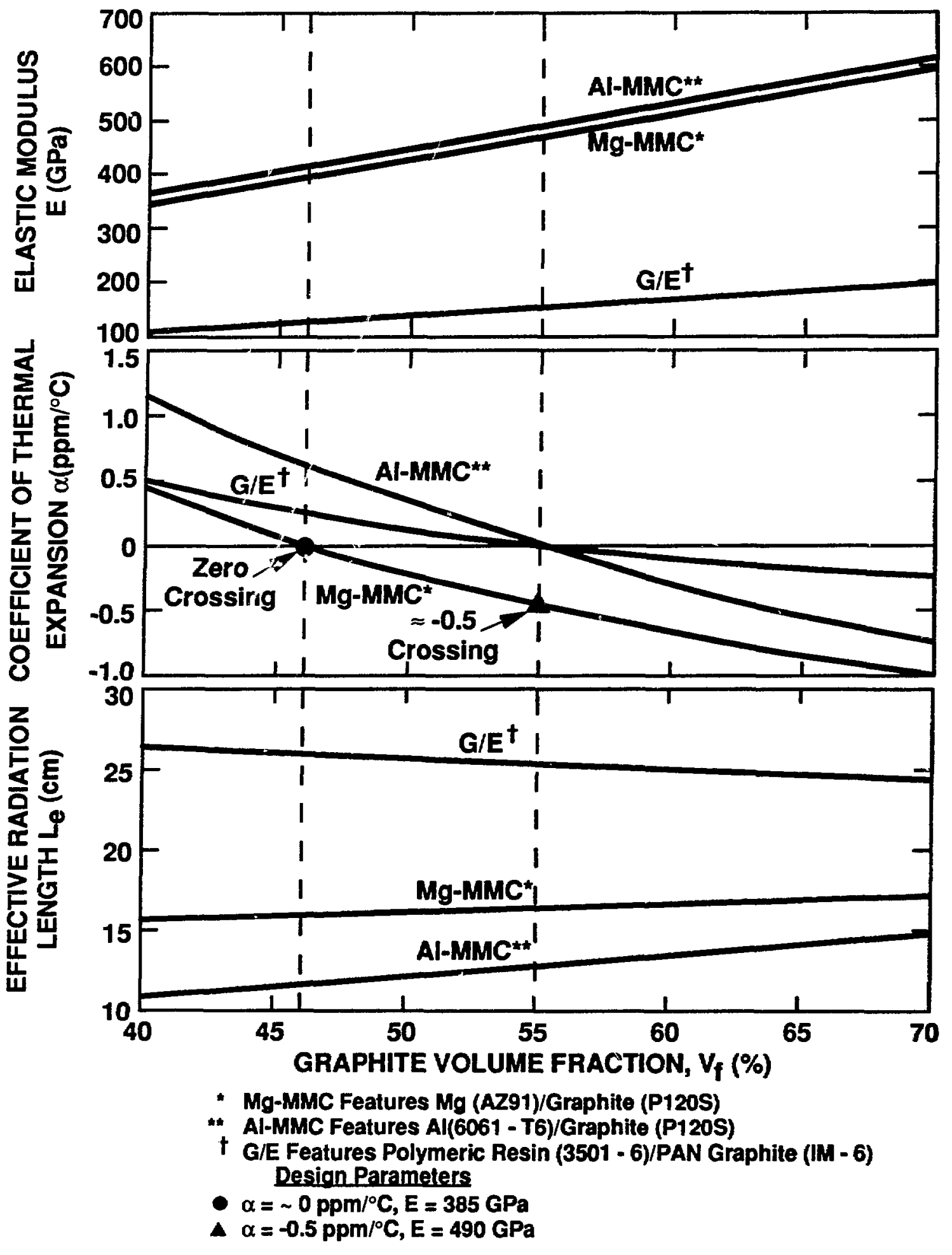

Figure 3-8. Unidirectional material properties. 


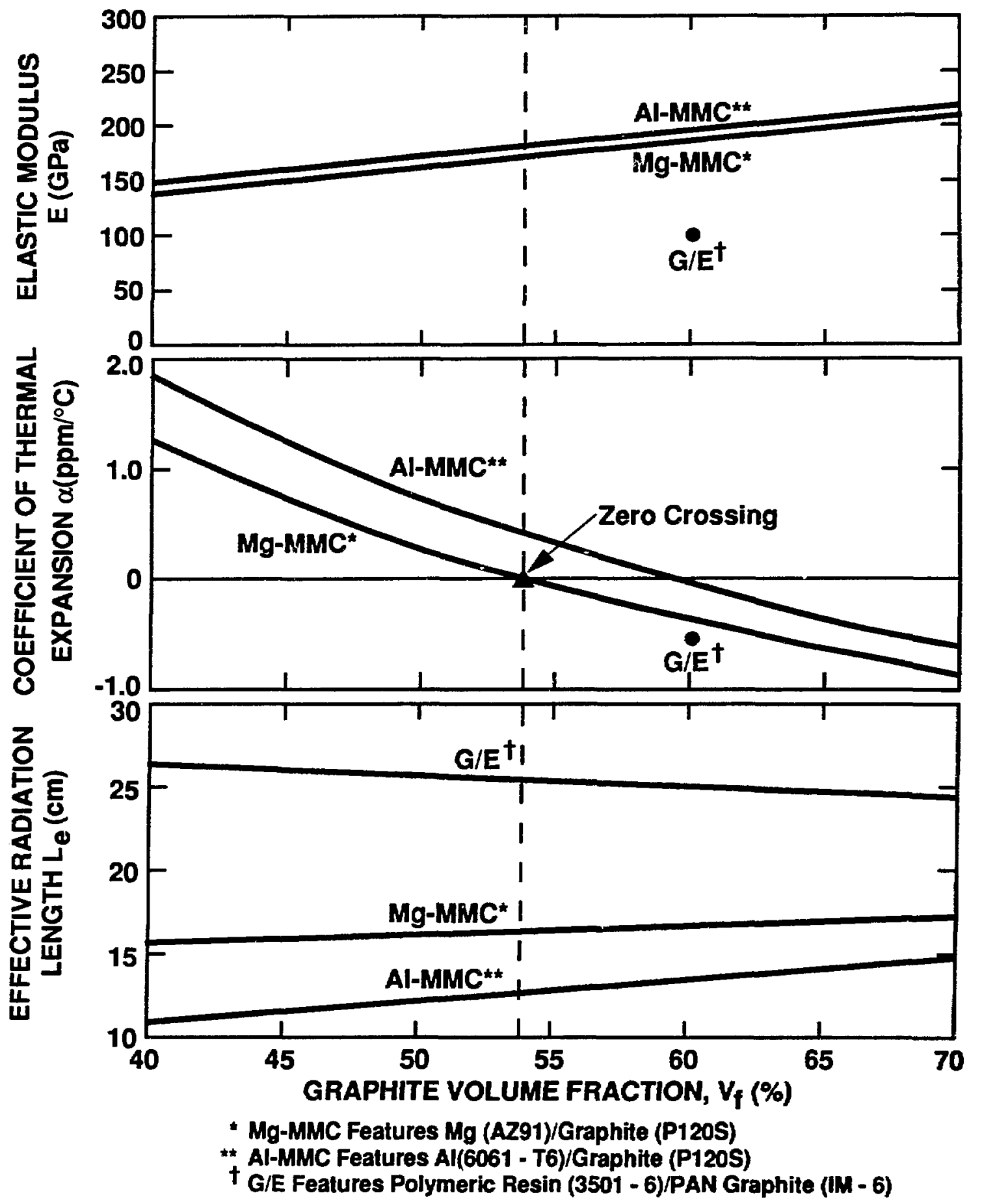

Figure 3-9. Quasi-isotropic material properties. 
capability appears to be 50 to $55 \%$. As our design progresses we will explore the higher volume fraction issue with the appropriate industrial concerns.

The metal matrix CTE can be tailored to achieve either a match with silicon or zero, as desired. Neither creep nor dimensional changes caused by vapor variations should be a problem. Hysteresis in thermal expansion has been reported for wide excursions in temperature. that is. -200 to $200^{\circ} \mathrm{F}$. The large temperature range results in matrix yielding, which accounts for hysteresis. Our limited temperature differential of $30^{\circ} \mathrm{C}$ is not sufficient to cause a problem.

In summary, beryllium is being studied as a candidate material. This material was chosen because of the need to achieve stringent effective radiation resistance in a chemical environment. Several factors must be considered in its application; for example, its high CTE and high possibility for creep potential. The high thermal expansitivity $\left(11.6 \mathrm{ppm} /{ }^{\circ} \mathrm{C}\right)$ will present a problem if the material is used to support the silicon wafer directly, that is, if it is used to support the coolingsupport ring structure. Beryllium will be best suited for support shell structures; as a pressure enclosure for the heat-pipe coolant vapor; or, possibly, for the truss space frame. If one chooses to make a sandwich shell structure out of beryllium an ingot sheet form would be desirable. Thingage, hot-rolled sheets can be achieved by using an ingot source form that is vacuum processed to eliminate beryllium oxide. Microyielding of this form has been recorded at stress levels as low as $1000 \mathrm{psi}$, depending upon its stress-relieved state. We intend to experimentally evaluate this prospect by fabricating a berylliun sandwich panel. In doing so, we will take the following into account:

- distributed support loads (to minimize stresses),

- stress relief history,

- cold working under repeated loading (to improve microyield properties), and

- additives during ingot processing (to elevate the microcreep properties in employing beryllium in this application).

Although we considered forming a beryllium/graphite fiber matrix, tailoring the CTE to match that of silicon would require extensive development. On the basis of our preliminary results, we find that it would take roughly $55 \%$ by volume GY70 fibers to achieve a composite CTE that matches that of the silicon, Fig. 3-10. One development issue that must be solved is the brittleness induced by the formation of beryllium carbide at the fiber/beryllium interface. One option being studied is to precoat the fiber with a thin layer of silicon before forming the beryllium/graphite composite. Although we are still interested in this material combination, development funds are currently unavailable for pursuing this topic.

It is clear that no one candidate material can satisfy all requirements, and in some instances, the capabilities of a material to fulfill the requirement are not even known. At this stage, a selection would be very subjective and would be wholly based on desired attributes and their ranking of importance. Since our primary material tests have not yet been completed, we have prepared a list of attributes and given our opinion regarding which candidate is best suited to achieve the desired requirement. Table 3-4 represents a subjective position based on our current understanding. This table reflects our interest in three candidates: beryllium, magnesium-metal matrix composite, (Mg-MMC) and graphite/epoxy composite. All of these are undergoing evaluation.

\subsubsection{Design Activities}

At the outset, the silicon tracking system was conceived to be roughly $3 \mathrm{~m}$ in length and $1 \mathrm{~m}$ in diam. Sixteen layers of nominally $6-$ by $6-\mathrm{cm}$ wafers were planned for the central region, with 10 planar arrays of silicon for each for the forward region. Figure 3-11 depicts the earlier configuration versus the present design concept. A major contrast between the designs was the plan to individually mount each wafer, approximately 10,000 in all, in the earlier configuration. Each wafer carried its own electronics circuitry, necessitating individual cooling. To simplify the wafer cooling, we proposed a heat pipe cooling network to cool the wafer support shells; heat was removed from the electronics by conduction to the actively cooled shell surface. However, our analysis results indicate that excessive wafer temperatures would likely occur. An alternative cooling configuration called for wicking the heat pipe working fluid directly beneath the electronics 


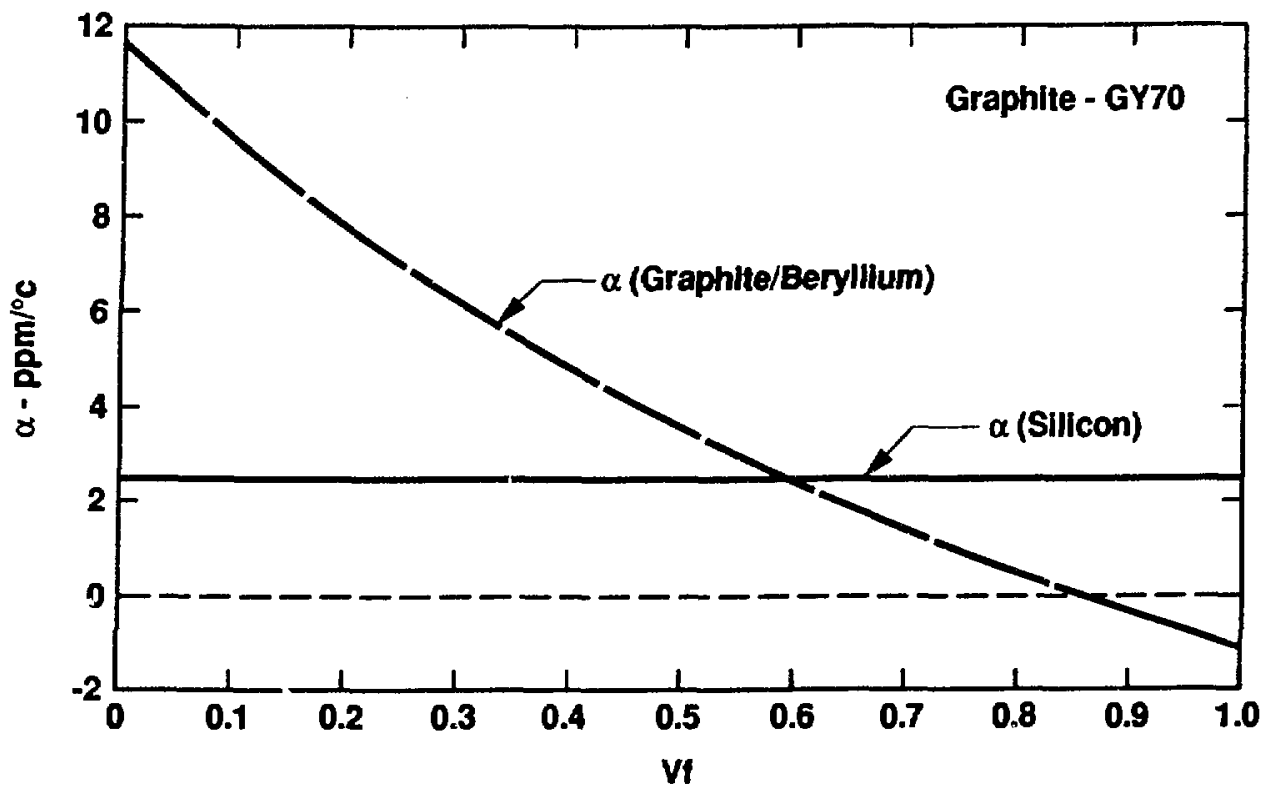

Figure 3-10. CTE of graphite composites expressed as a function of volume fraction of graphite.

TABLE 3-4. Silicon Tracking System Materials Study

\begin{aligned} & \hline \multicolumn{1}{c}{ Attributes } Material Options \\ & \hline Most favorable radiation length Beryllium \\ & Inherent dimensional stability $\begin{array}{l}\text { Aluminum-MMC } \\ \text { Beryllium }\end{array} \\ &$ Best match to silicon CTE Silicon carbide \\ & Tailorability of CTE Magnesium-MMC \\ & Highest thermal conductivity Magnesium-MMC \\ & $\begin{array}{l}\text { Aluminum-MMC } \\ \text { Silicon carbide }\end{array} \\ &$ Least difficult to fabricate Graphite/epoxy \\ & Aluminum-MMC \\ & Most difficult to fabricate Boron carbide \\ & \hline \hline\end{aligned}

circuitry, but with this technique, we would have to make 10,000 individual heat pipe antery connections.

Our present configuration has greatly simplified the wafer cooling problem by joining individual 6-cm-long wafers into one long strip detector. The maximum active strip length is now $18 \mathrm{~cm}$. To achieve these strip lengths the individual wafers are wire-bonded together, and then edge-bonded to form a structural unit. Two such assemblies are bonded together to form one 36-cin-long module. As cited earlier, we have investigated combining these long module assemblies into a sandwich arrangement to maximize the wafer stiffness. The sandwich arrangement is essential, because, for example, a 30.5 -cm-long wafer will sag under its own weight, $0.235 \mathrm{~cm}$. A finite element model compares reasonably well with these measured results, as can be seen in 


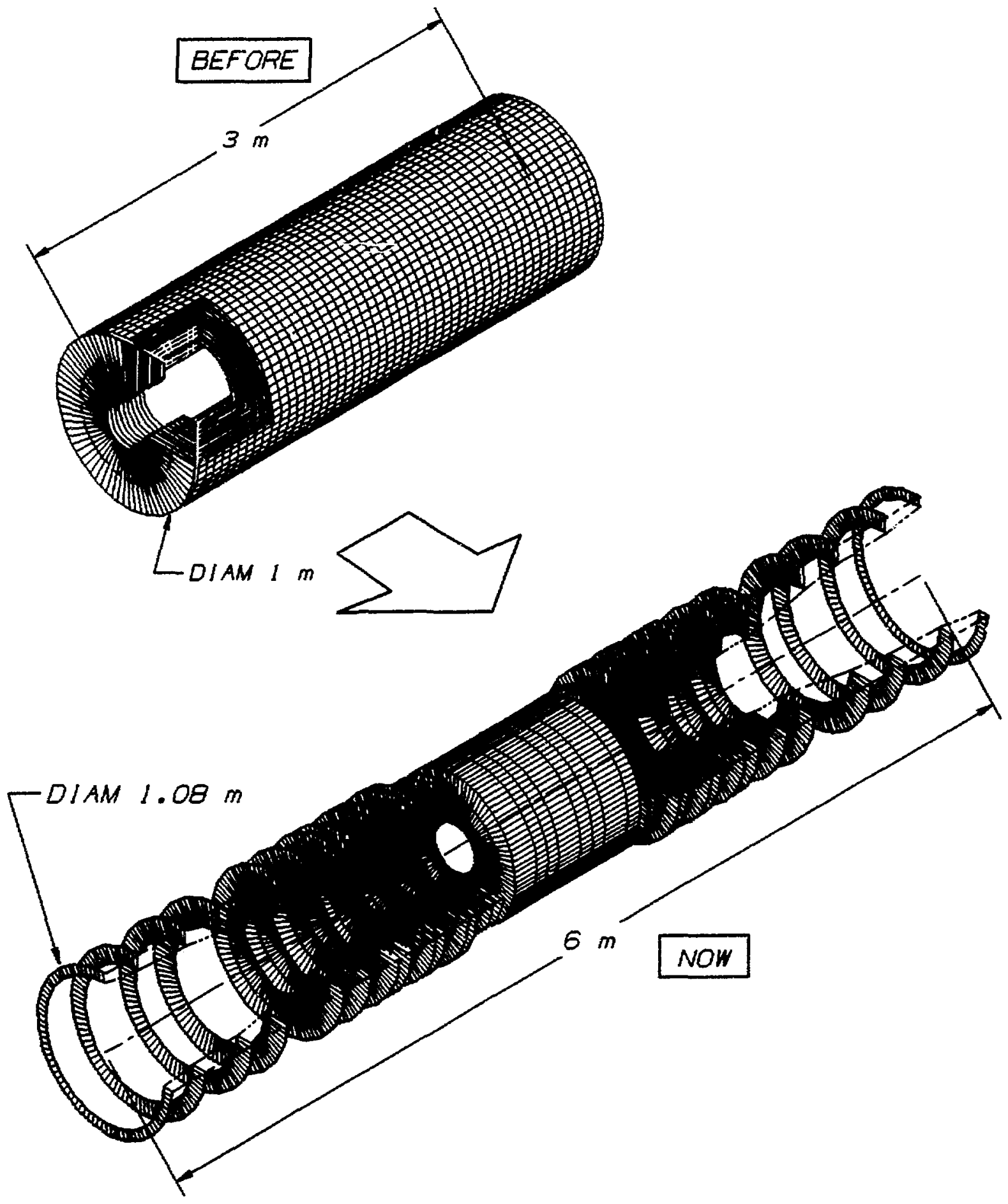

Figure 3-11. Silicon tracking system concept evolution. 
Fig. 3-12 (top). Our linear elastic solution overpredicts the deflection by $12 \%$. It is important to note that the analytical model did not simulate the potential effect of the three. 50 - $\mu \mathrm{m}$ adhesive joints. From all outward appearances, these bond lines do not contribute to any additional sag.

A three-point bend test of three 8-cm-long edge-bonded wafers was performed to explore the adhesive joint compliance. Again, our linear elastic model overpredicted the deflection but this time by $13 \%$, as seen in Fig. 3-12 (bottom).

The correlation between predicted and measured wafer bending could he improved by constructing a nonlinear large deflection model that accounts for in-plane stiffening effects. However. the deflection for the long unsupported bonded wafer assembly is roughly 100 times material thickness. The silicon sandwich design proposed for the silicon superlayers will not be a large deflection problem, but rather an entirely linear elastic problem. Otherwise, damage to the wafers would be likely. Verifying that the adhesive bond joints could be ignored in the linear elastic model was the main intent here.

The strength of the adhesive joint was tested. Tensile strength was measured to be nominally 5000 psi with Epotek H74, an electrically nonconductive material. When we initially began fabricating silicon sandwich structures. we chose Epotek $\mathrm{H} 72$ adhesive, a thermally conductive material rated at 10.000 psi. The adhesives were cured at $100^{\circ} \mathrm{C}$. Consequently, the substrate onto which the silicon was being bonded needed a CTE roughly equivalent to silicon to avoid internal stresses. This requirement leads to a reduction in residual stresses.

A finite element model and prototype of a silicon sandwich structure were developed to assess the structural rigidity and durability of such an assembly. The stiffness enhancement of adding AS4 graphite/epoxy end pieces was investigated with the finite element model. A substantial improvement over the previously tested edge-bonded wafers was observed, as displayed in Fig. 313 (top). The gravity sag predicted by the analysis was $0.0477 \mathrm{~cm}$. This model was also used to investigate the effects of intermediate supports. The initial case using 3 such supports diminished the sag to $0.012 \mathrm{~cm}$ as shown in Fig. 3-13 (bottom). A number and placement optimization study for these supports is in progress. A photograph of the silicon sandwich prototype is shown in Fig. 3-14.

We designed a cooling ring onto which these silicon sandwich structures are connected (see Fig. 3-3). Ring supports are provided at the two ends of these silicon modules, and the resulting assembly resembles a shell-like structure. The silicon shell assembly will be kinematically supported on two cooling rings. These cooling rings eliminate the prospect of having to connect individual heat pipe wick arteries to each wafer. In short, the present configuration represents a major improvement over earlier cooling concepts.

Simplifications in mounting and cooling wafers has been achieved at the expense of increased silicont-wafer wire bonding requirements. For the present, this concession seems appropriate. One can also imagine that improved manufacturing techniques for joining individual strips will evolve that may entirely eliminate wire bonding. At the very least, this process lends itself to proven high-production techniques.

Preliminary thermal/structural analyses of the wafer sandwich arrangement have been completed. Distortions can be controlled to less than $5 \mu \mathrm{m}$ by appropriately matching material CTEs to that of silicon. Our analyses will be updated after final selection of the ring material and geometry. Present material candidates are AS series/3501-6 graphite composite and Mg-MMC. Both candidates would have their CTEs tailored to match that of silicon.

A space frame for supporting the large silicon array has evolved (see Figure 3-15). We elected to replace the concentric support shell concept chosen in the very early stage of the study. The openness of the space frame contributes significantly to satisfying the radiation length restriction and represents a marked improvement in simplicity and cost. Preliminary structural analyses have been completed (Sec. 3.3.2), although much more work is needed in this area.

The prime material candidate for the space frame is a metal matrix composite, that is. $\mathbf{M g}$ MMC. We are discussing our conceptual design approach with MMC fabricators. Much is yet to be learned regarding fabrication and assembly techniques, material property data, and compatibility with the heat pipe working fiuid. Preliminary tests are underway to identify whether the working 

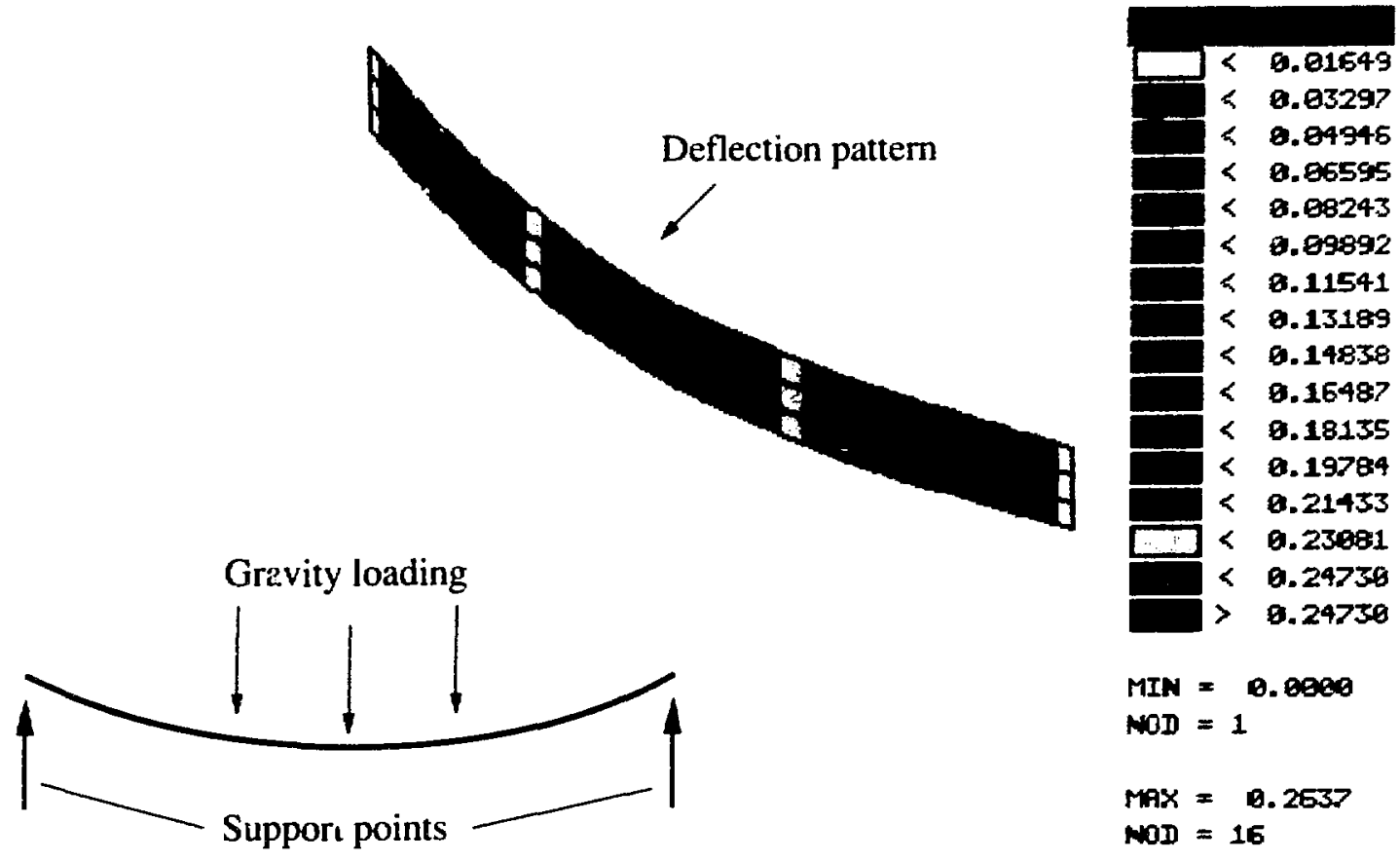

$$
\begin{aligned}
& \text { MIN }=0.6060 \\
& \text { MOD }=1 \\
& \text { MAX }=0.2637 \\
& \text { MOD }=16
\end{aligned}
$$
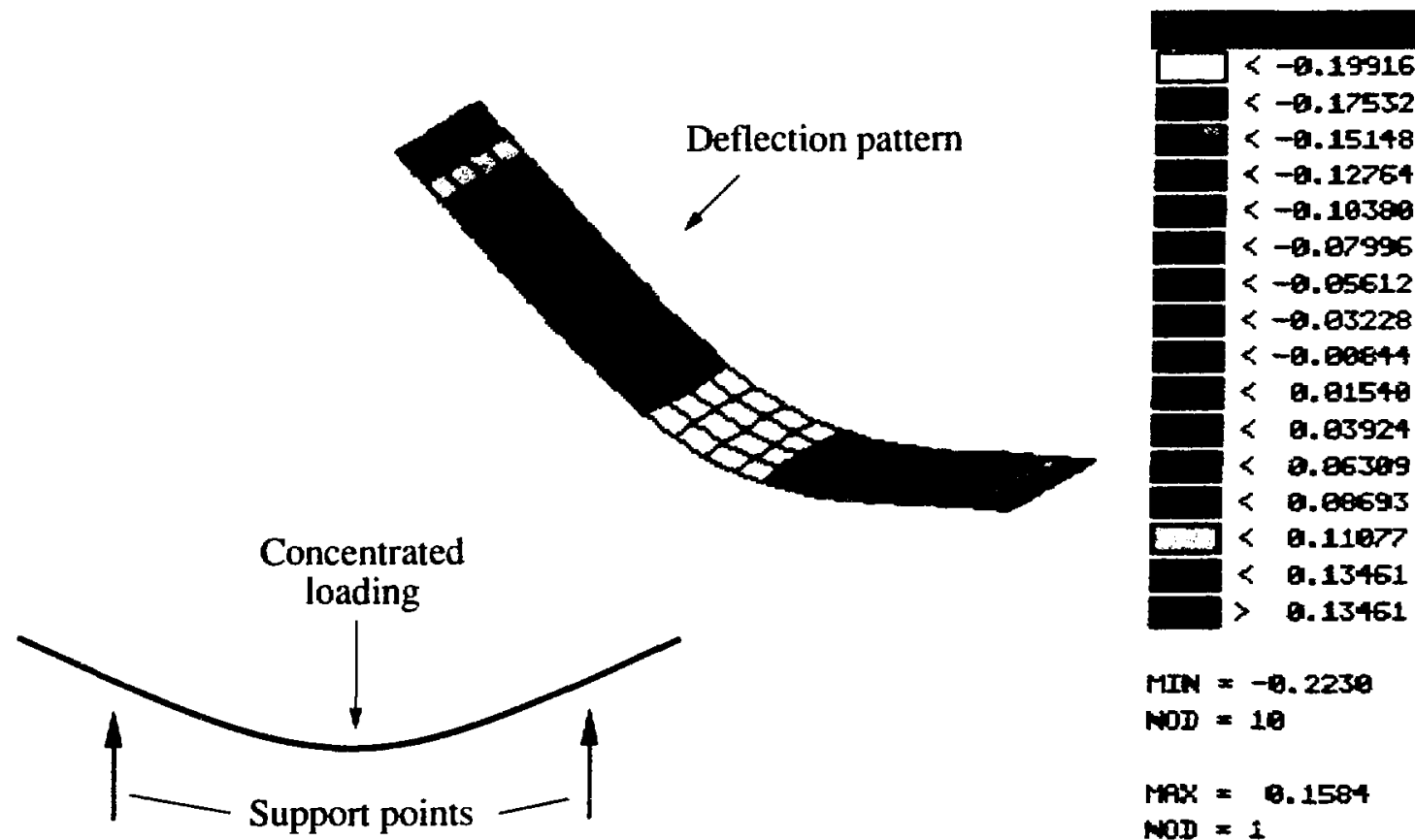

$$
\begin{aligned}
& \text { MIN }=-0.2230 \\
& \text { MOD }=10 \\
& \text { MAX }=0.1584 \\
& \operatorname{MOD}=1
\end{aligned}
$$

Figure 3-12. (Top) Finite element and experimental deflection results for a 30-cm-long, simply supported. edge-bonded wafer assembly. $0.264 \mathrm{~cm}$ FE vs $0.235 \mathrm{~cm}$ measured, and (Bottom) a 24-cm-long three-point bend tested, edge-bonded wafer assembly, $0.223 \mathrm{~cm}$ FE vs $0.198 \mathrm{~cm}$ measured. 

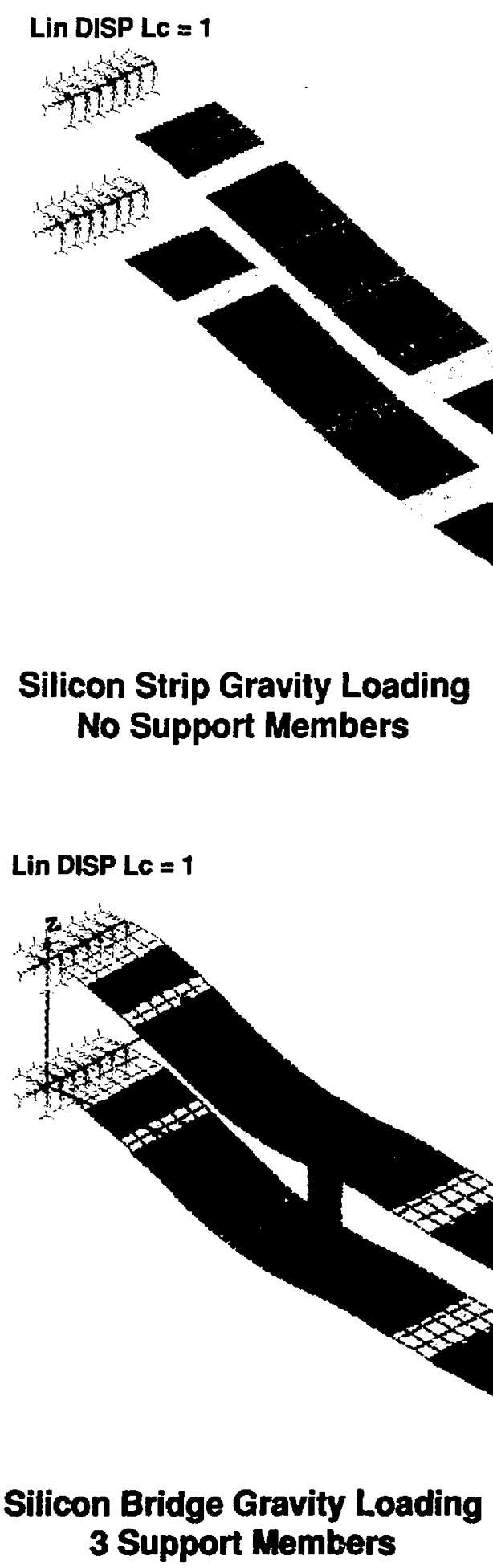

\section{Silicon Strip Gravity Loading No Support Members}

Displacement (mm)

o. 47741

0.44558

0.41376

0.38193

0.3581

0.31827

Q .28645

0.25462

0.22279

0.19896

0.15914

0.12731

0.09548z

0.063655

0.031827 $12-16$ 477 microns
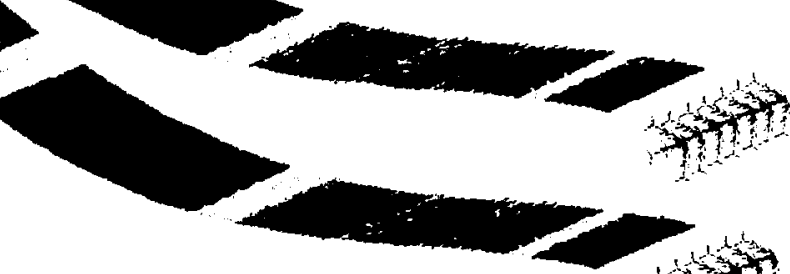

Fixed Edge

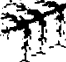
Support

Displacement (mm)

0.11926

0.11131

0.10336

0.095406

0.007455

0.079505

0.071554

0.063604

0.055653

0.047703

0.039752

0.031002 120 microns

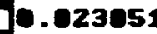

0.015901

0.007950s

12-16

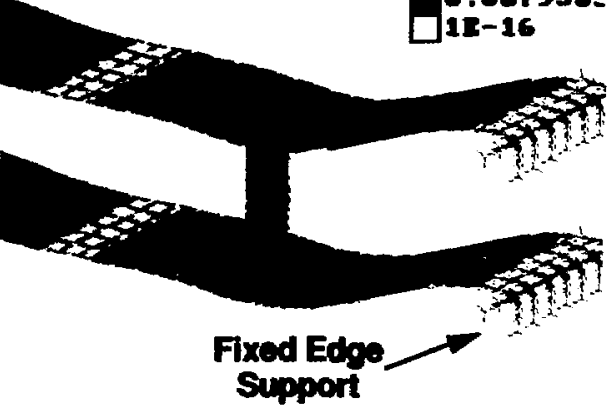

Figure 3-13. Finite element deflection results for two 30-cm-long, fixed-end silicon sandwiches under gravity loading. (Top) maximum deflection without intermediate supports $(0.0477 \mathrm{~cm})$, (Bottom) with intermediate supports $(0.0120 \mathrm{~cm}$. 


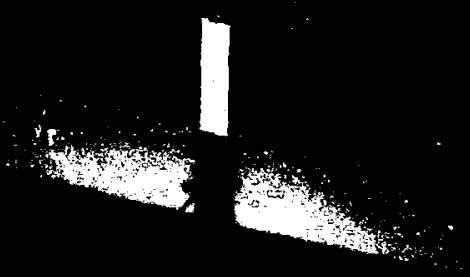




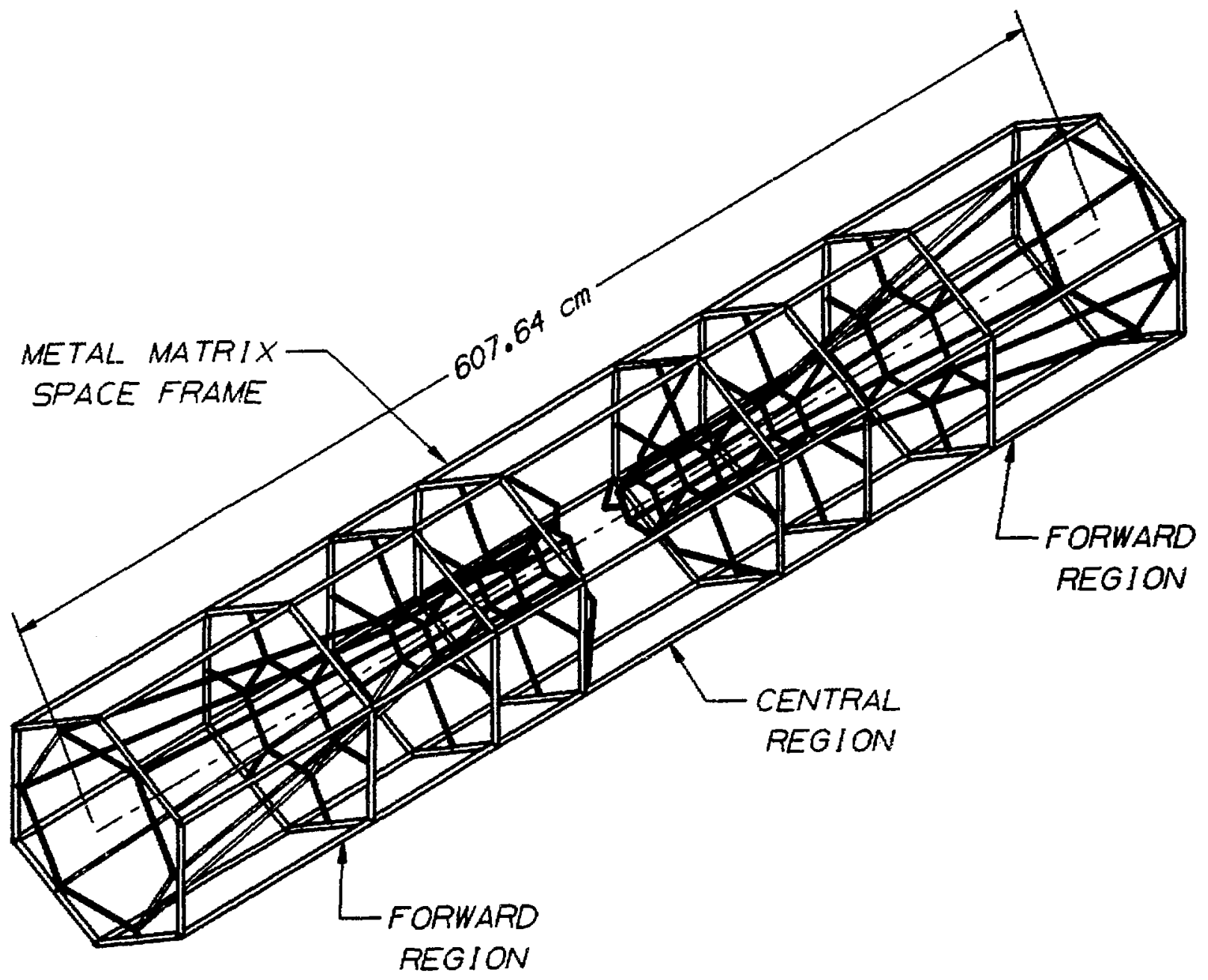

Figure 3-15. Metal matrix space 'rame.

fluid will infiltrate the inatrix, potentially causing material stability problems. This probability is considered to be highly remote. In dissimilar materials, as in this case, galvanic corrosion will result if an electrolyte is present. Although we feel that our choice of fluids precludes this possibility, a thin polyurethane coating can be used to suppress this corrosive action if a problem develops.

Containment of the heat pipe working fluid is provided by an external pressure housing. In the present design, we are proposing to use the beam tube as the innermost wall. With respect to the pressure housing, a preliminary concept has been prepared, and ROM costs have been established for two separate materials, beryllium and graphite/epoxy composite.

\subsubsection{Detector Shape and Deformation Measurement}

A comprehensive set of tests will determine the structural shape of the assembled detector prototype. These measurements

- confirm the design or indicate directions for design improvements, 
- experimentally check the assumptions used in the finite element (FE) design model,

- promote confidence in the FE model predictive capability for alternate detector operating conditions, and

- provide a test bed for developing measurement instrumentation for the larger final detector that will be built later.

An outline of the workflow required for testing the prototype detector is shown in Fig. 3-16. The first measurements will determine the prototype detector shape relative to an absolute standard model. The following assembled shape characteristics will be important

- relative wafer-to-wafer placement,

- assembled shape relative to a perfect cylinder,

- qualitative information about structural defects and high-strain regions, and

- vibration mode shapes and associated frequencies.

In addition, deformations will be measured and correlated with FE predictions when experimental conditions such as the following are modified:

- the detector is rotated,

- prescribed forces are applied, or

- the temperature is changed.

Techniques for measuring the shape and deformations are well known, but the large cylindrical shape presents special requirements and challenging details. The measurement techniques available generally fall into one of the following categories

- conventional optical/mechanical probes,

- interferometric techniques, or

- x-ray probes.

Conventional optical/mechanical probes are useful for measuring the assembled shape of the detector relative to an ideal reference shape. The technique is not ideal for measuring deformations that occur when measurement conditions change. A major advantage of conventional optical/mechanical probes is that data analysis is straightforward and easy to correlate with the FE model. However, the data collected is relatively sparse. It is not the continuous qualitative information about strain and structure flaws that is most useful for improving the mechanical design.

A preliminary concept for a conventional measuring machine is shown in Fig. 3-17. A frame is constructed from Zerodur, a glass ceramic with a room temperature-CTE about an order of magnitude less than the expansion coefficient of the least thermally expansive carbon composites. The Zerodur frame has an ideal shape and enough structural stability to be used as a standard reference, even when the temperature is changed to $0^{\circ} \mathrm{C}$. Targets are placed on every detector, preferably during detector/wafer fabrication, and the position and tilt of the targets are used to make a point-by-point detector surface map. In this concept, the measurement head contains a microscope to sense the target position and an autocollimator to sense the detector tilt angle. Detector characteristics are determined by first measuring the detector shape relative to the Zerodur standard and second by remeasuring the detector after a change in rotation, force, or temperature. Several heads may be required so that each head has a sweep range that moves between the detector support frames.

Measurements are always made relative to the standard reference frame. The measurement head is positioned relative to this standard frame before it measures the position and tilt of target on the detector. Reference positions are established by single mode fibers in the frame and in the measuring head. When the positioning fiber in the measurement head is aligned to a reference fiber in the standard frame, the measurement head is in the correct position for a measurement.

Interferometric techniques conveniently provide the continuous qualitative information about deformation strain and structural flaws that occur when experimental conditions are changed. However, quantitative data reduction can be difficult and error prone. Holographic techniques also require interferometrically stable test beds. Speckle pattern photography or TV holography are alternatives to holographic interferometry. They can be used for measuring the surface bending and warping and they do not require as high a degree of interferometric stability and are more 


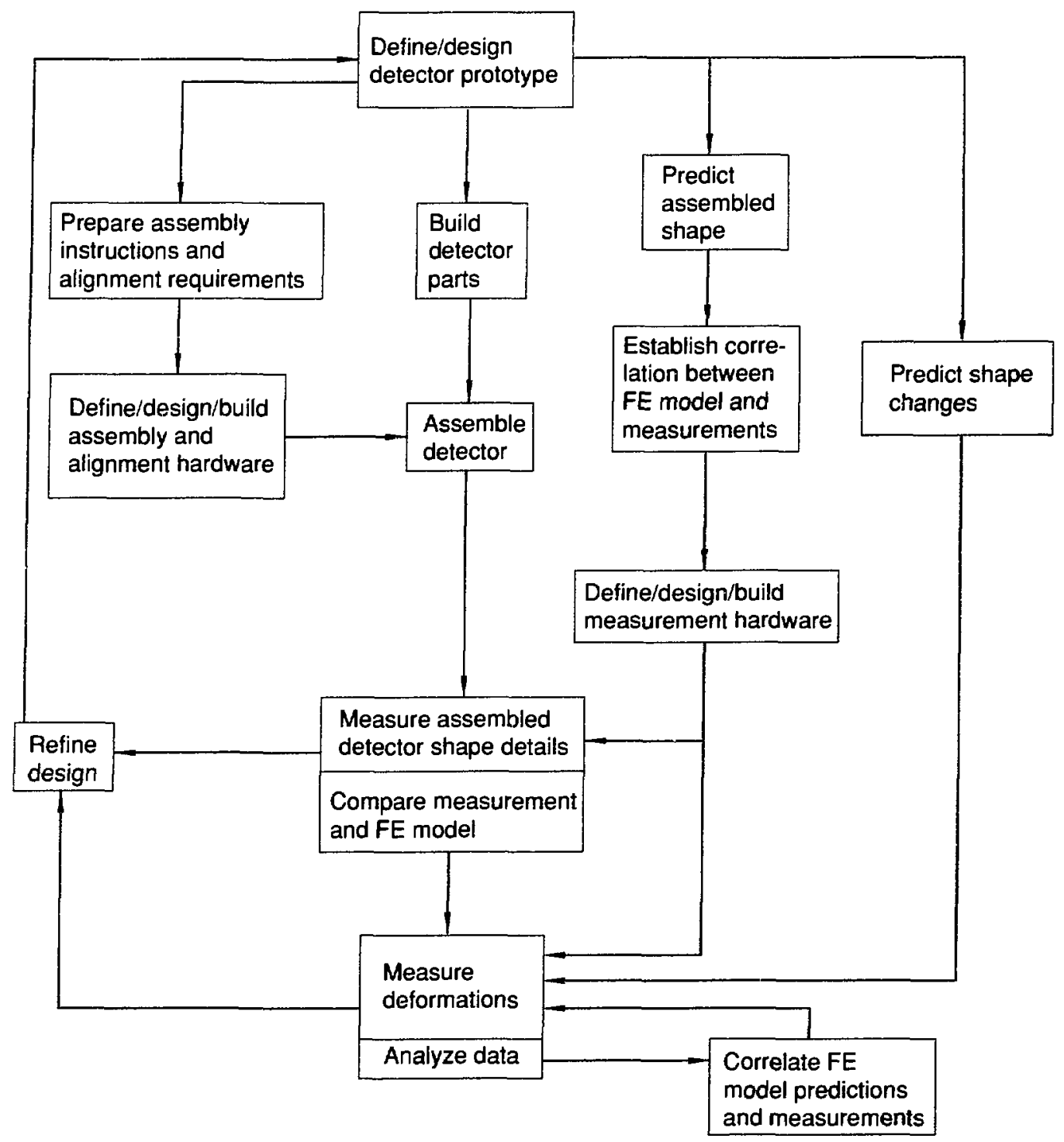

Figure 3-16. Detector prototype workflow for measuring detector shape and deformations.

flexible for conveniently covering larger shapes. This is an important advantage for the large, curved detector geometry.

One conceptual interferometric arrangement is the speckle pattern photography (SPP) layout shown in Fig. 3-18. This arrangement was used by Ennos and Virdee ${ }^{7}$ to measure surf a $a$ motions and tilt of a $1-\mathrm{m}$-Iong cylinder with a $0.5-\mathrm{m}$ diam. This geometry is similar to the proposed prototype. Ennos and Virdee carefully measured and compared the results of holographic interferometry and SPP and concluded that SPP was the preferable technique for several important practical reasons, including the following:

- SPP does not require as high a degree of optical system stability,

- the sensitivity of SPP and holographic interferometry are comparable (to a linit of about $0.1 \mu \mathrm{m})$, and

- SPP is more convenient for isolating in-plane surface motion and surface tilt components. $\mathrm{X}$-ray profiling is probably the best technique for measuring the detector characteristics in the 


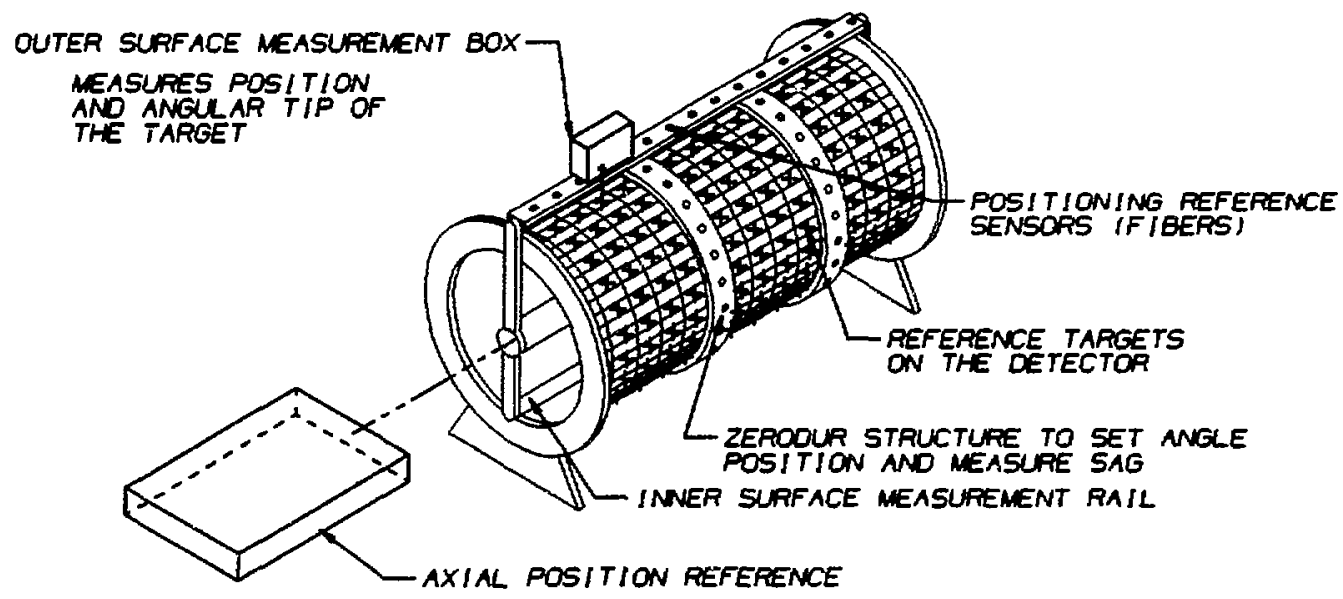

Figure 3-17. Conventional shape measurement concept.

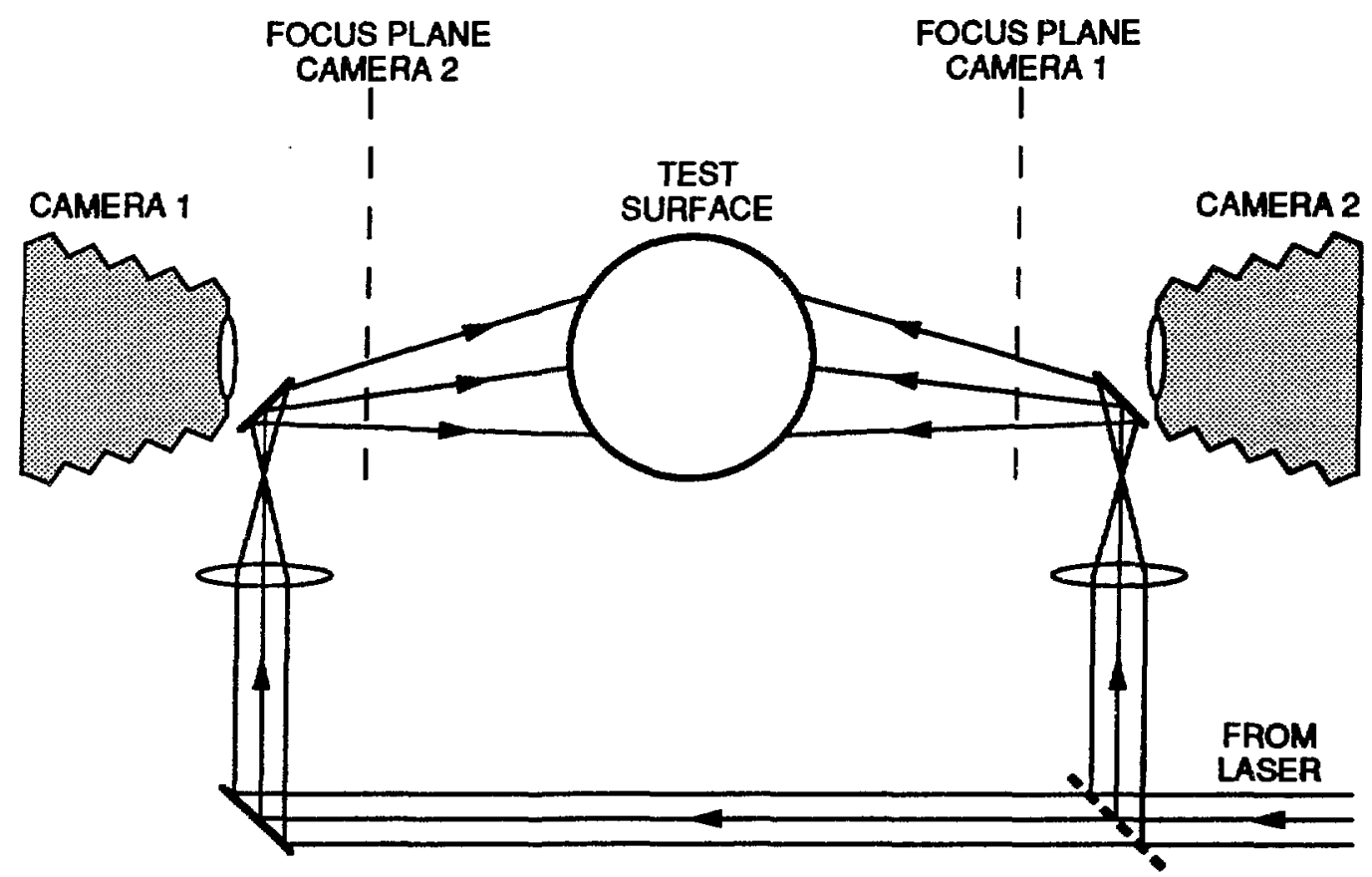

Figure 3-18. Speckle photography optical setup.

field. For that reason, the $\mathrm{x}$-ray techniques need to be developed into meaningful and convenient measurement tools. X-ray profiling is not, however, the best technique to study to obtain an understanding of the prototype structural deformation characteristics. It requires installing detector electronics and signal processing the data to find relative detector positions, and it gives little data about the detector structural characteristics, which are the primary issues for early prototypes. 
These preliminary studies suggest that a combination of conventional mapping, interferumetric. and $x$-ray profiling techniques will be required to completely characterize the detector. Conventional probes are best for measuring the assembled detector shape; interferometry is best for measuring shape changes, and $x$-ray profiling is best for measuring the performance of the detector, including electronic checkout. Subsets of measurements can give partial information at reduced cost. Measuring the detector will be a significant fraction of the work and will add significantly to the cost of building the detector.

\subsection{RADIATION LENGTH CONSIDERATIONS}

The capability to accurately follow the track of an individual particle within the silicon central tracker is fundamental to the success of the detector. Fast digital algorithms will be developed to discriminate the paths of the individual charged particles in an effort to describe their flight path and measure their momentum. The desired effect is to minimize the scattering of the particles in the central tracker. Scattering interactions reduce the momentum and change the paths of the particles, making them difficult to track and yielding an inaccurate determination of their initial momentum. Furthermore, highly energetic photons interact with the material in the tracker producing electron-positron pairs. Background events with such interactions can mimic signal events. The interaction probability for photons, electrons, and positrons is determined by the number of radiation lengths of material encountered by these particles as they traverse the detector. A brief discussion of the analytical treatment of the influence of material parameters on radiation length follows.

\subsubsection{Radiation Length Analytical Discussion}

One radiation length is defined as the average distance, $L_{R}$, over which a high energy electron $\left(E_{e^{\ddagger}} \geq 1 \mathrm{GeV}\right.$ ) loses all but $1 / e(37 \%)$ of its energy to Bremsstrahlung. ${ }^{8}$ Similarly, for photons of infinite energy, the total cross section for producing electron-positron pairs, $\sigma_{p p}$, is

$$
\sigma_{p p}=7 A /\left(9 L_{R} N_{A}\right) .
$$

where $N_{A}$ is Avogadro's number, and $A$ is the atomic weight. The inverse $L_{R}\left(1 / L_{R}\right)$ dependence of the cross section, coupled with the approximately inverse square dependence of $L_{R}$ on the atomic number $Z$ and direct proportionality to $A\left(A / Z^{2}\right)$, clearly demonstrates the need for a sparse mechanical structure of very low $Z$ composition. A single $300-\mu$ m-thick silicon detector represents $0.0032 L_{R}$. Ten such layers comprise $3.2 \%$ of a radiation length. However, the silicon detectors must be supported and serviced by a mechanical structure. Therefore, an attempt must be made to rigidly support the detection medium with as little structural mass as possible. Our objective is to achieve an even more demanding design stability tolerance using less than an equivalent quantity of structural mass as payload mass. One goal is to keep the structural materials and necessary services, such as power cables and cooling, from presenting no more, on the average, than an equivalent radiation length as the detection medium. The term average is required because certain particle trajectories that intercept the tubular space frame, electronics, or cooling rings that perform essential services, encounter somewhat more than the nominal material amount. Every attempt is being made to minimize the fractional volume where this occurs. These stringent requirements have stimulated considerable interest in highly advanced composite materials, such as the MMC tubing examined in Sec. 3.3.2 and the sparse core sandwich constructions elucidated in Sec. 3.3.4. Calculations of radiation lengths have been performed and appear in Table 32 for selected candidate materials. Elemental materials values for $L_{R}$ can be readily found. ${ }^{9}$ However, for compounds such as polymer-based epoxies, each constituent's radiation length must be weighted by its weight fraction present in the compound. The compound's resultant radiation length is then expressed as a summation 


$$
\frac{1}{L_{R}}=\sum \frac{W_{i}}{L_{i}}
$$

where $W_{i}$ is the weight fraction of each constituent and $L_{i}$ is the radiation length of each. The resultant composite radiation length is also similarly weighted for an advanced composite material, such as a fiber-reinforced metal matrix. The most useful figure of merit for a material to be used in the central tracking region is the effective radiation length, $L_{R e}$. This is defined as the radiation length divided by the density of the material. This parameter quantifies the $Z$ of each atom of material and accounts for the number of such atoms in a unit volume. Hence, $L_{R e}$ has units of length and can be used directly in the energy equation $E(x)=E_{0} e^{-x / L_{R}}$ to obtain estimates of the energy losı by a particle traversing a particular medium. Table 3-2 lists values of $L_{R c}$ for selected candidate materials. Among these are silicon $\left(L_{R e}=9.37 \mathrm{~cm}\right)$, graphite/epoxy composite $\left(L_{R e}=25.0 \mathrm{~cm}\right)$, magnesium metal matrix composite $\left(L_{R c}=16.8 \mathrm{~cm}\right)$, and beryllium $\left(L_{R e}=35.43 \mathrm{~cm}\right)$. Clearly, based solely on radiation length considerations, a suppon structure composed of beryllium is the material of choice. An in-depth discussion of other facets of these materials is presented in Sec. 3.3.

\subsubsection{Radiation Length Preliminary Results}

The study is based on a design limit for the structure and on the associated cooling components of $2 \%$ of a radiation length. This stringent requirement forces the trade-off of geometry and material properties.

The present radiation length calculation is based solely on the structural arrangement and, as such, includes none of the details such as electronic packaging and cabling. As a point of reference, the $2 \%$ radiation length for beryllium is $0.71 \mathrm{~cm}$.

Radiation path length is a function of radius, $r$, longitudinal angle, $\theta$, and azimuthal circumferential angle, $\phi$. The angle $\phi$ determines when discrete tubular members of the frame will be intercepted, and $\theta$ is an indicator of deviation to the surface normal, effectively increasing the material thickness in the forward region.

Table 3-5 displays the dependency of the material type, the angle at which the material is intercepted, and the effect of the sparse space frame.

In the forward region, particles encounter structural members at very shallow trajectories; consequently, the effective material intercepted is influenced by this shallow angle. As theta increases from 0 to 90 degrees, a particle would proceed from the forward to the central region, and the effective amount of material would diminish. At shallow angles, the effective material thickness will be three to five times the actual material thickness chosen. The $2 \%$ radiation length requirement has been specified for normal incidence. Furthermore, the design of the structural arrangement is driven by the need to achieve near-normal incidence wherever practical.

It is clear from the table that the design exceeds the $2 \%$. radiation limit for shallow angular trajectories such as those in the forward region. The major contributing factor is the inner shell wall that confines the heat pipe vapor system. If we eliminate this contribution by making the beam tube part of the enclosure, the percentage of a radiation length encountered will diminish significantly.

Table 3-5 shows that for the central region and $\theta=65^{\circ}$, if beryllium is used throughout the structures, the $2 \%$ limit would be achieved. However, beryllium's high CTE disqualifies it from use in the area of the cooling rings and in the space frame where cooldown would cause changes in wafer location. The material options and the reasons for using the various materials for the individual components are discussed in Secs. 3.1.2.2 and 3.3. The baseline design uses graphite/epoxy materials for the composite shell structures and a magnesium metal matrix for the cooling rings and space frame members.

In the baseline design being studied, the $2 \%$ radiation length limit set as a design goal is largely achieved. This project will also include a preliminary design of the structure and of the cabling for the electronics. The radiation length analysis must consider these additional effects to complete this area of study. The overall limiting goal for all materials considered is $3 \%$. This goal 
TABLE 3-5. Radiation Length Calculations

\begin{tabular}{|c|c|c|c|c|}
\hline \multicolumn{5}{|c|}{ FORWARD REGION } \\
\hline Configuration & $\begin{array}{l}\text { Incidence } \\
\text { Angle } \theta \\
\text { (deg) }\end{array}$ & $\begin{array}{l}\text { Azimuthal } \\
\text { Angle } \varphi \\
\text { (deg) }\end{array}$ & $\begin{array}{l}\text { Radiation Length } \\
\text { Beryllium }{ }^{a} \\
(\%)\end{array}$ & $\begin{array}{c}\text { Radiation Length } \\
\text { Graphite/Epoxy } \\
(\%)\end{array}$ \\
\hline With inner shell & 10 & 0 & 2.56 & 4.00 \\
\hline With inner shell & 10 & 30 & 5.90 & 11.0 \\
\hline Without inner shell & 10 & 0 & 1.36 & 2.80 \\
\hline Without inner shell & 10 & 30 & 4.70 & 9.70 \\
\hline Without inner shell & 30 & 0 & 1.60 & 2.60 \\
\hline Without inner shell & 30 & 30 & 1.20 & 1.90 \\
\hline \multicolumn{5}{|c|}{ CENTRAL REGION } \\
\hline Without inner shell & 65 & 0 & 1.90 & 3.20 \\
\hline Without inner shell & 65 & 30 & 1.40 & 2.20 \\
\hline
\end{tabular}

can be achieved if significant advances can be made in the area of cabling for the electronics. Two options are (1) to use the metal matrix space frame tubes as electrical conductors for delivering power to the electronics and (2) to use fiber optics for data iransmission. These areas need to be studied before assurance that the $2-3 \%$ radiation length requirements will be met.

\subsection{STRUCTURAL ANALYSIS AND MATERIALS TESTING}

When undertaking a task with the enormous complexity and stringent operational constraints of an SSC subsystem, it is necessary to design and use materials that represent the forefront of technology. Many potential problems exist in this arena. For example, the complexity mandates a thoughtful design that meets all structural, thermal, and electronics requirements, while the high operational performance criteria mandate the minimum use of materials, and low safety factors or margins for error. A great deal of prototyping and physical testing is needed to cope with this dilemma, but this is both expensive and time consuming. Another approach would be to do a limited amount of prototyping and physical testing and use these results to verify and fine tune mathematical or predictive models that can be used to evaluate and optimize potential designs. We have successfully used such techniques in the past and feel that such an approach is ideally suited to the silicon tracking subsystem of the SSC.

\subsubsection{Development of Predictive Methods}

These robust predictive techniques will be used in many aspects of the design including

- polymeric matrix and graphite composite sandwich constructions,

- metal Matrix and graphite composite planar and tubular constructions, and

- homogeneous metal planar and tubular constructions.

Because predictive methodology and physical testing are necessary to ensure accuracy in our methods, our methods are based largely on FE procedures and classical mechanical testing. After- 
wards, detailed results from such tests and a comparison with predicted values will be presented for all completed tests.

3.3.1.1 Composite Sandwich Predictive Methods. The silicon tracking device conceptual design incorporates the use of advanced composite material sandwich constructions. The use of sandwich panels results in an efficient use of materials and provides a geometry inherently unobtrusive to the radial path of the energetic particles. A detailed structural analysis of the components currently slated for this technology is essential. However, it is neither practical nor desirable to geometrically describe the sections of sandwich material as two facings and a core adhered together. Therefore, it is necessary to describe the geometry and structural behavior of a representative segment of tnis construction in simpler terms. To this end, past experience was useful but insufficient. Some innovations were required to optimize this technology for silicon tracker use.

Advanced composite material sandwich constructions have been successfully used by engineers. Quasi-isotropic graphite fiber facings were used with aramid honeycomb cores to produce stiff, lightweight panels for the wire and fluorescent fiber offset grid (WAFFOG) experiment. These panels featured coefficients of thermal expansion of the order of $0.1 \mathrm{ppm} /{ }^{\circ} \mathrm{C}$ and flexural stiffness to weight ratios nearly 6 times better than monolithic aluminum. However, the minimal mass constraints imposed on the SSC silicon tracker support structure mandate the use of novel sandwich constructions. The core material spatially separates the face sheets and promotes their bending about a neutral axis midway between them. This increases the moment of inertia of the cross section without adding unwanted mass. This is exactly analagous to the I-beam where $20 \%$ of the structure bears $80 \%$ of the load in flexure. The I-beam web and the honeycomb core provide a flexurally stiff medium that separates the load bearing fianges or facings. The conceptual design for its sandwich panels features an ultralight core that allows some localized departure from a common neutral axis for both facings but macroscopically performs its separation task. The analysis tools developed to describe the behavior and predict the performance of the these ultralight panels are addressed in the following paragraphs.

Sandwich constructions depend on the core to transfer bending loads to the facings via shear forces. Hence, the most important parameter for quantifying the the value of an ultralight core is its shear modulus. Candidate core geometries can be evaluated easily by developing a detailed FE model of a few representative corrugations and creating a sandwich element array based on appropriate material properties. This simple model can be loaded in the plane defined by the model with opposing forces above and below its neutral axis.

The shear modulus of the core is determined from the resultant static deformation. If desired, the compressive modulus of the core can be determined from the same model by applying the loading perpendicular to the plane defined by the model and observing the resultant static deformation. Detailed results from an FE prediction and a physical test designed to provide the shear modulus of a polymeric matrix and graphite fiber sandwich panel are presented in Sec. 3.3.4 of this report.

3.3.1.2 Composite Tubing Predictive Methods. The silicon tracking device conceptual design incorporates the use of MMC constructions. These space-age material constructions represent the state of the art in high stiffness-to-weight ratios. Unfortunately, there is a poverty of performance data on these materials, and vendor-supplied data are the sole source of our incomplete information base. The magnesium matrix tubing currently being investigated as a means of structual support for the silicon tracker is thin walled and has an ultralow effective density, yet it has very high bending stiffness. This structure is arranged around the tracker and cradles it in a space frame arrangement. Although it should be designed primarily to resist bending due to inertial loading, the tendency for the thin walls to kink or dent under load is not well known. The space frame can be seen in Fig. 3-15. We plan to develop an FE model of a representative tube from this structure, subject it to bending and axial loading, and predict its resultant deformations. To validate and optimize this prediction, we will similarly constrain, load, and compare an actual 
Mg-MMC tube prototype with the computer model prediction. Kink and dent tests will also be performed to complete our in-service performance scenario for this material candidate.

A frequency spectrum analysis will be performed on the tube, before and after testing, for comparison with FE predictions. A change in the spectrum of natural frequencies of vibration of a composite material provides information regarding delamination and microcracking. The frequency spectrum is a function of the component's mass and stiffness. If the mass remains constant, interply failure will decrease the stiffness of the component and alter the spectrum. The FE models provide accurate frequency spectra of components that are well modeled. The prediction of natural frequencies will provide another checkpoint for model correctitude.

\subsubsection{Space Frame}

The space frame provides structural support for the silicon wafers and related cooling rings. The design criteria applied to the development of this structure are based largely upon dimensional stability, high stiffness to weight ratio, minimal intrusion on the paths of energetic particles emanating from the interaction region, and structural integrity. Each criterion is important for assuring that the silicon tracking system is capable of achieving its operational objectives. However, the interrelation of these with particular materials and constructions is complicated. An effort will be made to describe the detailed effects of material choices and configurations on system performance.

Stringent dimensional stability is required of the space frame. Achieving the demanding baseline design requirements for the detector assembly enumerated in Table 3-1 rests primarily on the structural performance of the space framie. Monolithic metals possess CTEs large enough to exceed the dimensional tolerance of wafer placement during a temperature excursion of less than $1^{\circ} \mathrm{C}$. This is only one motivation for exploring the use of advanced composite materials as the primary candidates for space-frame construction.

Highly advanced materials such as MMCs are frequently used by the aerospace industry. These materials have been successfully deployed in space shuttles and in the recently launched Hubble Space Telescope. It is currently envisioned that commercial aircraft will make greater use of these materials in the next generation of civilian air transport. The strength, flexibility, and tailorability of the MMCs provide them with a distinct advantage over the more conventional monolithic metals and the polymeric matrix composite materials.

However, the engineering of MMCs is much like that of the more familiar polymeric matrix composites. For example, the "rule of mixture" indicates that when materials are combined, the percentage of certain properties added from each element will emerge proportionately in the newly created composite, or in an MMC with 50\% fiber and 50\% matrix, the trade-off of performance properties should be equal. Photomicrographs of the heterogeneous nature of these composites are shown in Fig. 3-19, courtesy of DWA Composite Specialties, Inc.

For MMCs, fibers increase modulus and strength, and allow tailoring of such properties as CTE and thermal conductivity. Matrix materials are useful structural elements in their own right. The appropriate selection of fibers, matrix, and layer orientations can allow properties of a component to be tailored to meet specific design needs. Strength and stiffness could be specified in one direction, for instance, with CTE in another. Unidirectional continuous-fiber MMCs are nonisotropic, that is, they are stronger and stiffer in the direction of the fibers than perpendicular to them. Transverse strength, however, has proven great enough for use in components such as stiffeners and struts on military aircraft and scientific experiments.

The CTE information presented in Figs. 3-8 and 3-9 reflects the large tailorability range, expressed as a function of fiber volume fraction, that is possible with polymeric and metal matrix composites. The effect of fiber volume fraction variation on elastic modulus must be considered in concert with that of CTE. To ensure the axial dimensional stability of the 6-m-long space frame requires a CTE approximately equal to zero. This can be accomplished with a unidirectional or a quasi-isotropic construction composed of either a polymeric- or a metal graphite-reinforced matrix. ${ }^{11}$ The quasi-isotropic construction would provide a nearly zero CTE in both the axial and transverse dimensions of the body. The effective elastic modulus of this structure would be much less than a unidirectional construction possessing a CTE near zero. In fact, the tubular design of 

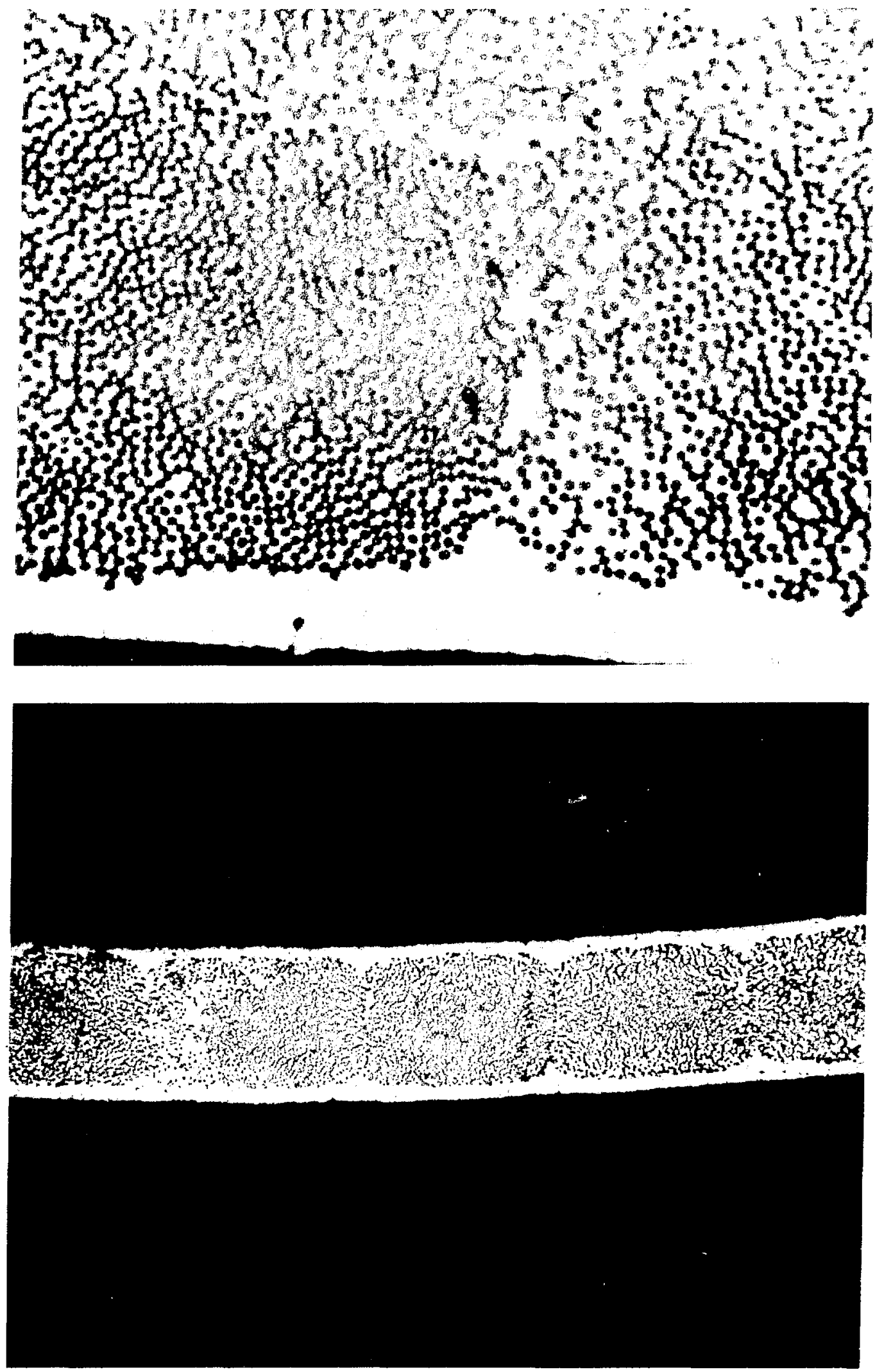

Figure 3-19. (Top) Typical P100 graphite/aluminum 2-ply tube with 45\% fiber by volume; (Bottom) Typical P100 graphite/aluminum I-ply tube with $40 \%$ fiber by volume. Pholo courtesy of DWA Composite Specialties, Inc. 
the space frame reduces the importance of the transverse CTE because of the small lengths for expansion present in the tubes radial directions. Thus, on the basis of this scenario. the $\mathrm{Mg}-\mathrm{MMC}$ construction, coniposed of approximately $55 \%$ graphite fiber with a CTE nearly zero and an axial elastic modulus of about $485 \mathrm{GPa}$, is the baseline choice for the space frame's structural members.

The information presented in the selected material candidates table, Table 3-2, includes calculations of stiffness-to-weight ratios and specific stiffnesses of selected materials. Among these are monolithic metals and polymeric and metal fiber-reinforced matrix composites. Larger specific stiffness values are desired because they represent an efficient use of structural materials. This is particularly critical in the central tracking region where any material atoms, other than the detection medium, represent sources of background noise and signal loss, as described in Sec. 3.2. Meeting the stringent structural requirements of the detector requires using, sparingly, the stiffest materials in existence. As shown in Table 3-2, based solely upon specific stiffness criteria, the graphite and epoxy composite material is preferable. However, it should be noted that the specific stiffness value of $20 \times 10^{8} \mathrm{~cm}$ shown for P75 graphite and epoxy is a unidirectional value. This implies that only the axial direction possesses such a high value. An isotropic material, such as boron-carbide, with a specific stiftness of about $18.15 \times 10^{8} \mathrm{~cm}$, has no preferential direction of excellence. However, the CTE of boron-carbide is approximately $4.73 \mathrm{ppm} /{ }^{\circ} \mathrm{C}$ and cannot be altered. A more important consideration in the use of this material is its excessive hardness. This makes it an extremely difficult construction material to use. Accounting for all considerations introduced thus far, polymeric and metal-fiber-reinforced matrix composites are best overall.

As previously mentioned, the need to keep the quantity of structure in the central tracking region to a minimum is required. This subject is explored in depth in the radiation length consideration section, Sec. 3.2. Table 3-2 lists the effective radiation lengths ( $L_{R e}$ ) of various material candidates. Beryllium tops this list, with a thickness of $35.43 \mathrm{~cm}$ required to reduce the energy of a high-energy electron to $37 \%$ of its incident energy. Graphite reinforced epoxy is second, with an $L_{R e}$ of $25 \mathrm{~cm}$. The MMCs are a bit lower but still provide reasonable values of 13 to $17 \mathrm{~cm}$. The impressive $L_{R e}$ of beryllium must be considered concurrent with its CTE and cost disadvantages.

The broad heading of structural integrity includes some of the aspects of the space frame previously explored and several others. This shouid not be confused with integrity that focuses on the study of the failure of a connection or joint, but rather it refers to the appropriate choice of structural members and supports and to the resultant dynamic response of the structure. This kind of analysis is amenable to numerical solution. FE computer programs are capable of numerically solving a mathematical model that approximates the structural configuration and its structural components, supports, and loadings. This is a powerful design tool, and it is also described as a predictive tool in the predictive methods section (Sec. 3.3.1).

Many FE cases were run in an effort to estimate the static deflection and structural modes of vibration as a function of the structural tubing size and modulus and the support method. In this analysis, we considered the following masses: $33.4 \mathrm{~kg}$ of silicon, representing 48 vertical planes and 10 cylinders: $33.2 \mathrm{~kg}$ of cooling rings, using both graphite/epoxy and aluminum MMC: and the mass of the space-frame structural tubing. Table 3-6 provides information regarding the structural mass for the four cases of interest. Figure 3-20 displays the fundamental vibrational frequency and the maximum displacement for each case.

For a long cylinder, a bending mode existing as the fundamental, first, natural frequency indicates a more sound structural support arrangement. As shown in Fig. 3-20, this bending mode is generally achieved where four discrete points are used for structural support. Unfortunately, this method is not ideal from a kinematics standpoint. This figure also shows maximum deflection and first bending mode expressed as a function of elastic modulus and tube size, and displays ihe wall thickness, and number of support points. A stiffer structure would exhibit less deflection and possess a higher fundamental frequency value. For example, if the space frame were constructed solely of $33.7-\mathrm{mm}(1-3 / 8$-in.) tubing with a wall thickness of $1.1 \mathrm{~mm}(0.045 \mathrm{in.})$, an elastic modulus of $515 \mathrm{GPa}$, and a 4-point support scheme, the maxinum deflection would be $0.22 \mathrm{~mm}$ and in its fundamental natural mode of vibration bending would occur at approximately $35.7 \mathrm{~Hz}$. 
TABLE 3-6. Space Frame Structural Member Dimensions and Resulting Structural Mass

\begin{tabular}{cccc}
\hline Case & \multicolumn{2}{c}{ Structural Member Dimensions } \\
\cline { 2 - 3 } & $\begin{array}{c}\text { Inside Tube } \\
(\mathrm{mm})\end{array}$ & $\begin{array}{c}\text { Outside Tube } \\
(\mathrm{mm})\end{array}$ & $\begin{array}{c}\text { Structural } \\
\text { Mass } \\
(\mathrm{kg})\end{array}$ \\
\hline A & $35(1.1)$ & $35(1.1)$ & 31.7 \\
B & $35(1.1)$ & $25(1.1)$ & 27.2 \\
C & $35(1.1)$ & $17(0.8)$ & 18.9 \\
D & $25(1.1)$ & $17(0.8)$ & 16.3
\end{tabular}

a Tube diameter and (wall thickness).

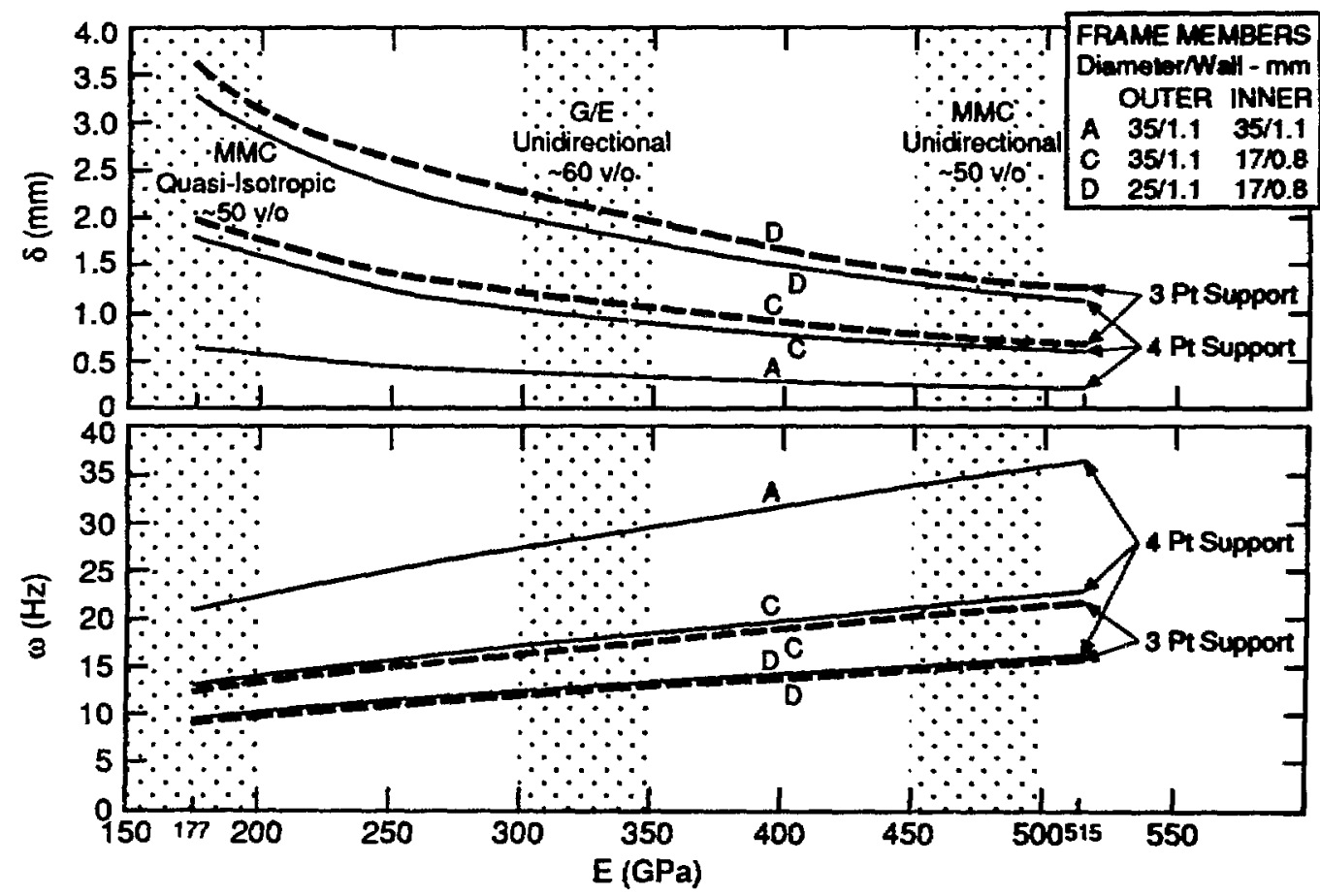

Figure 3-20. Space frame gravity-induced displacements, $\delta$, and fundamental natural vibration bending frequency, $f$.

The gravily-defonned configuration is shown in Fig. 3-21. A more optimal engineering design will be sought to maintain the low deflections and high fundamental frequencies achieved by this baseline case while minimizing material mass and maximizing radiation length properties. Trade- 


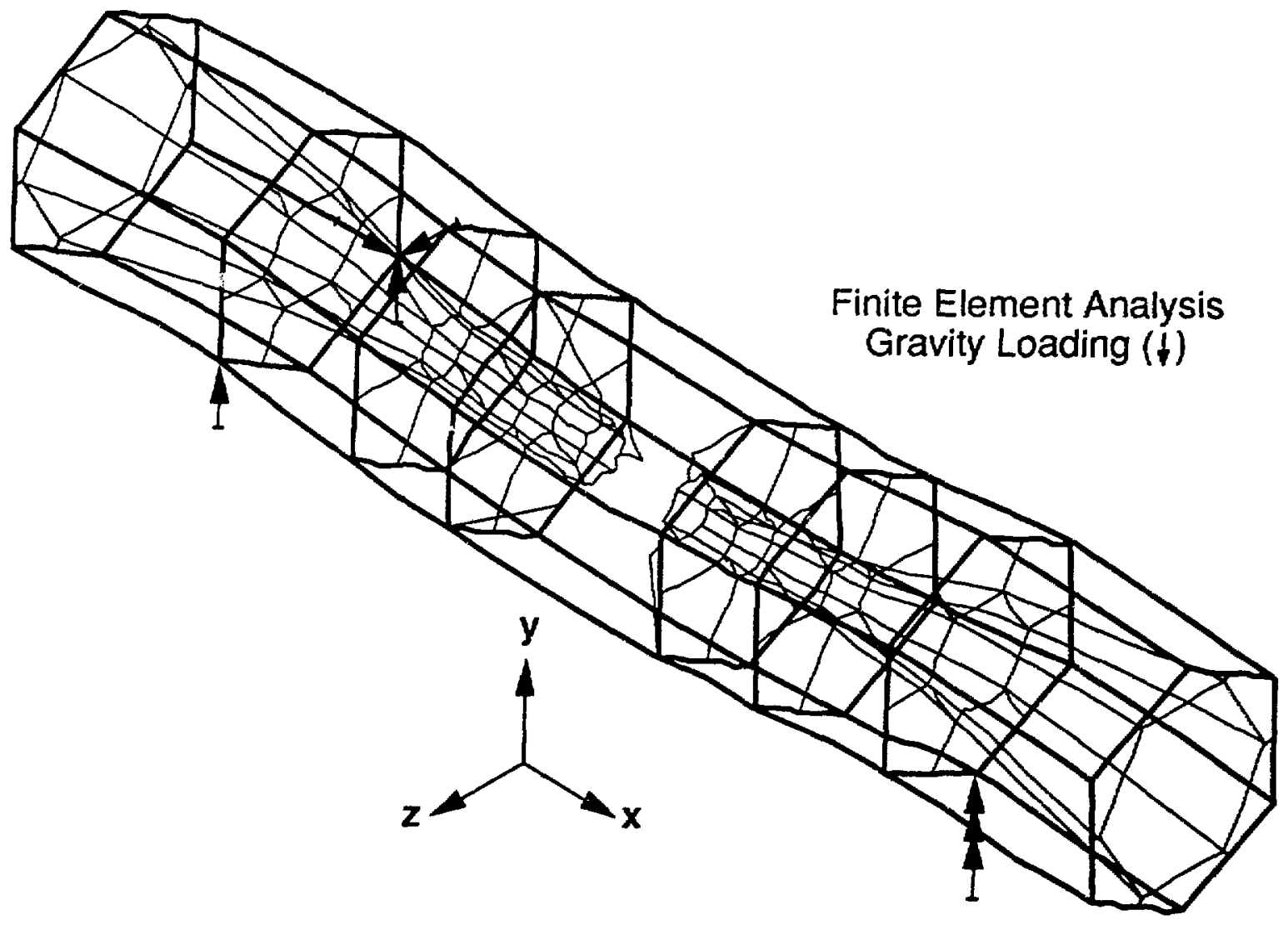

Figure 3-21. Metal matrix space frame (defomed configuration). 
offs of stiffness, mass, CTE, and radiation length are always required. The current space-frame design effor focuses on an optimization of all of these parameters.

\subsubsection{Sandwich Panels}

The lightweight requirements for the central detector have mandated sparse suppon of the silicon wafers. Even a very low effective density and high efficiency construction using a honeycomb geometry will not suffice. The need for high specific stiffness and high radiation length have precluded the use of more conventional materials and construction techniques. A study of material candidates was undertaken to evaluate possible detector materials. Table 3-2 enumerates the materials candidates. Most of the materials studied were selected for their high specific stiffnesses and high radiation lengths. Some monolithic materials and advanced composite materials are among the materials studied.

Beryllium is a unique metal with good specific stiffness and excellent radiation length properties. Beryllium is used in numerous space applications. Recently, considerable interest has been placed on its use in the NASP program. Graphite/epoxies have been chosen as a candidate for the cylindrical support shel!. An open chamber design is required for service access and to reduce the radiation length ossociated with conventional honeycomb structures. Graphite/epoxy construction can be engineered to particular design requirements, such as CTE, stiffness. and cost. This flexibility in design provides a wide range of design options.

The cylindrical panel geometry used for silicon wafer support will incorporate ultralightweight panels. These panels will have facings and a core optimized for strength and CTE. Al this point in the design process, it is important to understand the mechanics of such panels.

Analytical, and experimental techniques were used to explore and verify the design concept. Prototype panels are being built from graphite/epoxy and beryllium to verify our analytical methods. These sample sandwich panel fabrications are also providing useful infornation regarding manufacturing techniques. Although the sandwich geometry selected is not necessarily the final configuration, the construction features will demonstrate most of the requirements for a detector component.

3.3.3.1 Sandwich Panel Core Optimization. An optimization study for a graphite/epoxy panel has been performed. The objeclive of the study was to parametrically investigate the effects of material geometry trade-offs on the panels physical properties. Two analytical models were constructed. The first consists of the entire panel modeled as a sandwich, (Fig. 3-22), and the second is a detailed section of the panel (Fig. 3-23). The sandwich model assumes that the user has prior knowledge of the core material properties. Because the core is sparse and the only known properties are those of the laminate used to form it, a second numerical model was needed to obtain the adjusted core properties. This detailed finite element model of the rib was used to recover the core engineering properties.

The full panel was then used to predict deflection resulting from the four-point bend test shown schematically in Fig. 3-24. The actual hardware (Fig. 3-25) was prepared for testing then used to verify the analytical model. This step is essential for further designs to ensure a proper understanding of the panels' behavior. The calculated core shear modulus is $2.0 \mathrm{MPa}$ using the theoretical model. Fig. 3-26 demonstrates the numerical results for the test panel. Using the calculated shear modulus, the predicled deflection is $0.624 \mathrm{~mm}$. The actual measured deflection (average of two outer measurements and one midpoint measurement) is $0.592 \mathrm{~mm}$. This excellent agreement, within $5 \%$, was achieved even though deflection is a function of rapidly varying shear modulus for the case analyzed.

The first optimization trade-off was to look at the effect of the core thickness on the core shear modulus. Three cases were studied: and core angles of $45^{\circ} .60^{\circ}$, and $75^{\circ}$. Although the geometry selected closely resembles the $60^{\circ}$ case, it was not feasible to match the areal densities exactly. Therefore, the density was conservatively selected to be higher for the $75^{\circ}$ case and lower for the $45^{\circ}$ case. Results of this sludy, shown in Fig. 3-27. indicate that the $45^{\circ}$ case has substantially higher core shear modulus for a given thickness. Another interesting phenomenon 


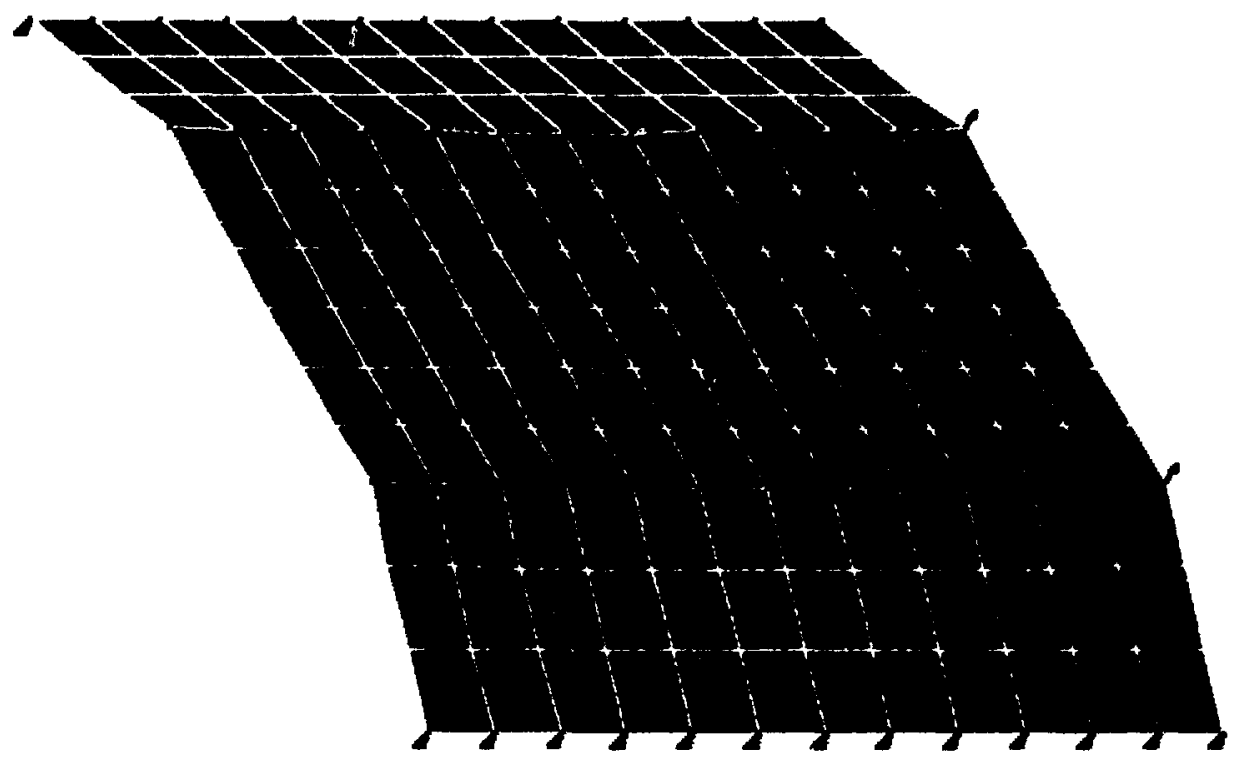

Figure 3-22. FE model of the full sandwich panel with constraints used for the four-point bend test..

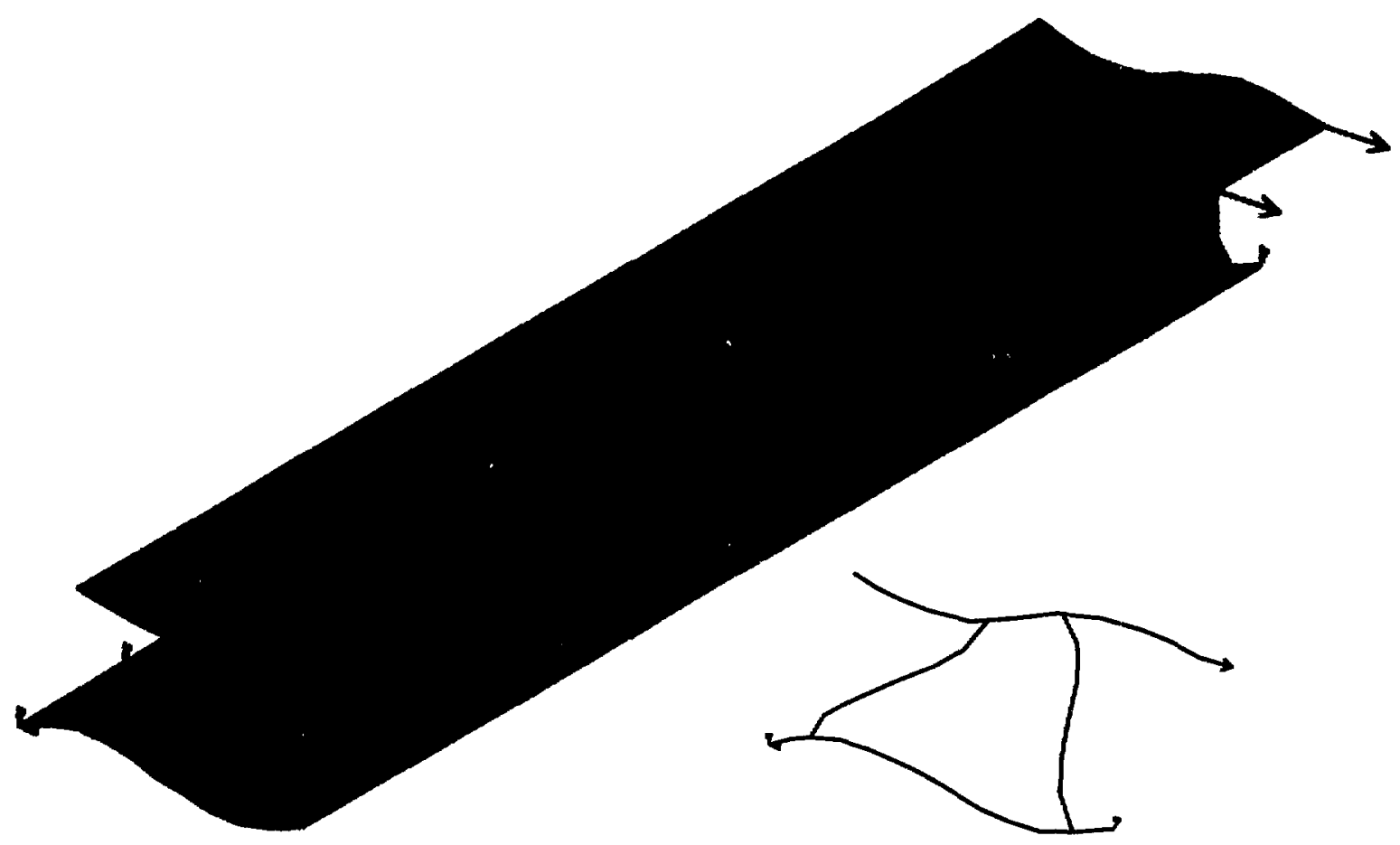

Figure 3-23. Detailed FE model used to predict core shear modulus (pictorial and end views). 


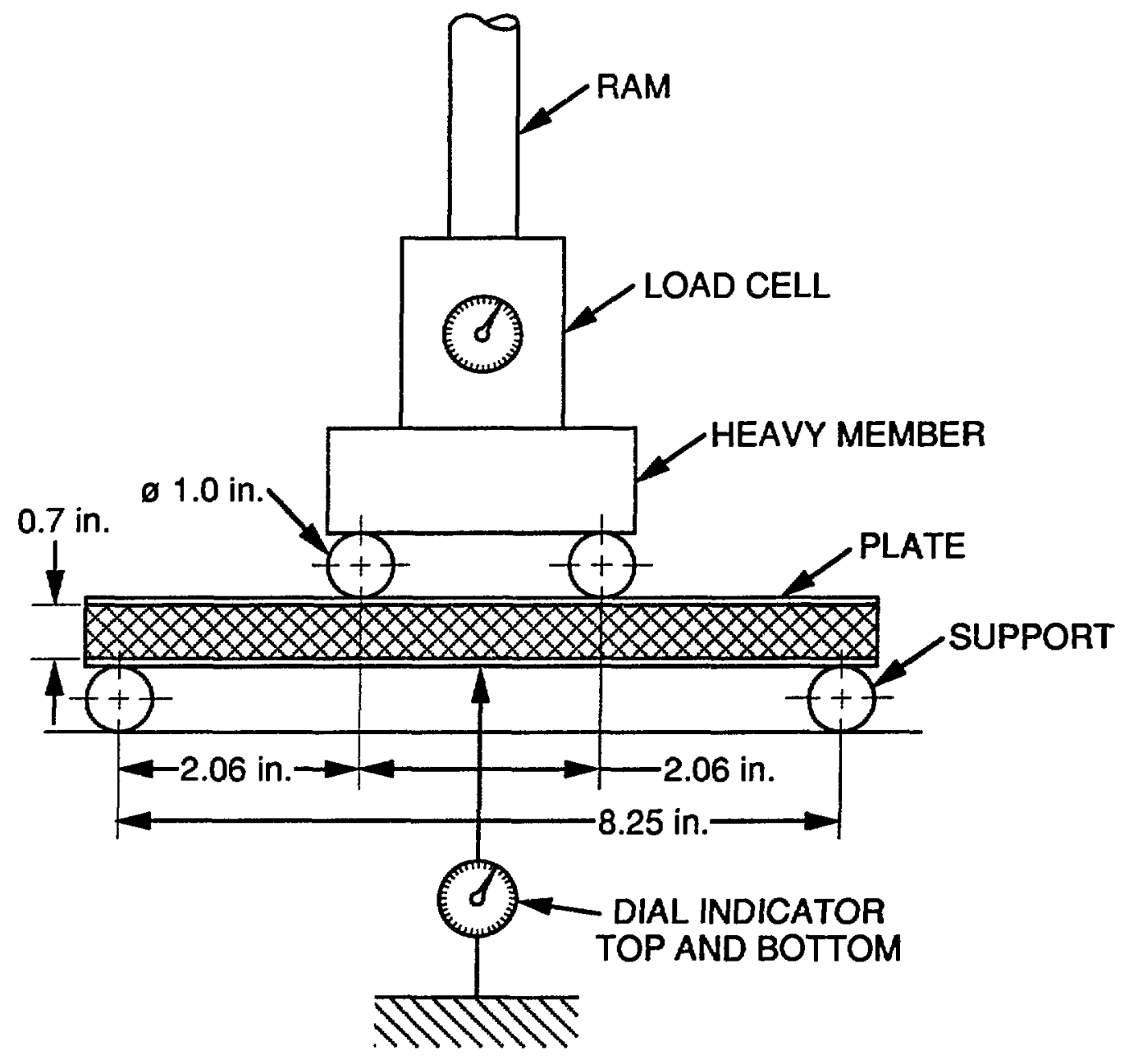

Figure 3-24. Four-point bend test schematic. 


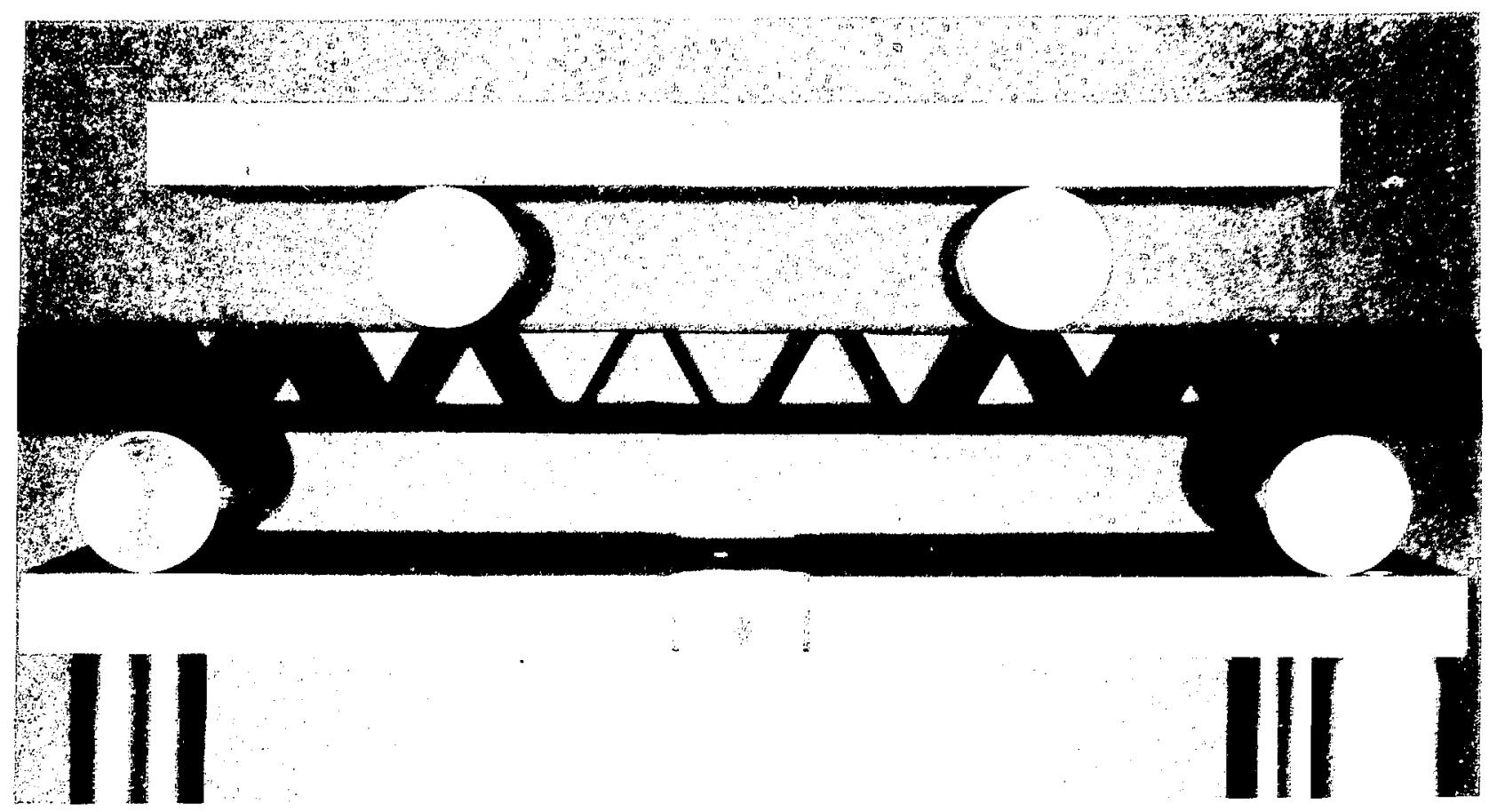

Figure 3-25. Four-point bend test experimental setup.

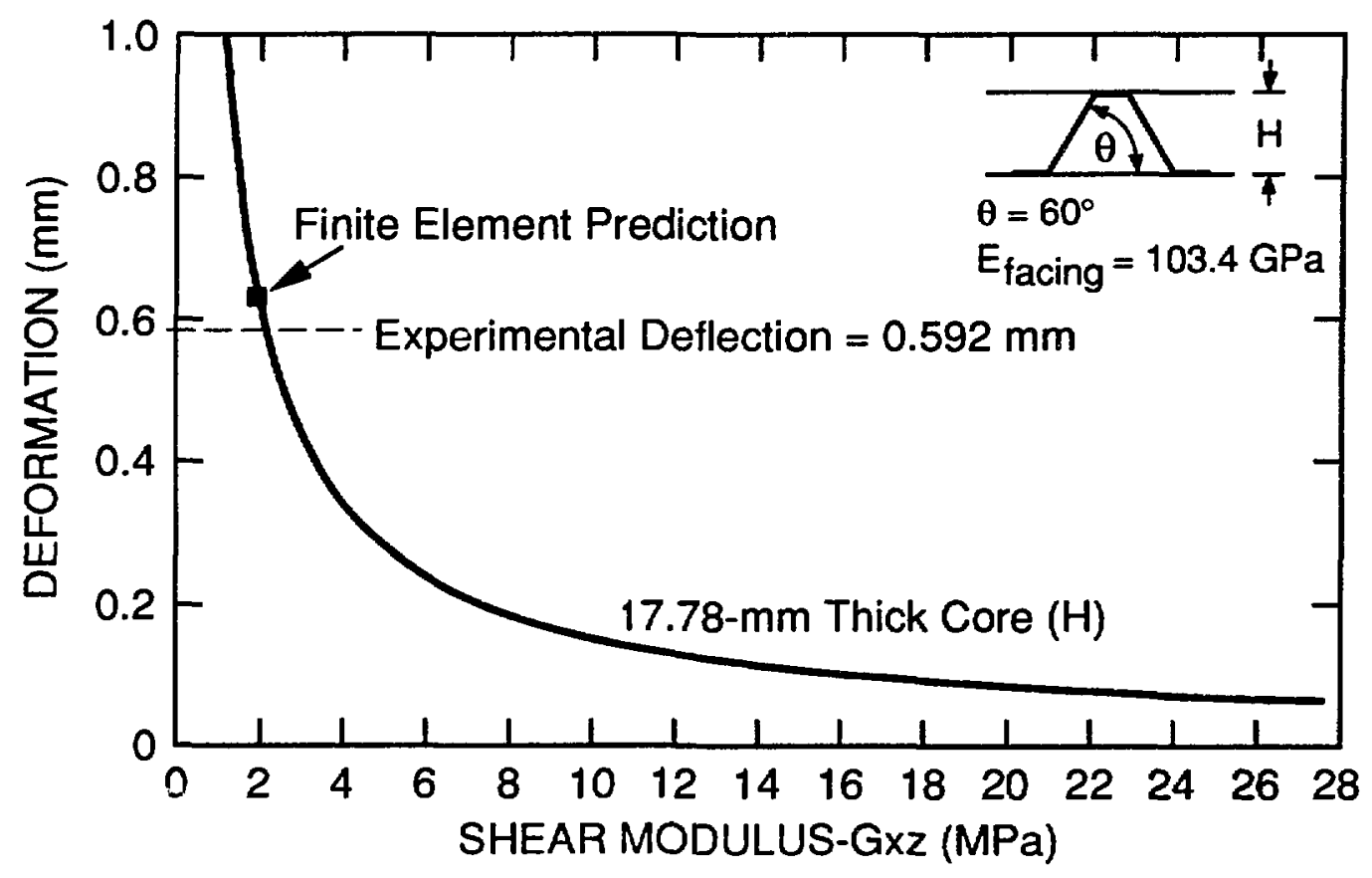

Figure 3-26. Numerical and experimental results of four-point bend test. 


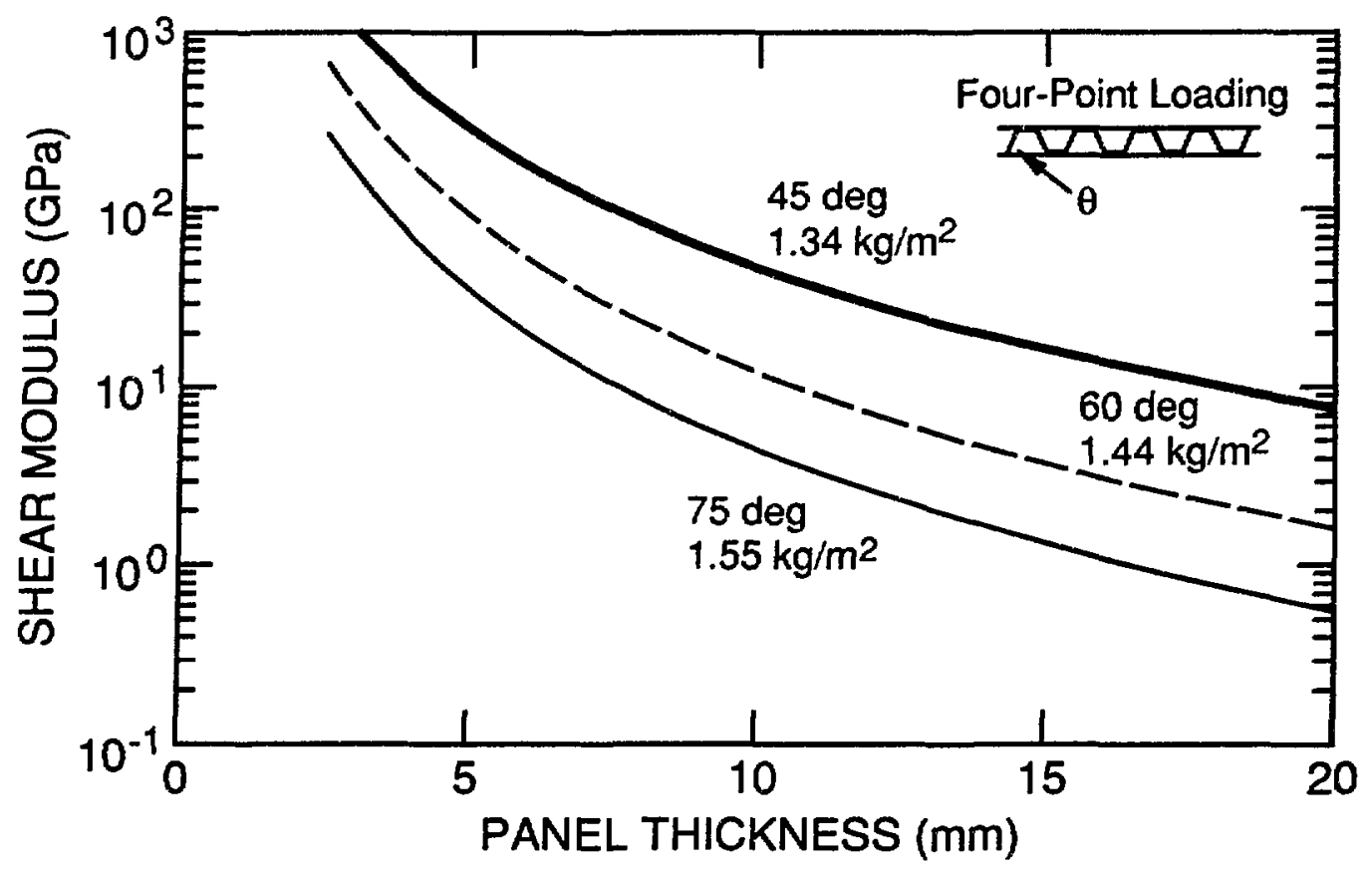

Figure 3-27. Shear modulus optimization expressed as a function of areal density.

is the rapid decay of the core shear modulus with increasing core thickness. Low shear modulus results in a high degree of coupling between deflection and core shear mudulus. This plot considers the effect of web angle and panel thickness on the shear modulus.

The second optimization trade study was to balance panel deflection caused by bending and shear effects. A family of plots were constructed showing the panel deflection as a function of panel thickness. This process uncovers a minima where the deflection can be minimized. The optimization trades core shear stiffness for face bending stiffness. The two effects are independent of each other and can be linearly superimposed. The results of this study are shown in Fig. 3-28. Two interesting results should be noted. The first is that to the right of the minima, shear effects dominate, and to the left, bending effects dominate. The second clearly shows the $45^{\circ}$ case to be stiffer for our constraints.

The next logical optimization step in looking at the panel geometry is to see which panel thickness is least sensitive to changes in areal density. For this study the $60^{\circ}$ case was selected for the baseline. It is apparent from Fig. $3-29$ that, at an areal density of $1.45 \mathrm{~kg} / \mathrm{m}^{2}$, the four different janel thicknesses show only small differences in deflection. However, as areal density decreases (thinner material laminate), a substantial difference occurs. This effect is dominated by the core shear modulus in the thicker panels.

Further optimization will be undertaken to study curvature effects. To date, only the deflection in a flat panel has been addressed, but further studies will look at an entire cylinder made from the graphite panel. These studies will show the effect of trading panel thickness on longitudinal deflection. These studies can be compared with the panel thicknesses versus local deflections shown in Fig. 3-28. Studies undertaken to date clearly show the importance of going to another panel geometry than was originally selected. But until further engineering trade studies are undertaken to determine the cylindrical geometry effects on the overall maximum sag in the structure, it would be premature to assume the new geometry configuration.

Some early conclusions that can be drawn from this initial study are

1. The geometry selected will have to be evaluated extensively to evaluate overall structural performance. 


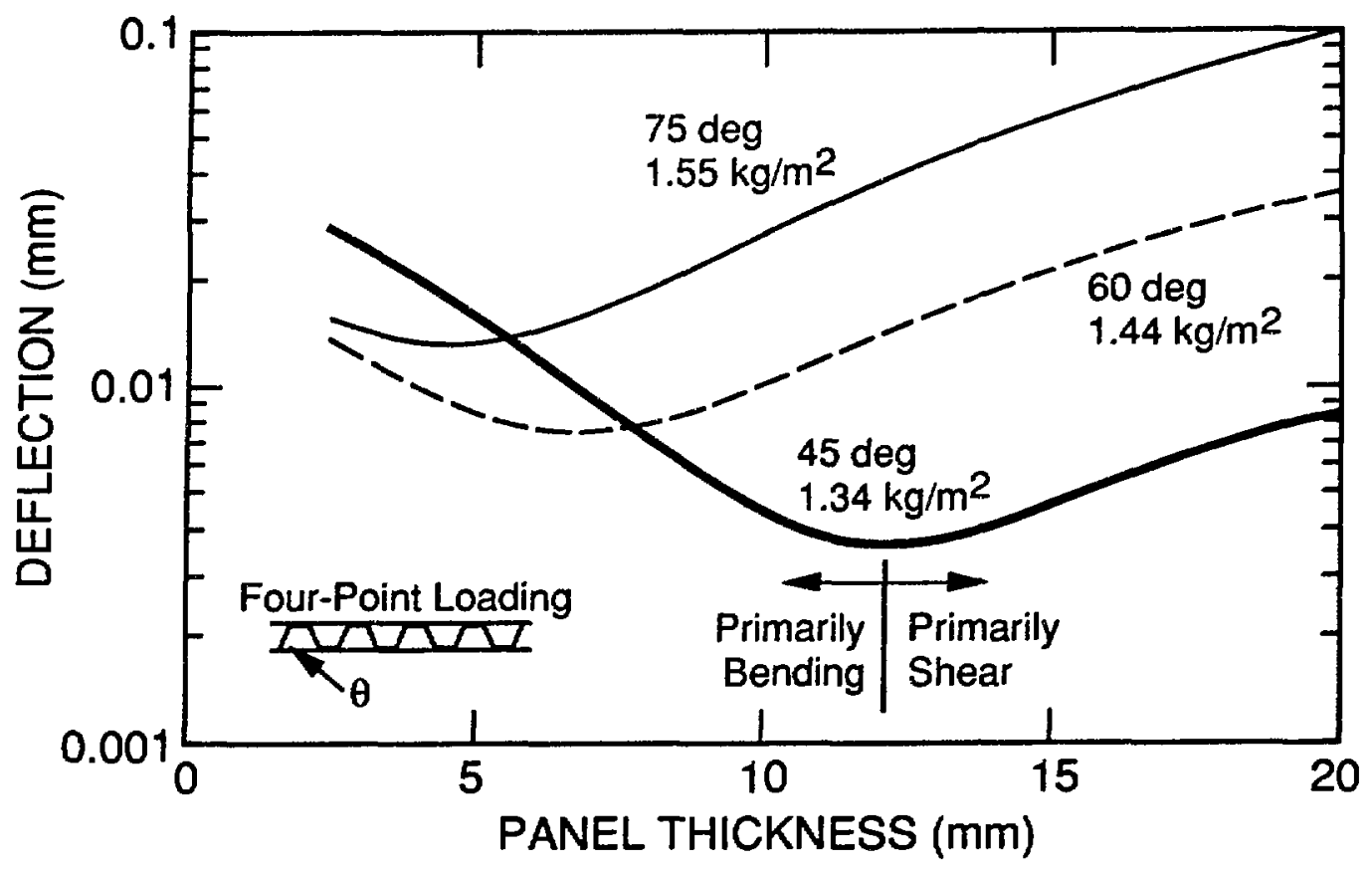

Figure 3-28. Sandwich Panel geometry optimization expressed as a function of areal density.

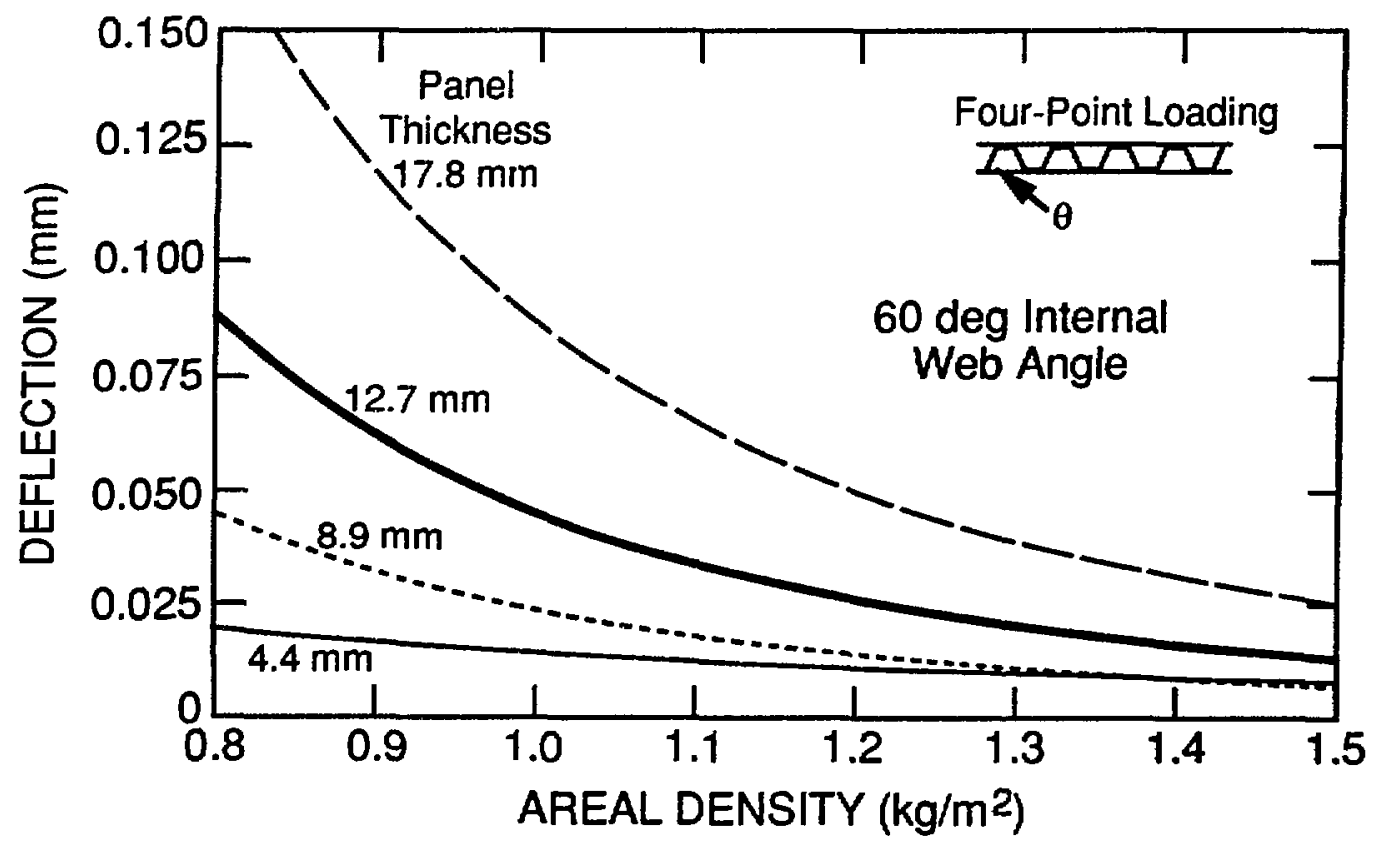

Figure 3-29. Sandwich Panel core optimization. 
2. Other factors, such as utilities, cooling, and cabling, will have a strong bearing on the design. These considerations will be integrated into the design as it matures.

3.3.3.2 Beryllium Sandwich Panels. the use of beryllium as a design material in the silicon tracker can be found in the material options section (Sec. 3.1.2.2) and the radiation length analytical discussion and preliminary results sections (Secs. 3.2.1 and 3.2.2). A beryllium sandwich panel will be delivered and tested for effective core shear modulus, isotropy, and resistance to radiation bombardment. FE models of the panel will be constructed to optimize sandwich panel parameters such as core height and included angle.

\subsubsection{Materials Testing}

Materials have been subjected to physical tests and radiation tests to quantify their suitability for the SSC operating environment. Detailed results from this testing will be presented in the following two sections.

3.3.4.1 Physical Testing. Material swatches were fabricated to undergo tensile specimen testing. Fifteen pieces were prepared, ten were used in chemical baths to simulate the two cooling fluid candidates, and five will be used for high-dose radiation damage testing. Baseline tensile tests were conducted prior to soaking, and the same tests were performed after soaking. The results of the tensile specimen tests are shown in Table 3-7. The results indicate that there are no apparent incompatibilities between the graphite/epoxies and working fluids. The small changes in elastic modulus are of no concern at this time.

The panel-facing material properties were calculated analytically and were subsequently verified in a standard tensile test. The tensile pull tests revealed an error in the ratio of graphite fiber to epoxy in the material used. Vendor specifications are $55 \%$ graphite and $45 \%$ epoxy by volume. Testing demonstrated $38 \%$ graphite and the remainder epoxy. Table 3-8 shows the analytical and experimental predictions for the tensile pull-test pieces. The quasi-isotropic modulus of the panel should have been approximately $106.4 \mathrm{GPa}$ for $60 \%$ graphite composition, but it was found to be closer to $70.3 \mathrm{GPa}$, indicating approximately $38 \%$ graphite fiber by volume. The analytical elastic modulus in Table 3-8 is based on the corrected value of fiber volume fraction.

3.3.4.2 Radiation Testing. Troubling questions regarding how graphite/epoxies will perform in the SSC operating environment necessitated some preliminary material testing. A study plan was devised to look at the first-order effects of radiation and chemical degradation.

A maximum radiation dosage of $10 \mathrm{Mrads}$ is anticipated over the 10-year life of the detector. One of the primary issues in the study of the feasibility of the silicon tracking system is that of radiation damage. The survivability of the detectors and their associated front-end electronics are questionable, and the capability of the support structure in maintaining the highly precise $(\sim 5 \mu \mathrm{m})$ positional stability of the detectors in the radiation environrnent must be verified. ${ }^{12}$

The mechanical support structure for the silicon tracker will be subjected to radiation damage from charged particles and photons that emanate directly from the interaction point and neutrons that result from the interactions of the primary particles and their interaction products in the calorimeter. Over the 10-year lifetime of the experiment, at a radial distance of $10 \mathrm{~cm}$, the total fluences are expected to consist of approximately $10^{14}$ charged particles $/ \mathrm{cm}^{2}$, an equivalent fluence of photons, and on the order of $10^{13}$ neutrons $/ \mathrm{cm}^{2}$. The charged particle fluence will have an inverse square spatial dependence $\left(1 / R^{2}\right)$. At small radii, the photons will have a similar radial dependence, but at larger radii the fluence will begin to become constant because the population will be dominated by albedo photons from the calorimeter. The neutron fluence is essentially independent of radius, but it is quite sensitive to the geometry of the central cavity. It can be reduced by using a layer of moderator-absorber, such as $\mathrm{CH}_{2}$-Boral. A 5-cm-thick layer will give roughly a factor of 3 reduction in the integral number of neutrons with an energy greater than $100 \mathrm{keV}$. 


\begin{tabular}{lccc}
\hline TABLE 3-7. & \multicolumn{3}{c}{$\begin{array}{l}\text { Graphite/Epoxy Tension Test Results, Before and } \\
\text { After Hydrocarbon Soak }\end{array}$} \\
\hline \multirow{3}{*}{ Fluid } & \multicolumn{2}{c}{$E$ (GPa) } & \\
\hline cis-2-Butene & Before & After & \% Change \\
& 65.1 & 64.8 & 0.5 \\
& 64.3 & 63.9 & 0.6 \\
& 65.3 & 65.0 & 0.5 \\
Butane & 69.0 & 54.1 & $21.6^{a}$ \\
& 68.4 & 68.4 & 0.0 \\
& 73.1 & 67.9 & 7.1 \\
& 63.0 & 63.6 & 0.9 \\
& 68.6 & 69.8 & 1.7 \\
& 64.7 & 63.2 & 2.3
\end{tabular}

Note: Material used-P75/1939-3, Quasi-isotropic, 8-ply laminate; $38 \%$ graphite by volume; prediction would be $70.8 \mathrm{GPa}$. Soak period: 13 days @ 24 ${ }^{\circ} \mathrm{C}$.

a Suspected strain-gage failure.

\begin{tabular}{lcr}
\hline TABLE 3-8. & \multicolumn{2}{c}{ Graphite/Epoxy Moduli and Poisson Ra- } \\
& tio Analytical and Tension Test Results \\
\hline & $E(\mathrm{GPa})$ & $\nu$ \\
\hline Analytical & 70.3 & 0.31 \\
Experimental & 67.6 & 0.30 \\
(15 averages) & & \\
\hline \hline
\end{tabular}

Although these radiation levels are low compared with those commonly encountered and tested for in fission power reactor facilities, the problem here is of a different scope and involves unique materials and structures. We are interested in effects such as creep, warping, and swelling, which lead to the slightest dimensional changes of the items these structures support. The required positional stability of any part of the structure relative to any other is approximately $5 \mu \mathrm{m}$. This applies to a structure that is up to $6 \mathrm{~m}$ long and over $1 \mathrm{~m}$ in diam. Because it is necessary to attain maximum stiffness of the structure, using minimal support mass, degradation of the mechanical properties of the materials used to construct the structure must be known.

Another potential problem is the interaction of the materials in the radiation environment with the working fluid of the heat pipe that we propose to use for cooling the detector array. Although the doses expected at the SSC were not high compared with those studied in typical material radiation tolerance tests, the tolerance tests examined only the gross properties of the materials. We are interested in knowing which of the effects in chemical environments might be imposed by the heat pipe cooling scheme currently being investigated. The materials effort is seen as a several year project. This effort will begin with an examination of samples of various materials and will evolve into testing full-scale modules.

A graphite epoxy sandwich construction panel is being exposed to neutrons at the Los Alamos Spallation Radiation Effects Facility (LASREF). The panel is located behind several meters of iron shielding from the point at which the $800-\mathrm{MeV}$ and $\sim 1-\mathrm{mA}$ proton beam of the Los Alamos Meson Physics Facility (LAMPF) strikes the beam stop. This provides the engineers 
with an opportunity to observe the performance of the structural materials as they accumulate a total dose near that expected at the SSC over the lifetime of the system.

Some materials data on epoxy resins are available; however these data are sufficiently vague to require further testing of each resin of interest. The materials literature indicates that there is no appreciable loss of strength for the epoxies selected. However. no information is available on the dimensional stability of the mate $i$ al. It is believed that the aromatic isocyanate and aromatic amine epoxies will perform equally well in the SSC radiation environment. One further potential problem is the interaction of the materials in a radiation environment with the working fluid of the heat pipe that we propose to use for cooling the detector array.

Two sandwich panels were fabricated and mapped for flatness prior to exposing the panels to radiation. The intent is to identify whether dimensional problems will be encountered as the result of a 10-Mrad radiation dosage, the expected SSC level. It is conceivable that the radiation could cause the residual stresses to relax and, thus, alter the shape of the panels. The panel mapping is required to satisfy our concerns regarding the anticipated SSC dosage levels.

The initial panel, having acquired a neutron fluence of approximately $3 \times 10^{13} \mathrm{nts} / \mathrm{cm}^{2}$, was removed from the neutron flux, inspected for ply delamination, core debonding, and gross warping, and was then remapped. No catastrophic conditions were observed. In fact, the fiducial marks from the initial surface mapping were intact. Unfortunately, the mapping exercise was not performed on a device whose accuracy was greater than our maximum tolerance, and the remapping, which indicated a maximum departure from the initial state of nearly $25 \mu \mathrm{m}$, should be considered to be a noisy measurement. This circumstance results from the previously perceived requirement of remapping the panel in an environment suitable for measuring entities with residual radioactivity. However, a cooldown time of 3 weeks was sufficient to bring the panel to a nearbackground radiation level. In future studies, more accurate measurement devices will be used in radiation-free areas for initial and after-bombardment surface mappings. The current panel has been irradiated and will soon be remapped.

Graphite/epoxy is hygroscopic and will probably be dimensionally affected by some fluids. This is a one time bias change, and in a constant environment, can be calibrated out experimentally.

These material tests will provide the first critical step in assessing which materials will perform satisfactorily in the given physical environment. It is important to verify the suitability of candidate materials early in the program. In principle, the high-intensity beams and facilities available at LAMPF and the high-intensity ${ }^{60} \mathrm{Co}$ source at the University of California at Santa Cruz make it possible to easily achieve that goal. The doses accumulated over the lifetime of an SSC experiment can be achieved at our facilities over a time period of several weeks. However, because of limited funds, we will be able to examine only a few materials. The tests will be expanded to cover all of the crucial structural materials, both independently and in the presence of the hydrocarbon working fluids we are considering for use in the heat pipes. In addition to the studies being performed with neutrons, similar tests will need to be performed using ionizing radiation. The precision of the tests will also have to increase to allow us to extrapolate from the changes seen in the small samples to those expected in the overall structure.

\subsection{HEAT PIPE COOLING}

The mechanical stability requirements of the SSC detector array dictates precise thermal control of the entire array to a nominal operating temperature with minimal thermal gradient within the array. The design goal is to control the overall temperature excursions within the system to $\pm 0.1^{\circ} \mathrm{C}$. This goal must be attained in the presence of operating conditions with a maximum thermal gradient of $0.25^{\circ} \mathrm{C}$ within the detector array resulting from nonisothermalities in the cooling process. These temperature control objectives are necessary to assure the detector stability to within $5 \mu \mathrm{m}$. Evaporative cooling is the only option for realizing these design objectives. Heat pipe cooling is evaporative cooling in which the liquid is distributed over the surfaces to be cooled by using a combination of hydrostatic and capillary forces; vapor is removed by the pressure gradient generated by the condensing process that closes the fluid loop. This fluid cycle is fully 
contained in a hermetic enclosure at a positive pressure with respect to the outside atmosphere. No noncondensible gases are present to aid or impede the heat transfer. The hermetic enclosure encloses the entire detector array. A gaseous nitrogen manifold around the seals of the hermetic enclosure is designed to prevent leaks between the enclosure and the inside of the detector building.

A detailed description of the heat pipe cooling system for the detector array, as it is now conceived, will be provided. In areas of special concern or where the design constraints, such as operating temperature, location of condensing unit relative to the detector array, and fiuid line sizes are still being discussed, as are the effects of parametric variations on the system design and performance, detailed current ideas will be presented.

\subsubsection{Working Fluid}

A phase change working fluid removes thermal energy by its latent heal of vaporization in a heat pipe cooling system. This is a highly efficient process in terms of the mass flow required to remove a given heat load. It is also an equilibrium process with a well-defined temperaturepressure relationship that expedites precise thermal control. However, the working fiuid must be carefully chosen to meet system requirements, which, in the case of the SSC detector array, are particularly stringent. Although heat pipes are usually designed to operate at pressures from below 0.1 bar to several bars, an operating pressure of nominally 1 bar has been requested for the SSC. Additional constraints on the choice of working fluid include material compatibility and safety.

The fluorocarbon refrigerants have been considered for this application but are no longer serious candidates. These fluids were not considered because they are likely to be incompatible with silicon, particularly in a radiation environment that could create chlorine and fluorine radicals. Also, the design operating temperature has been set at $0^{\circ} \mathrm{C}$ to eliminate the more common fiuorocarbons. The fluorocarbon R-21 has a normal boiling point of $8.9^{\circ} \mathrm{C}$, but this product is no longer available because of its toxicity. $\mathrm{R}-114\left(\mathrm{CClF}_{2}-\mathrm{CClF}_{2}\right)$ with a normal boiling point of $3.8^{\circ} \mathrm{C}$ may be a viable candidate in a system where the silicon detectors are not exposed to the working fluid.

A number of hydrocarbons are potentially suitable for this application. But even though they are stable compiunds that have been analyzed and categorized, many of them have found little or no application in industry. As a result, they are either very expensive or unavailable. Table 3-9 lists all the identified candidate working fluids and comments on their availability. Table 3-10 is a cost comparison between the available candidates. Note that the compounds containing oxygen, chlorine, or fluorine are not considered viable candidates.

The last 3 fluids in Table 3-9 are referred to as amines. The amines are commonly used in fertilizer production and other industrial processes and are therefore readily available. They are unique compared with the other fluid candidates because they contain nitrogen. Under certain conditions, including heat and, presumably, interactions with high energy subatomic particles, the amines will decompose and form ammonia and a simple carbon-hydrogen molecule. The presence of ammonia is assumed to be unacceptable to the detector array. The amines are also flammable. toxic, and noxious.

Table 3-11 is a comparison of some of the hydrodynamic performance parameters for the candidate working fluids, specifically mass and volume flow rates per unit of power. Disregarding the amines, cis-2-butene and 1,2 butadiene offer the lowest overall flow requirements. However, the differences are not of sufficient magnitude to significantly influence the choice of working fluid.

The working fluid will be selected according to the following criteria. An operating temperature of $0^{\circ} \mathrm{C}$ is now being considered to minimize the detector leakage current. Leakage current can be reduced by a factor of about 2.5 for every $10^{\circ} \mathrm{C}$ temperature reduction. The fluids listed above are useful to temperatures as low as $-0.5^{\circ} \mathrm{C}$ at $1 \mathrm{~atm}$ of pressure. The fluids that can be used at temperatures as low as $-20^{\circ} \mathrm{C}$ are listed in Table 3-12. It should be noted that operating at these temperatures requires the use of a water-ethylene glycol mixture in the condenser cooling loop. This mixture will affect the refrigeration system size and the condenser surface area requirement. However, these operating temperature effects are not prohibitive. At this point, 
TABLE 3-9. List of Candidate Working Fluids, with Normal Boiling Points Near $0^{\circ} \mathrm{C}$, and their Availability Status

\begin{tabular}{|c|c|c|c|}
\hline Fluid & $\begin{array}{l}\text { Molecular } \\
\text { Formula }\end{array}$ & $\begin{array}{c}\text { Normal } \\
\text { Boiling Point }\end{array}$ & Availability \\
\hline Methanethiol & $\mathrm{CH}_{4} \mathrm{~S}$ & $6.8^{\circ} \mathrm{C}$ & $\mathrm{N} / \mathrm{A}$ \\
\hline 1-Butyne & $\mathrm{C}_{4} \mathrm{~F}_{6}$ & $8.7^{\circ} \mathrm{C}$ & $\mathrm{N} / \mathrm{A}$ \\
\hline 2-Butyne & $\mathrm{C}_{4} \mathrm{H}_{6}$ & $5.3^{\circ} \mathrm{C}$ & $\mathrm{N} / \mathrm{A}$ \\
\hline $\begin{array}{l}\text { 1,3-Butadiene } \\
\text { (Biacetylene) }\end{array}$ & $\mathrm{C}_{4} \mathrm{H}_{6}$ & $9.7^{\circ} \mathrm{C}$ & N/A \\
\hline $\begin{array}{l}\text { Cyclobutane } \\
\text { (Tetramethylene) }\end{array}$ & $\mathrm{C}_{4} \mathrm{H}_{8}$ & $12.9^{\circ} \mathrm{C}$ & N/A \\
\hline 1-Bromoethylene & $\mathrm{C}_{4} \mathrm{H}_{4} \mathrm{Br}$ & $15.8^{\circ} \mathrm{C}$ & $\mathrm{N} / \mathrm{A}$ \\
\hline $\begin{array}{l}\text { 2,2-Dimethylpropane } \\
\text { (Neopentane) }\end{array}$ & $\mathrm{C}_{5} \mathrm{H}_{12}$ & $9.5^{\circ} \mathrm{C}$ & $\begin{array}{l}\text { Wiley Organics } \\
20-50-1 \mathrm{~b} \text { minimum order } \\
\text { @ } \$ 450 / \mathrm{b} \\
100 \mathrm{~g} @ \$ 147 \text { as of July } 90\end{array}$ \\
\hline Butane & $\mathrm{C}_{4} \mathrm{H}_{10}$ & $-0.5^{\circ} \mathrm{C}$ & $\begin{array}{l}\text { Union Carbide } \\
\text { 11-lb cylinder @ } \$ 87 \\
\text { + shipping } \\
\text { Phillips } 66 \\
\text { 28-gal cyl. @ } \$ 350+\$ 200 \\
\text { cyl. deposit + shipping. }\end{array}$ \\
\hline 1,2-Butadiene & $\mathrm{C}_{4} \mathrm{H}_{6}$ & $10.9^{\circ} \mathrm{C}$ & $\begin{array}{l}\text { Wiley Organics } \\
5 \mathrm{~g} @ \$ 50 ; 100 \mathrm{~g} @ \$ 850\end{array}$ \\
\hline cis-2-Butene & $\mathrm{C}_{4} \mathrm{H}_{8}$ & $3.7^{\circ} \mathrm{C}$ & $\begin{array}{l}\text { Linde Corporation } \\
0.5-1 b \text { cyl. @ \$206 } \\
\text { 12.0-lb cyl. @ \$910 } \\
\text { Phillips 66 } \\
\text { 5-gal. cyl. (24 lb) @ \$595 } \\
\quad+\$ 100 \text { cyl. deposit } \\
\text { 28-gal. cyl. }(135 \mathrm{lb}) @ \$ 2380\end{array}$ \\
\hline $\begin{array}{l}\text { Ethylamine } \\
\text { (Monoethylamine) }\end{array}$ & $\mathrm{C}_{2} \mathrm{H}_{7} \mathrm{~N}$ & $16.6^{\circ} \mathrm{C}$ & $a$ \\
\hline Dimethylamine & $\mathrm{C}_{2} \mathrm{H}_{7} \mathrm{~N}$ & $7.4^{\circ} \mathrm{C}$ & $a$ \\
\hline $\begin{array}{l}\text { Methylamine } \\
\text { (Monomethylamine) }\end{array}$ & $\mathrm{CH}_{5} \mathrm{~N}$ & $-6.3^{\circ} \mathrm{C}$ & $a$ \\
\hline
\end{tabular}

a Available from Air Products and Chemicals, Inc., by the truckload, 35001b@\$0.42/lb (\$1470/truckload, \$0.0009/g). Free sample supplied (500 cc, anhydrous).

operating temperature is expected to have a greater influence on achieving mechanical stability than on the cooling system design. Lower system operating temperature may affect system startup and shutdown procedures by avoiding large overpressures; but, because the overpressure might already be sufficient to warrant special procedures with a $0^{\circ} \mathrm{C}$ operating temperature, lowering the temperature still further is not expected to be an issue in this regard. Butane is now considered the most viable working fluid because of its cost, availability, suitability in the radiation environment, and vapor pressure at the current design temperature. The following cooling system baseline 


\begin{tabular}{lc}
\hline TABLE 3-10. & $\begin{array}{l}\text { Working Fluid Cost } \\
\text { Comparison } \mathbf{( \$ / g )}\end{array}$ \\
\hline Neopentane & 0.99 \\
Butane & 0.017 \\
1.2-Butadiene & 8.50 \\
cis-2-Butene & 0.054 \\
Amines & 0.0009 \\
\hline \hline
\end{tabular}

\section{TABLE 3-11. Comparison of Candidate Working Fluids}

\begin{tabular}{|c|c|c|c|c|c|c|}
\hline Fluid & $\begin{array}{l}\text { Boiling Point } \\
\left({ }^{\circ} \mathrm{C}\right)\end{array}$ & $\begin{array}{l}\text { Molecular } \\
\text { Weight }\end{array}$ & $\rho(\mathrm{g} / \mathrm{cc})$ & $g / s-k W$ & $\mathrm{~V} / \mathrm{kW}^{a}$ & $\mathrm{~V} / \mathrm{k} \mathrm{W}^{b}$ \\
\hline Butane & -0.5 & 58.1 & 0.601 & 2.38 & 3.96 & 923 \\
\hline 1.2 Butadiene & 10.9 & 54.1 & 0.676 & 1.98 & 2.92 & 996 \\
\hline 2.2 Dimethylpropane & 9.5 & 72.2 & 0.613 & 3.05 & 4.98 & 948 \\
\hline cis-2-Butene & 3.7 & 56.1 & 0.621 & 2.09 & 3.37 & 868 \\
\hline Ethylamine & 16.6 & 45.1 & 0.683 & 1.57 & 2.30 & 811 \\
\hline Methylamine & -6.3 & 31.1 & 0.699 & 1.15 & 1.64 & 861 \\
\hline Dimethylamine & 7.4 & 45.1 & 0.680 & 1.61 & 2.37 & 831 \\
\hline
\end{tabular}

TABLE 3-12. List of Candidate Working Fluids, for a System Operating Temperature as Low as $-20^{\circ} \mathrm{C}$, and their Availability Status

\begin{tabular}{|c|c|c|c|}
\hline Fluid & $\begin{array}{l}\text { Molecular } \\
\text { Formula }\end{array}$ & $\begin{array}{c}\text { Normal } \\
\text { Boiling Point }\end{array}$ & Availability \\
\hline Cyanogen & $\mathrm{C}_{2} \mathrm{~N}_{2}$ & $-21.0^{\circ} \mathrm{C}$ & N/A \\
\hline Dimethylsilane & $\mathrm{C}_{2} \mathrm{H}_{8}^{-} \mathrm{Si}$ & $-20.1^{\circ} \mathrm{C}$ & $\begin{array}{l}\text { Perrarch Systems Inc: } \\
100 \mathrm{~g} @ \$ 211 \text { or } 1000 \mathrm{~g} @ \$ 1688\end{array}$ \\
\hline 1- Butene & $\mathrm{C}_{3} \mathrm{H}_{8}$ & $-6.3^{\circ} \mathrm{C}$ & $\begin{array}{l}\text { Texas Petrochemicals Corporation } \\
\text { 1-gal. sample for cost of shipping } \\
\text { available by the truckload }\end{array}$ \\
\hline 2-Methylpropane & $\mathrm{C}_{4} \mathrm{H}_{\mathrm{iO}}$ & $-11.7^{\circ} \mathrm{C}$ & $\begin{array}{l}\text { Aldrich Chemical Company } \\
350 \mathrm{~g} @ \$ 40.20\end{array}$ \\
\hline Propyne & $\mathrm{C}_{3} \mathrm{H}_{4}$ & $-23.3^{\circ} \mathrm{C}$ & $\begin{array}{l}\text { Wiley Oiganics } \\
\text { 1.0-lb cyl.@\$395 } \\
\text { 10.0-lb cyl.@\$950 }\end{array}$ \\
\hline
\end{tabular}


design and analysis was computed assuming butane as the working fluid.

Operating the detector array at a slightly positive gage pressure is advantageous because it dictates the direction of any system leaks. This concern influences the methodology for addressing the safe use of flammable working fluids. Currently, the two primary fluid candidates are cis-2-butene and butane, because of their availability and cost. A positive operating pressure requires operation above $-0.5^{\circ} \mathrm{C}$ for butane. Except from the standpoint of cooling, this operating temperature is a concern because it influences the ultimate sink temperature. The working fluid rejects its heat load to a liquid cooling loop that has been chilled by a standard freon refrigeration system to some temperature below the working fiuid temperature in the condenser. With a $0^{\circ} \mathrm{C}$ operating temperature, a glycol-water mixture is required to keep the water from freezing. Constraints on condenser size and shape are currently unknown. Again, the consequences of lewering the operating temperature to accommodate positive pressure with these fluids is expected to have a greater bearing on the mechanical design than on the cooling system. Hence, the mechanical design concerns should dictale the operating temperature.

Any leakage out of a positive pressure detector array containment must be sensed, and a response procedure must be implemented. The potential flammability of butane in air is bounded by lean and rich limits, also referred to as lower and upper explosive limits. These limits are expressed either as a percent by volume or as a percent of stoichiometric mixture. If ignition occurs between these limits, combustion will propagate through the mixture. For butane in air, the lean and rich limits are 1.9 and 8.5 volume percent. These values are typical of hydrocarbons, but the lean limit can be as low as $1 \%$ (octane) and the rich limit as high as $14 \%$ (methane).

For the safe operation of a positive pressure system, detecting and measuring the percentage of any hydrocarbon in air is a well established technology based on catalytic combustion. These sensors can detect from $0-100 \%$ of the lower explosive limit (LEL) or the lean limit, and they can be used to actuate a response plan.

Most of the working fluid is in the condenser, the accumulator. and the liquid return reservoir in the SSC detector array cooling loop. These are the components outside of the array. They can be doubly enclosed and the enclosure can be filled with nitrogen. Both hydrocarbon and oxygen sensors can be placed inside the enclosure for early detection of leaks. Additional sensors are placed outside the double enclosure to detect leaks from other parts of the system.

- If the sensors inside the secondary containment detect a small butane leak, then the flow rate of nitrogen through the secondary containment vessel is increased and the nitrogen/butane stream is vented to the atmosphere outside of the detector building.

- If a large leak is detected inside the secondary containment or if a measurable leak into the detector building is detected, then the response is to immediately isolate the leak. Leak isolation may require the complete shutdown of the detector array.

\subsubsection{Wafer Cooling}

Heat pipe cooling uses evaporation to remove the thermal load. The heat transfer coefficient at the liquid/vapor interface that results from this mechanism is so high that the thermal resistance at the liquid-vapor interface is negligible. (A heat transter coefficient is defined by the ratio: $h=q / T$, where $q$ is the power per unit area and $T$ is the required thermal potential.) For an evaporation process uninhibited by the presence of a noncondensable species, an order-ofmagnitude approximation of $h$ can be derived from molecular kinetic theory, yielding the following result:

$$
h=\frac{\rho_{\mathrm{v}} h_{f y}^{2}}{T \sqrt{2 \pi R T}} .
$$

where $\rho_{c}$ is the vapor density, $h_{f g}$ is the latent heat of vaporization, $T$ is the absolute temperature, and $R$ is the gas constant for that particular gas. For butane at $0^{\circ} \mathrm{C}, h=3.0 \times 10^{6} \mathrm{~W} / \mathrm{m}^{2}{ }^{\circ} \mathrm{C}$. Thus, the interface temperature drop is negligible by ariy reckoning. The temperature gradient between the electronics and the vapor is governed solely by conduction and contact resistances. 
There will be a temperature gradient through the salurated wick struclure. This linear gradient resuls from the conduction of heat to the liquid/vapor interface. A first order approximation of the thennal conductivity of the wetted wick can be made by assuming parallel heat flow paths through the two media, with the area for heat flow in each media weighted by the porosity of the wick (the void-to-total volume ratio). The thermal conductivity of the organic working fluids being considered for this application is around $0.11 \mathrm{~W} / \mathrm{m}-{ }^{\circ} \mathrm{C}$, whereas the thermal conductivity of the carbon wick is about $25.2 \mathrm{~W} / \mathrm{m}-{ }^{\circ} \mathrm{C}$. The effective conductivity is essentially 25.2 times the solid fraction. If the solid fraction is 0.6 , and the heat flux at the wick surface is $1.8 \mathrm{~W} / \mathrm{cm}^{2}$. the temperature drop through the wick will be $\left.0.12^{\circ} \mathrm{C} / 100\right) \mu \mathrm{m}$ of wick thickness.

\subsubsection{Wick Design}

The liquid distribution wick is the key component in terms of technology development for the heat pipe cooling system. The radiation length of the wick must be minimized by using low- $Z$ materials and limiting wick thickness. The wick nust be attached or bonded to a geometrically complex surface. High temperature or pressure processes such as thermal sintering, hot isostatic pressing, or plasma spraying are inappropriate for altaching wicks to high geometric tolerance parts, because some of the parts may be composites containing epoxy resins suitable for use only at low temperatures.

The baseline wick design involves a substrate with a sprayed-on coating of high-purity graphite particles. Graphite particles are available down to submicron sizes. The graphite can be formed into a coherent bonded wick structure by mixing it with sufficient epoxy to bond the particles without closing the capillary pores. The graphite/epoxy mixture is suspended in an organic carrier such as acetone or methyl ethyl ketone to facilitate spraying and to inhibit the epoxy from curing until the wick is in place. Early experimental results indicate that a viable process can be developed. However, a significant trial and error program will be necessary to achieve a suitable wick structure for the SSC application. The primary procedural parameters that must be optimized are graphite grade, graphite/epoxy/solvent ratios. and spray parameters such as distance from sprayer to surface, pressure in the sprayer, and application rate.

Some sprayed-on graphite/epoxy wick development has been accomplished. A wick made in this fashion, using graphite particles graded to a specification in which $61 \%$ are less than $20 \mu \mathrm{m}$ in diameter, resulted in a wick with a pore radius of less than $18 \mu \mathrm{m}$ (the measuring limit of the test apparatus). The design goal of $4 \mu \mathrm{m}$ should be achievable with limited trial and error experimentation. Some smaller diameter graphite has been procured. A more accuratc pore size and a permeability measuring device will be prepared for wick characterization.

The wick design requires the integration of an artery. an open flow passage that runs circumferentially around the support structure. The artery provides a low-impedance flow path through and is hydrologically connected to the wick structure. For the sprayed on graphite. the antery may be a porous tube placed on the cooling ring before spraying. The pores in this tube must be small enough that the graphite does not penetrate; yet it must adhere to that surface to form a hydrologically connected capillary path. Another possible approach is to form the wick over a tube or wire that is subsequently dissolved to leave an open flow passage. Paper wick aneries could conceivably be incorporated into the pliant wick structure. The artery must be of sufticient strength to withstand the forces caused by the hydrostatic pressure.

The wick thickness required to distribute an adequate supply of liquid over the heated surface is a function of wick pore size, wick permeability, capillary pumping distance. and power density. The wick pore size defines the available maximum capillary pumping pressure. given by

$$
P_{c a \mu}=\frac{2 \sigma}{r_{p}}
$$

where $\sigma$ is the fluid surface tension and $r_{p}$ is the capillary pore size assuming perfect wetting. The maximum liquid pressure in the system is the local vapor pressure. If the liquid pressure exceeds the vapor pressure at any point, the liquid meniscus at the capillary pores is curved into the vapor 
space. It is theoretically possible to hold the liquid in the wick with a convex meniscus, but, in practice, the convex menisci coalesce to form a continuous film. In the presence of gravity, this film will flow off of or bleed from the wick surface. The point of highest liquid pressure is at the bottom of the artery. Because the design must be versatile enough to accommodate changes in therınal load that range from no load to maximum load, the arteries must be sized so that the flow-induced pressure drop is negligible. That is, the wick must support all of the gravitational head that is not reduced by viscous pressure drop. Therefore, the wick must be sized so that, in the limit,

$$
\frac{2 \sigma}{r_{p}}=\rho g h+\frac{\nu_{l} L_{\mathrm{eff}} Q}{A_{c s} K h_{f g}}
$$

The second term on the right is Darcy's law for pressure drop in a porous medium, where $\nu_{i}$ is the liquid kinematic viscosity, $L_{\text {eff }}$ is the effective path length, $Q$ is the total power, $A_{c s}$ is the wick cross-sectional area, and $K$ is the permeability. Unfortunately, smaller pore sizes inevitably lead to lower permeabilities. Furthermore, there is no rigorous, concise mathematical relationship between pore size and permeability because such a relationship depends on the relationship between solids and voids in the capillary structure. The only way to characterize a wick structure accurately is by taking actual measurements. However, with some types of wick structures sufficient experimental data are available from which estimates of the parameters of similar wicks can be made. In the case of packed powders, a hypothetical approximation can be made based on an idealization; specifically, on randomly packed spheres. In this case, the capillary pore radius is directly related to the particle radius:

$$
r_{p}=0.41 r
$$

and the permeability is given by

$$
K=\frac{(2 r)^{2} \epsilon^{3}}{150(1-\epsilon)^{2}}
$$

which clouds the issue by introducing another unknown, the porosity $\epsilon$. For example, the required particle size for a $4-\mu \mathrm{m}$ pore radius is $10 \mu \mathrm{m}$. Permeability as a function of porosity for a $10-\mu \mathrm{m}$ particle is shown in Fig. 3-30.

Combining Eqs. (3), (4), and (5), and expressing $Q$ in terms of power per unit length around the circumference of a cooling ring, the resulting equation for wick thickness, $\delta$, as a function of pore radius is

$$
\delta=\frac{\alpha}{\beta r_{p}-\gamma r_{p}^{2}}
$$

where

$$
\begin{gathered}
a=\frac{\nu_{l} L_{e f f} Q}{0.158\left(\frac{c^{3}}{1-\epsilon^{2}}\right) h_{f g}} . \\
\Im=2 \sigma .
\end{gathered}
$$

and

$$
\gamma=\rho g h .
$$

The length term, $L_{\mathrm{cff}}$, is the effective capillary pumping distance from the artery to the wick periphery. Nonheated surfaces spanned by a wick structure are termed adiabatic surfaces. The length of heated surfaces is effectively halved because the mean distance for liquid flow is one-half of the total distance. Thus, if the artery is centered on the cooling ring, the effective length is an adiabatic length of $1.5 \mathrm{~cm}$ plus half the width of the heated surface, $0.3 \mathrm{~cm}$, or $1.8 \mathrm{~cm}$ total. (The adiabatic length is based on the assumption that the artery will be centered on a cooling ring $3 \mathrm{~cm}$ wide.) 


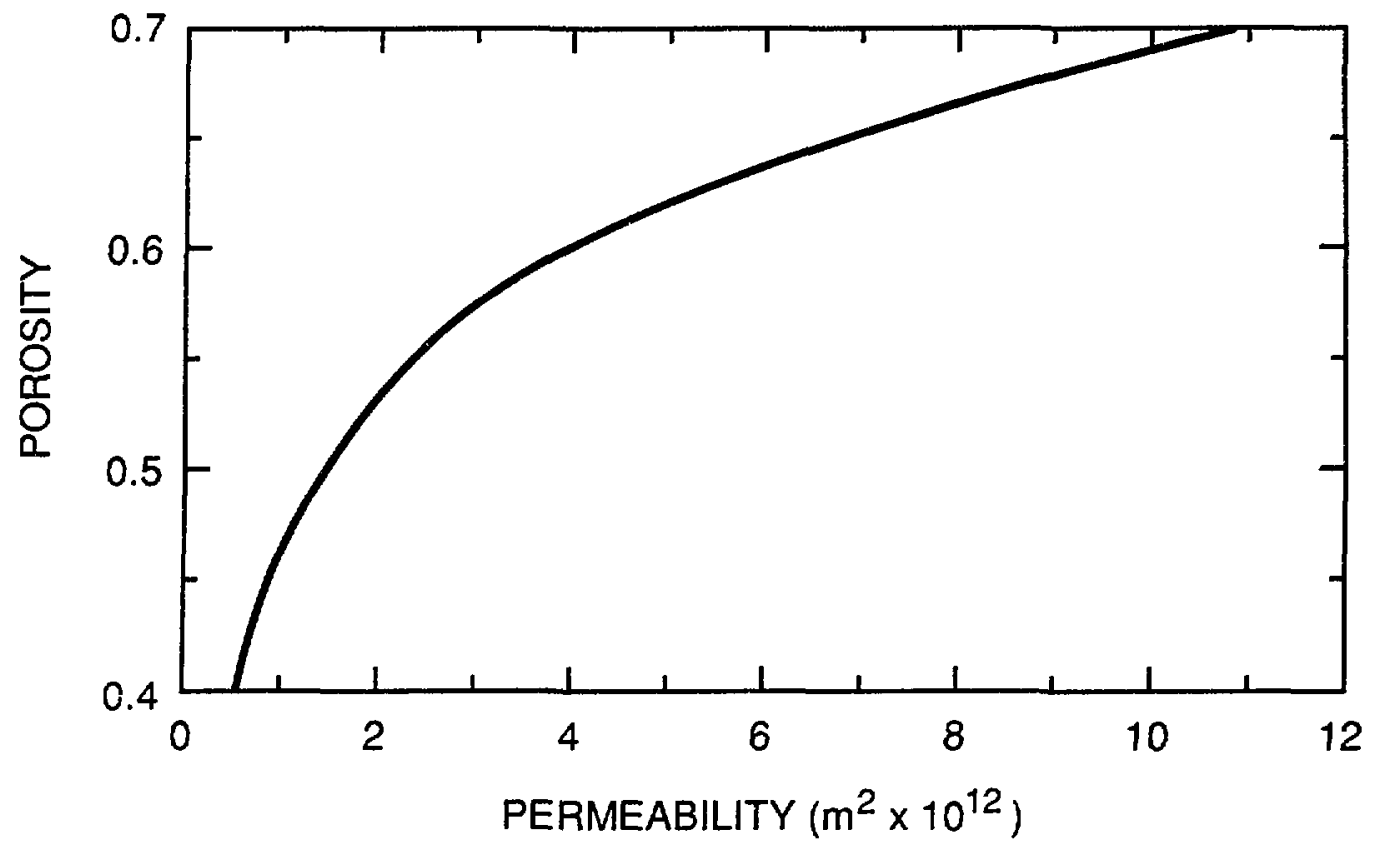

Figure 3-30. Permeability as a function of porosity for randomly packed $10 \mu \mathrm{m}$-radius spheres.

It is worthwhile to examine some solutions to $\mathrm{Ec}_{\mathrm{s}}$ (6) and to consider the effect on wick thickness of variations in system parameters. Consider butane again, as an example, with $Q=$ $1.1 \mathrm{~W} / \mathrm{cm}, \nu_{l}=0.32 \times 10^{-6} \mathrm{~m}^{2} / \mathrm{s}, h_{f g}=0.376 \times 10^{6} \mathrm{~J} / \mathrm{kg}, \sigma=0.0136 \mathrm{~N} / \mathrm{m}$, and $L_{\text {eff }}=1.75 \mathrm{~cm}$. The minimum wick thickness as a function of pore size is shown in Fig. 3-31 for three different vertical heights. The vertical height has a weighted significance because it appears in the highest order tcim in Eq. (6). Although it is not obvious from the graph, it is clear from the equation that there is a maximum pore size above which there is no physical solution to Eq. (6). These maximum pore sizes are $4.2,8.5$, and $16 \mathrm{~mm}$ for $1.09-, 0.54-$, and $0.29-\mathrm{m}$ wick heights, respectively. Figure 3-31 shows that there is a minimum wick thickness, and that thickness is a strong function of vertical height. A relatively broad band of pore sizes exist for which there is little change in minimum wick thickness.

It should be noted that the wick thicknesses shown in Fig. 3-31 are required only at the top of the cooling ring. The thickness is required to pump liquid through the wick across the heated surface after the liquid pressure is already reduced below the vapor pressure by an amount equal to the gravity term in Eq. (6). However, for all points below the top of the artery, there is an assisting component of the gravity vector from the artery to any point in the wick. The flow path from the artery to the wick periphery will be the path of least resistance that, in general, will not be normal to the artery. The thinner the wick, the steeper the path of least resistance. But at some distance from the highest point in the cooling ring, it is possible to significantly reduce the wick thickness. This advantage will be examined in detail as wick data become available.

Consider the effects of changes in other system parameters on the required wick thickness. The $\delta$ is linear with the linear terms in $\alpha\left[\mathrm{Eq}\right.$. (7)]; specifically, $Q$ and $L_{\mathrm{eff}}$. Doubling the power density will double the minimum wick thickness. Moving the arteries closer to the heated surface could significantly reduce the minimum wick thickness. If two arteries are placed in each cooling ring, each as close as possible to the electronics on the inner and outer circumference, the effective length can be reduced to $0.3 \mathrm{~cm}$ in the limit, thus reducing the required wick thickness by a factor of 7. The total amount of wick material could also be substantially reduced by not wicking the adiabatic portion of the cooling ring. Placing the arteries directly on the center of the heated part of the cooling ring would reduce the thickness by another factor of 2 . This would probably be 


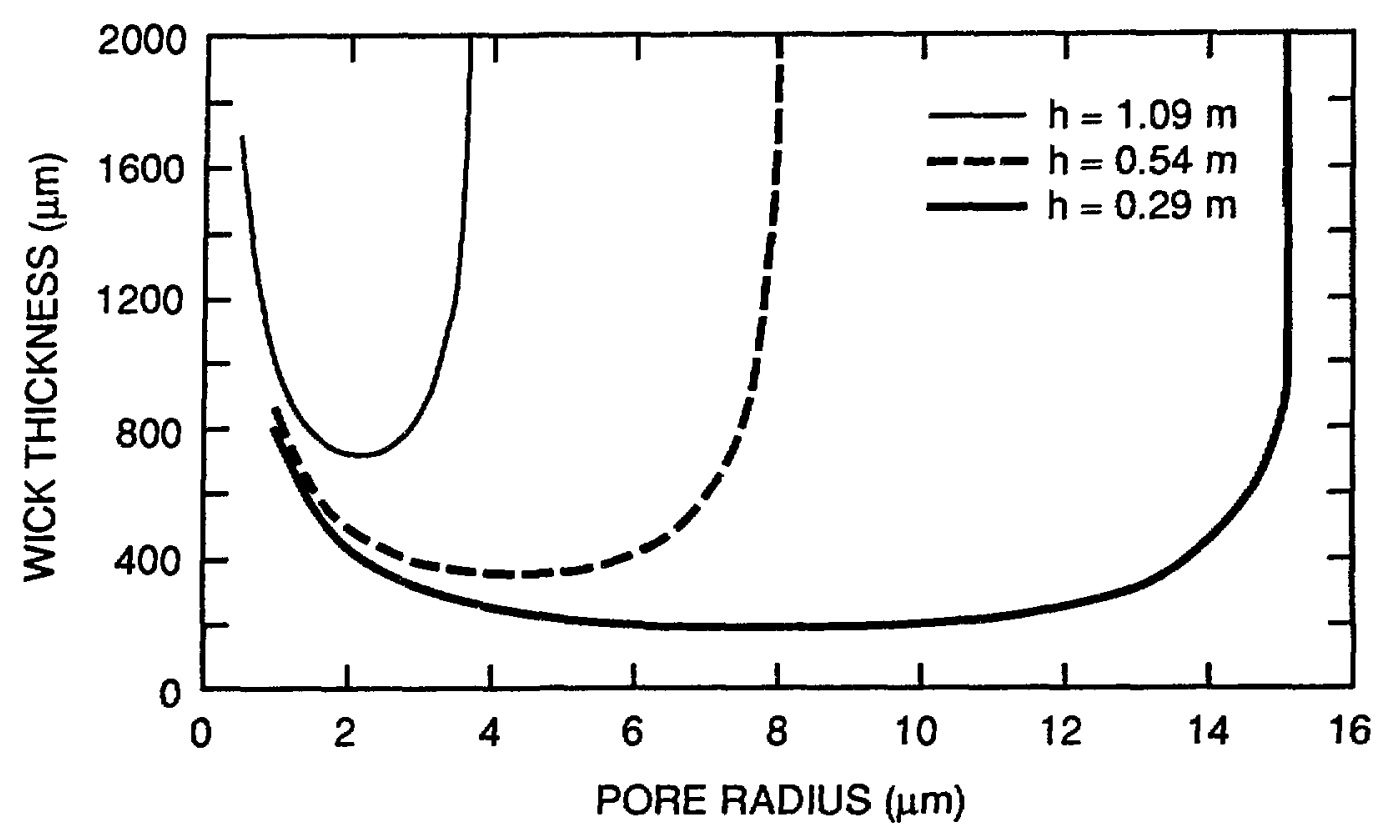

Figure 3-31. Minimum wick thickness as a function of pore radius for 3 vertical artery lengths assuming a porosity of 0.5 .

impractical because of the complex geometry and because of the possibility of generating vapor directly in the artery.

The nonlinear part of Eq. (7) results from the permeability dependence on the porosity of the wick. Figure 3-32 shows the effect of porosity on minimum wick thickness relative to a porosity of 0.5 . Wick thickness increases or decreases by a factor of almost 3 , with a porosity decrease to 0.4 or an increase to 0.6 , respectively. It should be emphasized that the information in Figs. 3-31 and 3-32 is based on an assumed pore size/permeability relationship. Only after suitable wicks have been fabricated and characterized can an accurate assessment of wick thickness requirements be made.

As discussed above, it is desirable to keep flow-induced pressure drop in the artery to a minimum. The total thermal load on a $108-\mathrm{cm}$-diam ring with a power distribution of $1.1 \mathrm{~W} / \mathrm{cm}$ is about $740 \mathrm{~W}$ (double-sided electronics on two sides of the cooling ring). The mass flow rate of butane into this cooling ring would be $1.76 \mathrm{~g} / \mathrm{s}$, or $2.9 \mathrm{cc} / \mathrm{s}$ liquid (from Table 3-11). Locally, the flow from the artery is about $2.4 \mathrm{mg} / \mathrm{s}$ per $\mathrm{cm}$ of length. Since the wick pores are sized to prevent wick bleeding with no flow, it is permissible to accept a flow-induced pressure drop equal to the hydrostatic pressure at the bottom of the cooling ring. For a single artery system, the artery diameter must be about $1 \mathrm{~mm}$. Because artery pressure drop is inversely proportional to the fourth power of the diameter, a double antery system, which divides the flow in half, reduces the required artery diameter to only $0.9 \mathrm{~mm}$.

The preceding discussion focused on the most severe cooling ring requirements, that is, to those of the largest diameter cooling ring. It may ultimately prove worthwhile to design a uniquely sized wick and artery for each cooling ring diameter. It may also be desirable or necessary to make multiple connections to the larger cooling rings and a single connection to the others. The mass savings would have to be traded off with the necessity of making more liquid line connections. These decisions should be deferred until the wicks have been made and characterized.

Because of the uncertainty in wick sizing, it is difficult to estimate with any confidence what the total wick volume or the volume of liquid in that wick will be. There are a total of 118 cooling rings, as currently configured, with an average diameter of about $0.67 \mathrm{~m}$. Approximately $4 \mathrm{~cm}$ 


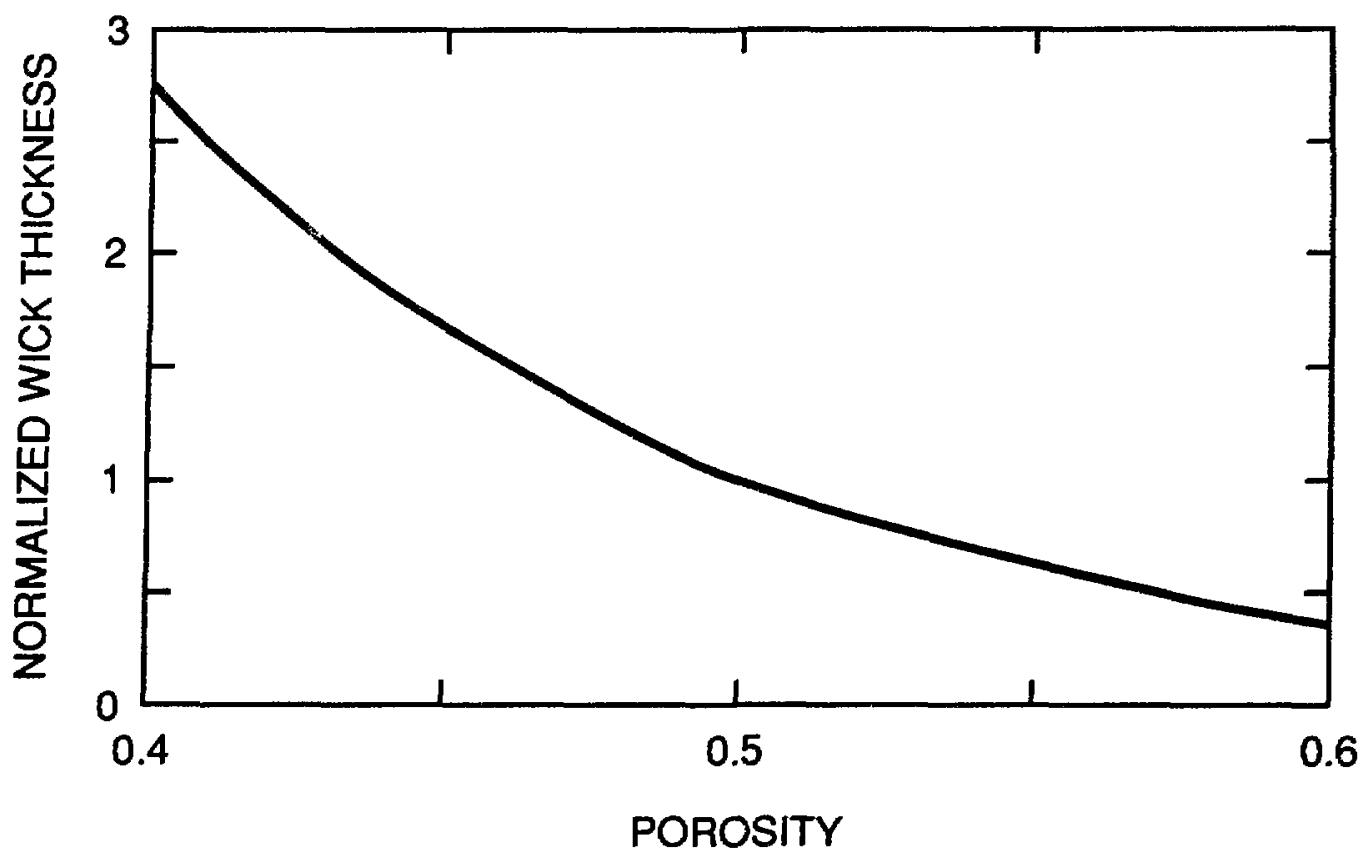

Figure 3-32. Effect of porosity on minimum wick thickness. Wick thickness has been normalized to $\epsilon=0.5$.

of surface is wicked at any cross section of the cooling ring. In rough numbers, that amounts to 1 liter of wick volume per $100 \mu \mathrm{m}$ of wick thickness, assuming wick thickness is uniform throughout the array. Approximately $50 \%$ of the wick volume will be low- $Z$ solids; the remainder will be filled with liquid.

\subsubsection{Condenser Design}

In the cooling loop, liquid is supplied to the heated surfaces where it evaporates in response to the thermal load. The working fluid vapor moves down a pressure gradient to the condenser, where the vapor is condensed to complete the cycle. At this point in the design study, it would be premature to attempt to optimize the condenser design. Designing a condenser adequate to the task and close in form and configuration to the final design is a starting point. Considerable design flexibility is available to accommodate whatever constraints may be imposed on this pan of the system.

The simplest condenser design is an annular water jacket around the vapor retum line. A slight downward tilt allows for removal of condensate from the lowest point at the extreme end of the tube. The required condenser length is about $3 \mathrm{~m}$, based on $-10^{\circ} \mathrm{C}$ water-glycol cooling fuid flow through the annulus at $5 \mathrm{~m} / \mathrm{s}$ and with aluminum as the wall material. With some optimizing for specific constraints, it may be possible to use this approach and shonen the length (surface area) requirement. The alternative is to transition to a large number of smaller tubes.

A more standard condenser design that allows for more heat transfer surface area in a smaller volume is a shell and tube condenser. An example is shown in Fig. 3-33. The shell and tube design is the baseline condenser. In establishing a condenser design, we can choose to have condensation occur on either the shell or the tube side of the condenser. In our design, we minimized vapor pressure drop by having the condensation occur on the shell side of the tubes. and a water-ethylene glycol mixture in the tubes.

A vertical orientation is preferred because the system control response mechanism will vary the condenser surface area by controlling the amount of condensate. That is, as condensate accumulates in the bottom of the condenser, part of the condenser tubes will be submerged. effectively 


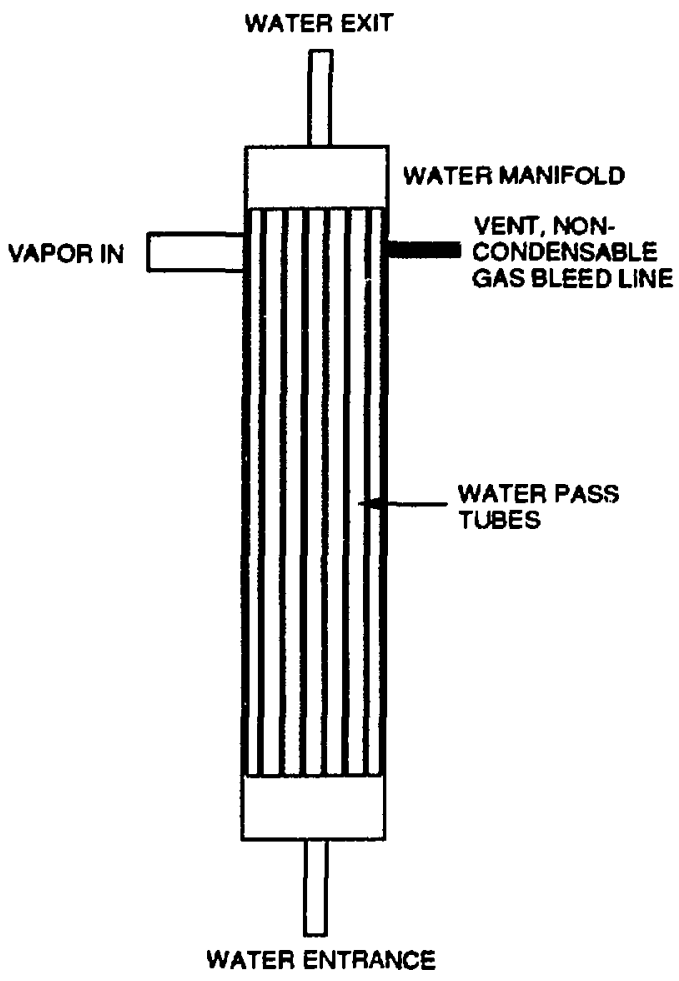

Figure 3-33. Shell and tube condenser design.

eliminating some of the heat transfer area. By actively controlling the level of the condensate, changes in thermal load are accommodated without changing the operating temperature.

A $40-\mathrm{kW}$ butane condenser can be made to operate at $0^{\circ} \mathrm{C}$ with water-glycol at $-10.2^{\circ} \mathrm{C}$ by using a 20 -tube shell-and-tube condenser with a $0.5-\mathrm{m}$-long tube. The design details are summarized in Table 3-13. The outside diameter of the condenser shell is approximate. The 20 tubes can be accommodated in a smaller diameter shell, but it is desirable to keep the tube spacing large to maintain low vapor velocities and to keep the pressure from dropping. The condenser design can be optimized to suit the geometric constraints when those constraints are known. Stainless steel is the selected material for the condenser because of its ease of fabrication, strength, and resistance to corrosion.

3.4.4.1 Liquid Distribution Line Sizing. There is some flexibility in sizing the liquid distribution lines that connect the arteries to the liquid supply reservoir some $25 \mathrm{~m}$ away. The critical issue, in terms of fluid distribution, is to know the pressure of the liquid at the bottom of the cooling ring, as explained in Sec. 3.4.3. The most conservative approach assumes that the pressure at the bottom of the cooling rings is the same as the pressure of the liquid in the supply reservoir plus the hydrostatic pressure. But the actual pressure is somewhat less because of line pressure drops. These line pressure drops should be minimized to reduce the uncertainty and the resulting required overdesign. If the line pressure drops are less than $10 \%$ of the available capillary head, or about $700 \mathrm{~Pa}$, then the overdesign required as a result of this uncertainty contributes little to the total system mass. If the resulting line sizes are excessive, a less conservative approach can be taken. Ultimately, an experimental program will be required to confirm system performance.

The liquid pressure drop relationships are the same as those for vapor flow, that is, the pressure drop is a strong function of line diameter, as expressed in Eqs. 10 and 13 in Sec. 3.4.4.3. The primary supply line is the line that connects the supply reservoir to the containment vessel. Pressure drop as a function of diameter of the primary supply line is shown in Fig. 3-34. The 


\begin{tabular}{lc}
\hline TABLE 3-13. & $\begin{array}{c}\text { Summary of Preliminary Shell and } \\
\text { Tube Condenser Design }\end{array}$ \\
\hline Number of tubes & 20 \\
Tube i.d. & $2.36 \mathrm{~cm}$ \\
Tube o.d. & $2.54 \mathrm{~cm}$ \\
Vapor temperature & $0^{\circ} \mathrm{C}$ \\
Cooling fluid velocity & $5 \mathrm{~m} / \mathrm{s}$ \\
Cooling fluid inlet temperature & $-10.2^{\circ} \mathrm{C}$ \\
Cooling fluid exit temperature & $-10^{\circ} \mathrm{C}$ \\
Condenser length & $0.50 \mathrm{~m}$ \\
Shell o.d. & $30 \mathrm{~cm}$ \\
Materials & $\mathrm{SST}$ \\
\hline \hline
\end{tabular}

information in Fig. 3-34 assumes that the system is split into two segments, with liquid fed into the system from both ends of the detector array.

A pressure drop also occurs in the secondary supply lines that connect the primary supply lines to the cooling rings and arteries. As required by the current silicon tracking-system specification there will be about $740 \mathrm{~W}$ of power dissipated on the largest cooling rings. The flow through these lines and the length of the lines will vary considerably from ring to ring. Therefore, it is all the more important that this pressure drop and the variations in this pressure drop be kept as low as possible. A line diameter of $3 \mathrm{~mm}$ is sufficient to keep this pressure drop below $100 \mathrm{~Pa}$.

3.4.4.2 Liquid Line Connections. The larger primary supply line is connected to a multitude of smaller secondary supply lines that are each connected to an artery. The primary to secondary connections should not pose any problems. These are solid tubes and the connections are made in a relatively open space. The connection between the secondary supply line and the artery will require careful design, especially since some of the cooling rings are difficult to access. The most viable approach for connecting to all cooling rings at any location is to bring the secondary supply line through the step in the sawtooth cooling ring, as shown in Fig. 3-35. The secondary supply line could end in a tee, with two artery connections in line with the top of the tee. shown in Fig. 3-35. The development of a suitable connection and connecting technique must evolve simultaneously with development of the wick and antery fabrication technique.

3.4.4.3 Vapor Return Lines. The vapor return line(s) connecting the detector array containment to the condenser may be as long as $25 \mathrm{~m}$. Geometric constraints require that this line be of small diameter relative to the detector array containment vessel. This means that the flow velocities in this line are significantly higher, resulting in significant pressure drop. There will also be a pressure drop associated with the area contraction between the array containment and the tube, and another pressure drop associated with the expansion from the vapor tube into the condenser. It is important to keep these pressure drops down to a reasonable level because the associated temperature drop will impact the condenser size. However, it is a fairly open-ended problem if condenser size in unconstrained. The condenser design given above assumes a $10^{\circ} \mathrm{C}$ temperature difference between vapor and cooling water, and essentially ignores pressure and temperature drops in the vapor return line.

Pressure drop in turbulent tube flow is given by

$$
P=f \frac{L}{D} \frac{\rho V^{2}}{2}
$$

where $L$ is the length, $D$ is the diameter, $\rho$ is the density, $V$ is the velocity, and $f$ is the friction factor. The friction factor, which accounts for viscous effects, is a function of Reynolds number. 


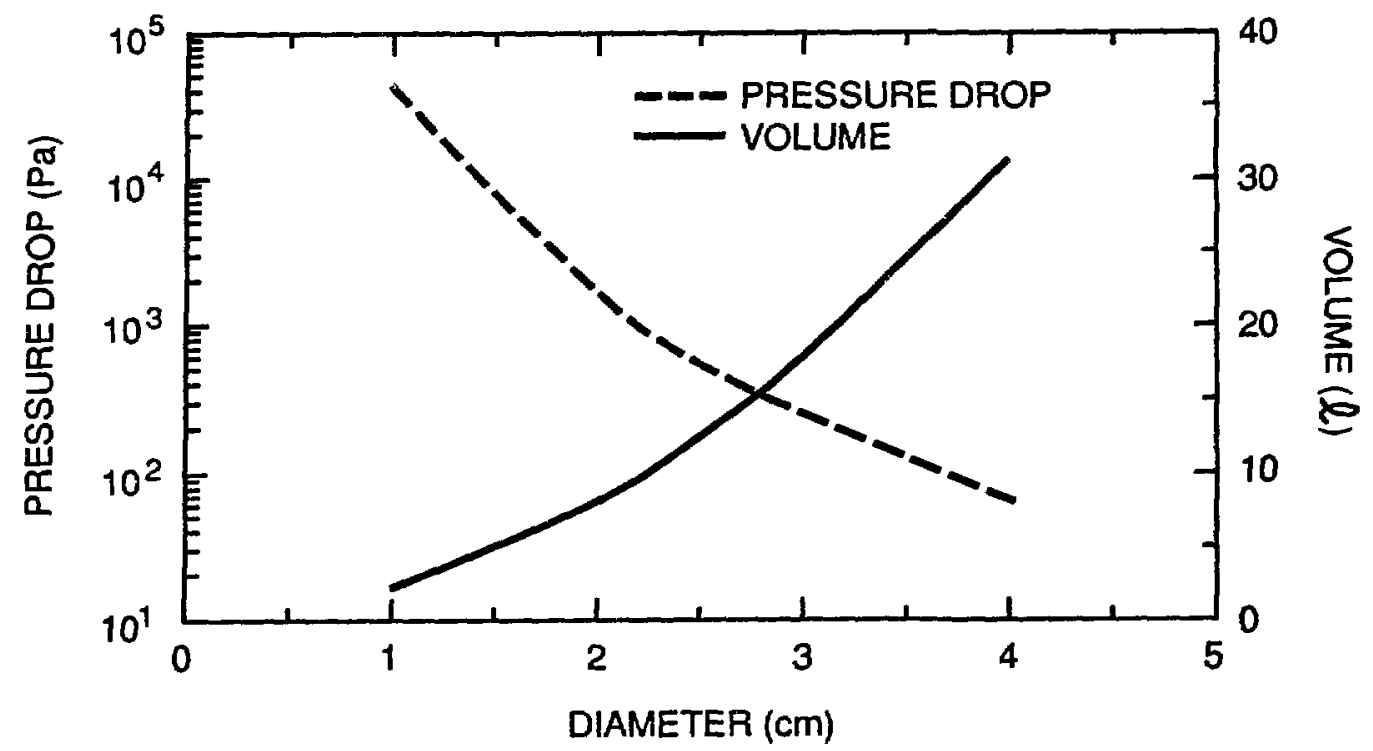

Figure 3-34. Primary liquid supply line pressure drop and volume as a function of line diameter.

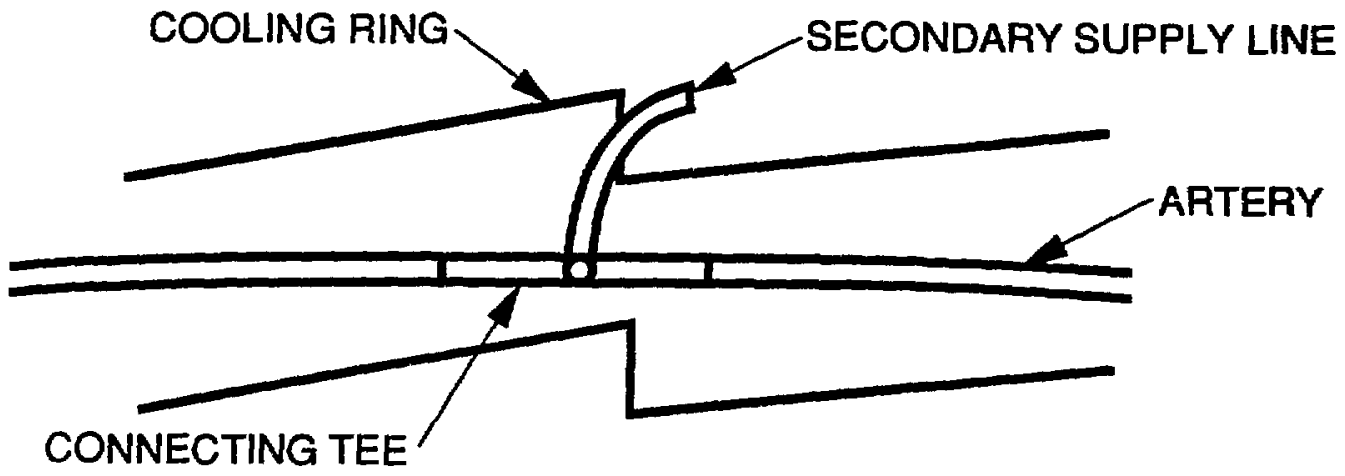

Figure 3-35. Tee configuration for connecting the secondary liquid supply line to the artery. Secondary line enters through step in cooling ring. 
The vapor flow must be turbulent to minimize the line diameter. Turbulence has been shown to occur in tube flow when the Reynolds number, $R e$, defined as

$$
R e=\frac{V D}{\nu}
$$

exceeds 2200, where $\nu$ is the kinematic viscosity. With butane vapor, the required diameter for laminar flow is greater than the diameter of the containment vessel. Velocity can be written in terms of total power, $Q$, and tube diameter as

$$
V=\frac{4 Q}{\pi D^{2} p h_{f g}}
$$

so Eq. (10) becomes

$$
P=0.81 f^{\prime} \frac{L}{D^{5} p}\left(\frac{Q}{h_{f g}}\right)^{2}
$$

Thus, the pressure drop is linear with length but, to a good approximation, inversely proportional to the fifth power of the diameter although not exactly because $f$ is a function of Reynolds number, which in turn is a function of diameter. The expansion and contraction pressure drops are estimated by empirically determined coefficients that are multiplied by the dynamic pressure $\rho V^{2} / 2$. The coefficient for a large diameter ratio contraction is 0.5 . For a large diameter ratio expansion, the coefficient is 1.0. As an example of the possible trade-offs, consider designing for a $1{ }^{\circ} \mathrm{C}$ temperature drop along the vapor tube (note that each $1{ }^{\circ} \mathrm{C}$ temperature drop requires an increased condenser surface area of approximately $10 \%$ relative to the example given above). The required line diameter, as a function of line length or separation distance between the array and the condenser, is shown in Fig. 3-36. Another comparison can be made by setting the line length at the anticipated value of $25 \mathrm{~m}$ and comparing pressure drop as a function of line diameter. This is illustrated in Fig. 3-37. From an engineering perspective, it is desirable, within the geometric constraints, to approach zero pressure drop. A $10-\mathrm{cm}$-diam line or several smaller diameter lines are now recommended. For a noncircular line, a correction would be required based on an equivalent hydraulic diameter. In essence, the flow cross-sectional area must be increased. The larger the aspect ratio (width to height) of a rectangular line, the greater the correction factor.

If it is necessary to protect the silicon and other system parts from exposure to the working fluid, each cooling ring must be hermetically sealed. Liquid feed and liquid distribution would be the same as described above. However, the vapor return system would be similar in appearance to the liquid feed system, with secondary vapor flow lines connecting each cooling ring to the long primary vapor return line. This would add to the total system mass and rad:ation length. It would also complicate the fabrication and assembly procedures.

Each secondary line would be connected to the same back pressure at the point where these lines converge to form a single line. However, the pressure drop from the cooling ring to the point of common pressure would vary from line to line. The pressure drop can be calculated with Eq. (13). The line length would vary from almost zero to about $3 \mathrm{~m}$. The power varies from $740 \mathrm{~W}$ at the largest rings to about 200 for the smallest rings. All of these rings must be maintained within $0.25^{\circ} \mathrm{C}$ of one another, which limits the pressure drop and sets the secondary vapor line diameter.

Consider butane as the working fluid as an example to illustrate the steps required to meet the $0.25^{\circ} \mathrm{C}$ temperature gradient design constraint. With a back pressure corresponding to $0^{\circ} \mathrm{C}$, the stagnation pressure in any ring can exceed this back pressure by $1200 \mathrm{~Pa}$, with the equilibrium vapor pressure change corresponding to $0.25^{\circ} \mathrm{C} \mathrm{T}$. It would be prudent to stay well below $1200 \mathrm{~Pa}$ if possible. As shown in Fig. 3-38, small changes in diameter significantly affect the pressure drop. The pressure drop could be held to about $300 \mathrm{~Pa}$, with a $1.0-\mathrm{cm}$ line for the large diameter rings that are located $3 \mathrm{~m}$ from the point of common pressure. The vapor velocity in this line would be $6.4 \mathrm{~m} / \mathrm{s}$. Because the pressure drop depends upon the power squared, a 200-W ring located $3 \mathrm{~m}$ from the point of common pressure would have a pressure drop of only $11 \mathrm{~Pa}$ through 


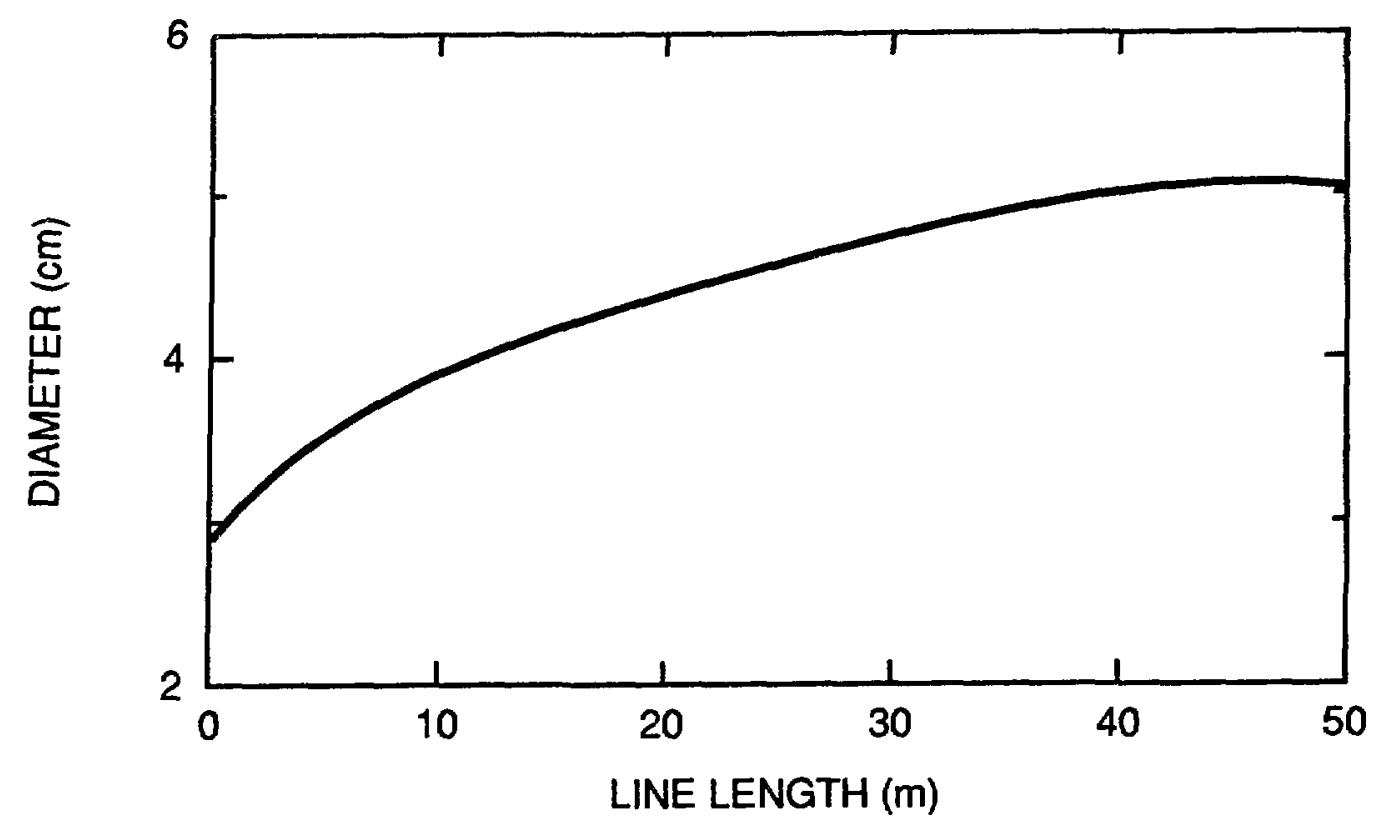

Figure 3-36. Relationship between vapor line diameter and length for a system that allows for a $1^{\circ} \mathrm{C}$ vapor temperature drop (4800-Pa pressure drop) along its length for a $40 \mathrm{~kW}$ system.

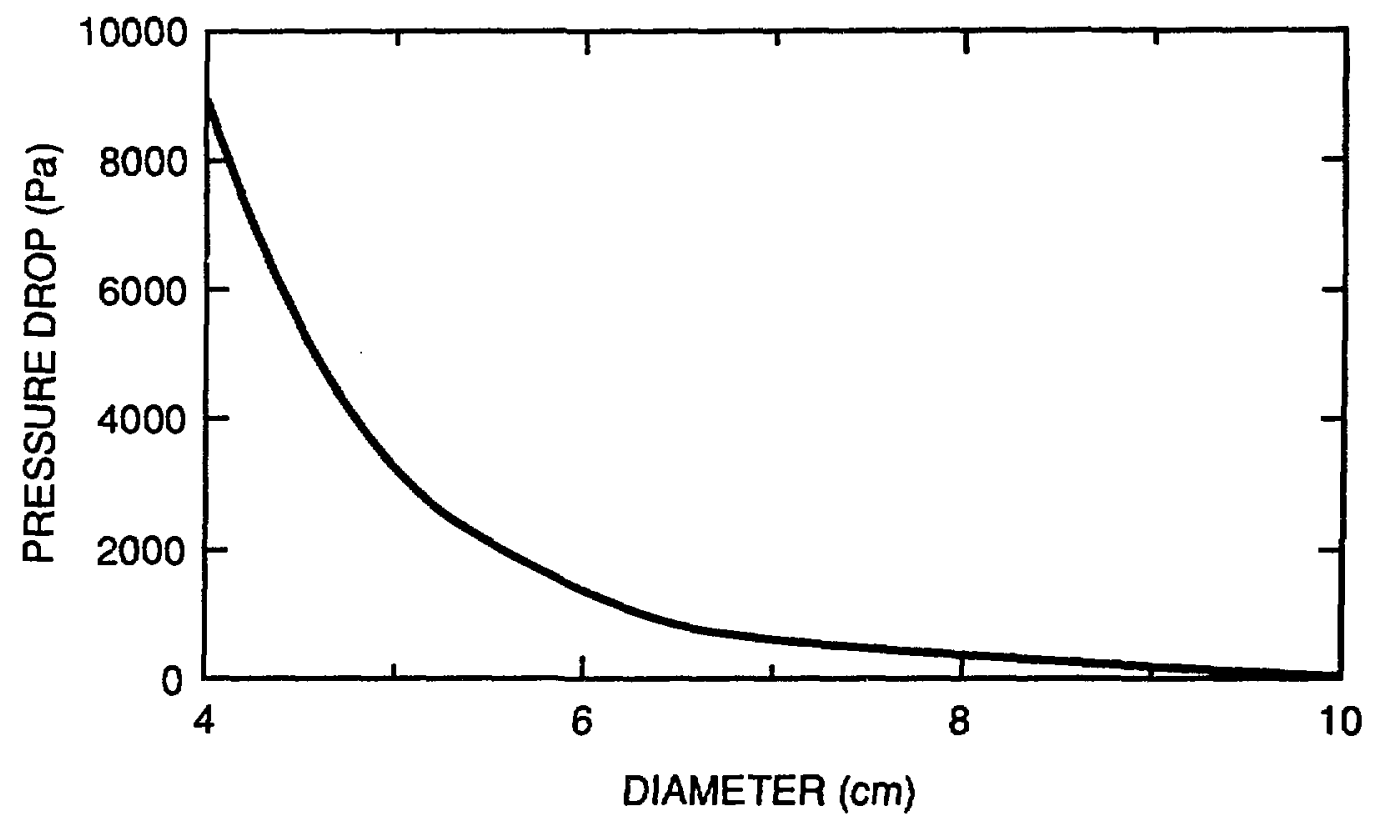

Figure 3-37. Pressure drop as a function of line diameter for a $25-\mathrm{m}$-long vapor return line for a 40-kW system. 


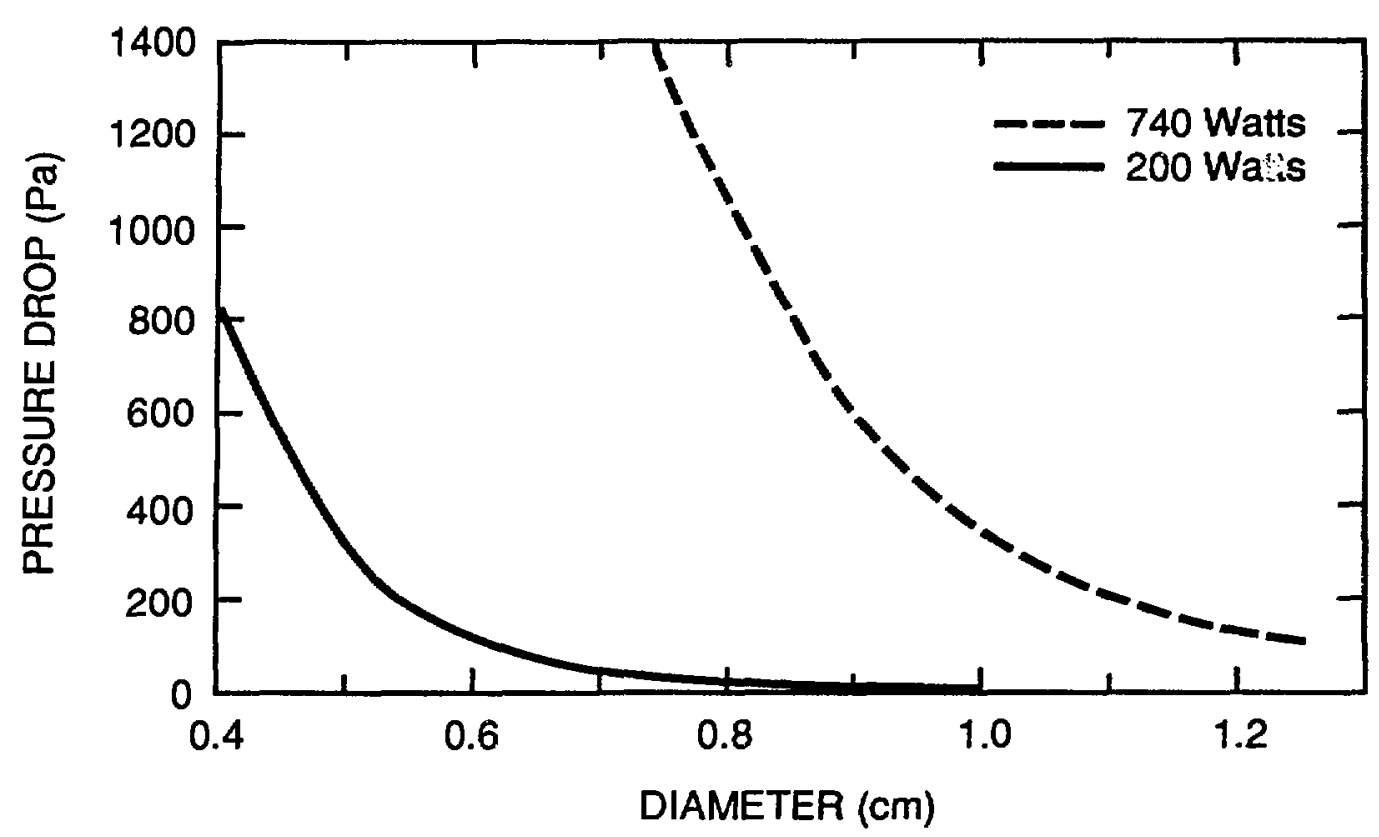

Figure 3-38. Pressure drop as a function of diameter for a large diameter $(740 \mathrm{~W})$ and a small diameter $(200 \mathrm{~W})$ cooling ring assuming a 3-m line length.

the same $1.0-\mathrm{cm}$ line. This line size could be reduced to $0.5 \mathrm{~cm}$ for the same $300-P a$ pressure drop. Also, for the cooling rings that are physically close to the point of common pressure, the pressure drop decreases linearly with distance. Distance ratios can be as high as 30 to 1 .

The baseline approach uses $1.0-\mathrm{cm}$-diam lines everywhere and accepts a temperature difference of less than $0.1^{\circ} \mathrm{C}$ from ring to ring.

This discussion ignores the vapor pressure drop in the cooling ring from the point of origin to the secondary vapor line. The cooling ring cross-sectional area is about $3 \mathrm{~cm}^{2}$ and the mean path length is one-quarter of the ring circumference. Consequently, it is not unreasonable to neglect this contribution at this time.

\subsubsection{Startup, Thermal Control, and Shutdown}

System procedures for startup and shutdown of the detector array are discussed in the sections below. Also considered are the control mechanisms for maintaining the detector at its precise operating temperature.

3.4.5.1 Startup. The baseline cooling system design assumes that the containment vessel is designed for a $1 \mathrm{~atm}$ differential pressure between the outside of the containment vessel and its interior. Cold nitrogen is assumed to be available for the initial system cooldown. Temperature and pressure sensors are located at appropriate parts of the array, and adequate vapor and liquid flow controls for transient responses and sufficiently sensitive hydrocarbon leak detectors are assumed to exist. The liquid level in the condenser is controlled by the flow of liquid in and out of the accumulator, and the liquid flow is controlled by the expansion and contraction of a gas bladder located inside the accumulator. A system schematic showing the external vapor and liquid flow loop is shown in Fig. 3-39. The detector array and the condenser are initially filled with air at room temperature and pressure. Both the vapor and the liquid return lines between the condenser and the primary containment vessel are initially open.

The condenser and the primary containment vessel and its pressure seal are evacuated to less than $10^{-6}$ torr for 10 hours to eliminate air, water vapor, and other volatiles from the detector 


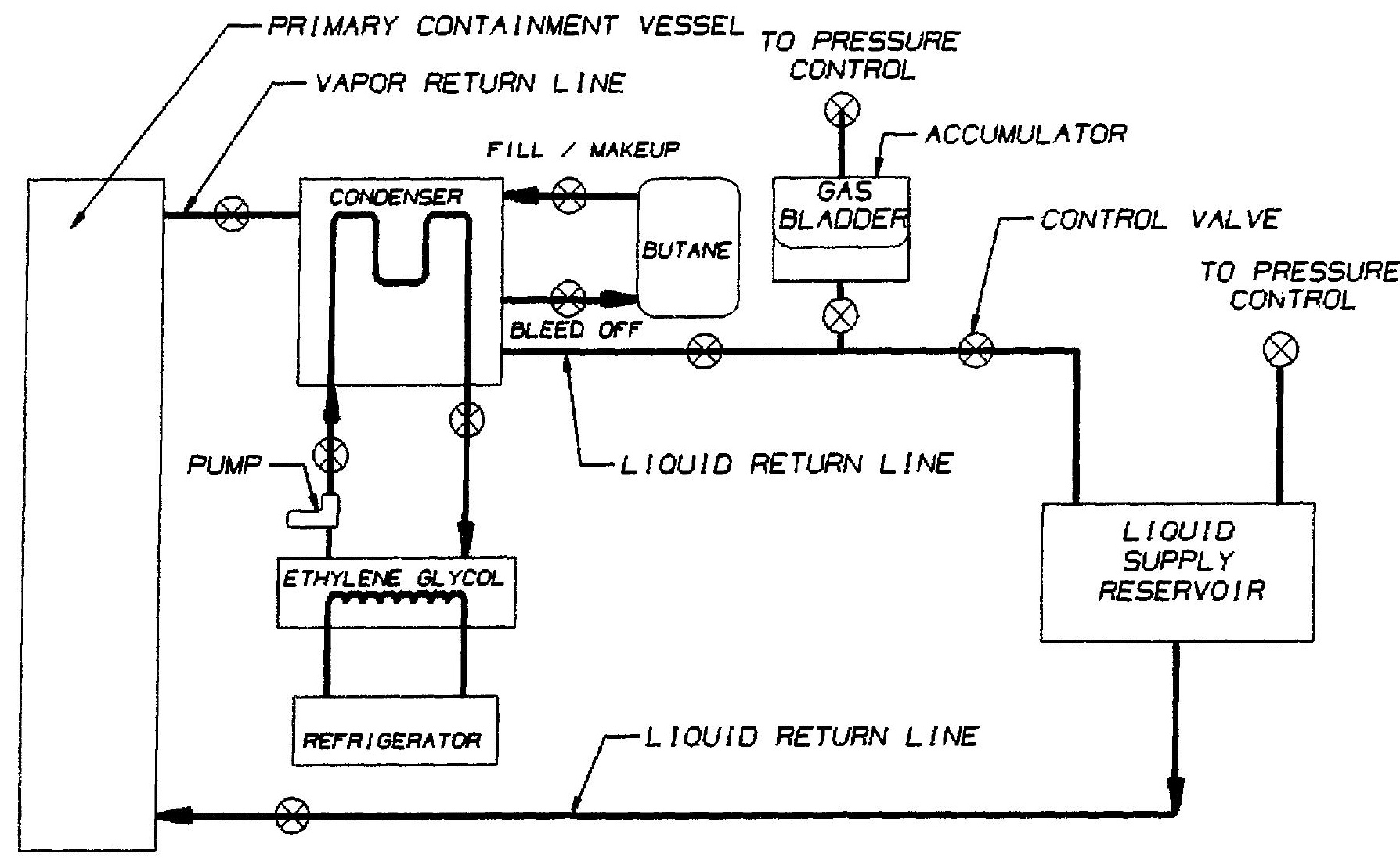

Figure 3-39. External fluid loop schematic.

array. Then they are backfilled with $\mathrm{N}_{2}$. Starting at room temperature, with the electronics off, dry nitrogen is circulated through the primary containment vessel and its seal and through the condenser. The cooling rate from room temperature to $0^{\circ} \mathrm{C}$ is controlled by varying the nitrogen flow rate and the nitrogen entrance temperature into the vessels and condenser. This transition should be gradual to reduce the thermal contraction rate. The nitrogen flow should also be controlled to avoid any structural damage to the detector array. When the system is cold soaked, the primary containment vessel and the condenser are evacuated to less than $10^{-4}$ torr pressure using a roughing pump. While the primary containment and the condenser are being evacuated, cold nitrogen continues to flow through the primary containment vessel seal as it does throughout the startup, operation, and shutdown of the detector array. The gas flow during the initial evacuation of the primary containment permits the vacuum system to detect any leaks between the primary containment vessel and its pressure seal. After the evacuation of the primary containment vessel is completed the vapor and liquid return lines are closed.

A water/ethylene glycol mixture that has been refrigerated to $0^{\circ} \mathrm{C}$ is then introduced into the tube side of the shell and into the tube condenser. When the condenser tubes are cooled to equilibrium, a valve supplying room-temperature butane is opened into the condenser. The butane mixture condenses on the condenser tubes, and the condensate collects in a pool at the bottom of the condenser. The butane is allowed to flow into the condenser until the liquid level is sufficient to charge the primary line, the secondary lines, the wick, and the condenser to the desired operating level. The liquid return line connecting the condenser to the primary containment vessel is then opened, and butane flows into the accumulator, liquid supply reservoir, and detector array. The butane flow into the array is monitored and controlled to prevent flooding of the primary containment by any excess butane that may have been supplied to the condenser. When sufficient 
liquid flows into the detector array to fill the lines and saturate the wick, the liquid return valve is shut downstream of the accumulator. The liquid level in the condenser is coarsely adjusted so that once the electronics are started, the condenser area is sufficient to keep the system at $0^{\circ} \mathrm{C}$. This intitial adjustment will be inade based on the experimentally determined heat transfer capabilities of the condenser. The vapor return valve is then opened and the electronics are started at a reduced load.

The startup dynamics of heat pipe systems are difficult to predict anaiytically. The optimal startup power versus time profile will be experimentally determined during the prototype test. When vapor is flowing into the condenser, the vapor space pressure will begin to rise above the operating point. As soon as the condenser pressure rises measurably above the operating point the liquid return line is reopened. The temperature of the ethylene glycol-water mixture flowing through the condenser tubes is lowered from $0^{\circ} \mathrm{C}$ to $-10^{\circ} \mathrm{C}$ to accommodate the heat load. Gas flow in and out of the accumulator is used to control the effective condenser area, which fine tunes the overall system temperature to around the $0^{\circ} \mathrm{C}$ operating point. During operation the static pressure of the nitrogen in the primary containment vessel pressure seal is slightly above atmospheric pressure, and the butane pressure in the detector array is slightly above the nitrogen pressure in the seal.

3.4.5.2 Thermal Control System. If the detector stability tolerance is to be met, the system temperature must be maintained at the specified operating temperature to within a tolerance of $\pm 0.1^{\circ} \mathrm{C}$. This level of control requires a system feedback loop with which to respond to changes in system operating conditions. In other words, it is necessary to respond to changes in the heat load caused by changes in the electronics thermal load or by changes in thermal boundary conditions at the containment vessel or the liquid and vapor access lines. No bounds have been set on which changes will be made in the thermal heat dissipation or in the system thermal boundary conditions. Nonetheless, a computer model has been written that will establish the requirements for a control system to meet whatever system disturbances may occur.

The temperature control system consists of a variable surface area condenser, as seen in Fig. 3-39. The pressure of the detector containment vessel is monitored continuously. Pressure changes as small as 0.1 torr ( $13 \mathrm{~Pa}$ ), with an absolute pressure of the order of $1 \mathrm{~atm}$, can be detected with standard electronic pressure transducers. This signal is fed back to an amplifier. If the pressure is deviating from the set point, the pressure in the accumulator, which is partially filled with working fluid, can be changed to force liquid into or out of the condenser, change the heat transfer rate, and lower or raise the pressure and temperature of the detector array. Preliminary calculations from the computer model, using the shell-and-tube heat exchanger described above, show that the heating load can vary by $5 \%(2 \mathrm{~kW}$ for the $40-\mathrm{kW}$ system) without causing a system temperature excursion of $0.1^{\circ} \mathrm{C}$ with a maximum condenser fluid volume rate of change of $315 \mathrm{cc} / \mathrm{s}$.

As stated above, we are not yet sure of the magnitude of thermal excursions that might be encountered. Operating at $0^{\circ} \mathrm{C}$, with a room temperature of $24^{\circ} \mathrm{C}$, the thermal load from the surroundings will be only a few hundred watts by natural convection, with no insulation ofher than the vessel wall itself. The changes in this load will be insignificant under these conditions.

Small deviations in the temperature of the liquid returning to the detector array from the liquid supply reservoir will not significantly affect the system operating temperature because the sensible heat exchange for establishing thermal equilibrium with the vapor is small compared with the latent heat. The liquid supply reservoir can be cooled, with a separate chill loop, to within the system tolerance to minimize thermal excursions caused by liquid return temperature.

3.4.5.3 Shutdown. In a complete shutdown the system is allowed to return to room temperature without rupturing the containment vessel or creating an unsafe or hazardous situation.

A complete shutdown with butane purge will be required if it is necessary to access the detector array or to shut down the condenser cooling system. Such a shutdown might be needed to fix a leak in the detector or prior to a prolonged accelerator shutdown. The shutdown of the detector array cooling system is gradual to allow for a smooth transition from the operating 
temperature to room temperature. Shutdown is initiated with a ramping down of the electronics load, during which the liquid level in the condenser is raised to keep the operating temperature at the set point.

When the electronics are shut down, the liquid return valve is shut off just upstream of the accumulator. The vapor return valve remains open. The butane in the primary containment vessel is allowed to evaporate. The principal heat source for the evaporation is the heat leak from the external environment into the primary containment vessel. The electronics may also be allowed to run at a very reduced level to assist in the vaporization frocess. As the butane vapor slowly returns to the condenser, the liquid level therein gradually rises. The system operating pressure and temperature rise correspondingly. The temperature rise is slowed by controlling the liquid level in the condenser. The butane inventory in the accumulator, liquid return lines. and liquid supply reservoir flows by gravity into the detector array where it is vaporized. When the liquid butane inventory has evaporated from the detector array, only the butane vapor at the saturation pressure of the condenser remains. The vapor relurn valve is closed, and the remaining butane vapor is evacuated from the array by a forced flow of nitrogen through the containment vessel. The temperature of the dry nitrogen entering the containment vessel is controlled to match the current temperature of the detector array to minimize the thermal expansion rate. The butane'nitrogen mixture is vented through the vapor bypass valve to the outside of the detector building. The butane concentration in the nitrogen is kept low so that, when the volatile vapor is exposed to the atmosphere, it is below the lean limit. The entrance temperature of the dry nitrogen is slowly increased to permit a gradual and spatially uniform transition of the detector array from its postshutdown temperature to room temperature.

A partial or complete shutdown of the detector array electronics may accompany large changes in the system operating conditions without changing the temperature of the detector array. It is permissible to turn the detector heat loads off without purging the system of coolant if the condenser is functioning. The only constraint to this procedure is that the electronics must be ramped down in power so that the condenser can respond to the load change by increasing its liquid level to keep the system at the setpoint temperature. The condenser will remove residual heat loads from the surroundings and, via a temperature feedback control system, will maintain the setpoint temperature.

The partial shutdown procedure is as follows. The electronics load is ramped down to the desired level. The required power dissipation versus time profile will be dictated by the response time of the condenser to the load change. As the load is reduced, the liquid level in the condenser is increased by forcing liquid out of the ac cumulator. This reduces the surface area available for condensation of the working fluid and keeps the system temperature stable. The profile might be a gradual and continuous rampdown or it might be a series of small changes. The condenser response to load changes will be determined during the system experimental characterization. 


\section{CONCLUSIONS AND FY 1991 PROGRAM PLAN}

The 2-year mechanical research and development effort ending in FY 1991 will demonstrate the viability of a silicon-based elementary particle tracking device and identify a design, based upon proven concepts, for such a system. All known mechanical engineering issues will be addressed. Key issues, such as dimensional stability, cooling, and radiation length restrictions will be explored both by analysis (during FY 1990) and protolype testing (during FY 1991).

The field of material candidates for various structures has been narrowed significantly. However, much work remains to be accomplished in FY 1991. Some material development is needed to tailor discrete material properies, such as, stiffness, strength, and CTE, to meet the silicon tracking system design goals. Material development progress made in the NASP and SDl progranıs is being drawn upon to achieve silicon tracking system material-design objectives. These external endeavors will resolve many of the processing and fabrication issues: however, the radiation hardness, radiation length, and stability issues will still need to be addressed.

Compatibility of the silicon detector with hydrocarbon lluids and adhesives must be demonstrated in a radiation environment. During FY 1991, prototype silicon detectors will be tested after exposure to radiation and after the potential effects on leakage current and interstrip resistance are established.

Before prototype module tests can be conducted, a substantial experimental program that addresses all cooling system components must be completed. In the heat pipe experimental development phase we will study system thennal stability for a complete, but scaled-down, cooling loop on a partial system. Such a system will include one cooling ring with attached wick and artery. connecting liquid and vapor lines, condenser, accumulator, liquid supply reservoir, and simulated heat sources. The experiment will be fully instrumented for direct pressure and temperature measurements. A simplified control system will be implemented to respond to changes in operating conditions without changing temperature. The prototype cooling ring emerging from these tests will be used in the full silicon tracking system module test progran.

The greatest immediate uncertainty is the wick structure. The wick structure will incorporate a circumferential anery around the cooling ring. The antery provides a low-impedance flow path in the circumferential plane, significantly reducing the capillary pumping requirement. The number of connections between secondary supply lines and the cooling ring arteries that will be required will affect wick thickness and, consequently, design trade-offs that can not be fully quantitied at this time. The fabrication technique, the resulting wick hydrological propenies, artery design, and interface with the liq̨uid distribution system will be emphasized in FY 1991.

Designs have been completed for most of the mechanical features, with the most notable exception being the kinematic supponts that stabilize the silicon sandwich structures. Sufficient interface detail has been established to permit a meaningful component design study. This is one of several remaining design issues that will be addressed in FY 1991. Further attention will also be devoted to the electrical cabling and data transmission lines because they have a direct bearing on the mechanical structure and system layout.

The FY 1991 prototype tests will be designed to address critical issues such as

- material and component radiation and chemical exposure compatibility:

- materials characteristics and stability:

- selectively enhanced polymeric and metal matrix composite engineering properties. such as CTE and elastic modulus:

- cooling ring construction and wick development and their optinization:

- silicon module stability under electrical load simulation: and

- kinematic mounting and overall structural constraint.

Figure 4-1 shows the estimated schedule for the FY 1991 activities. 


\section{Task}

Prototype Module

Design/Analysis

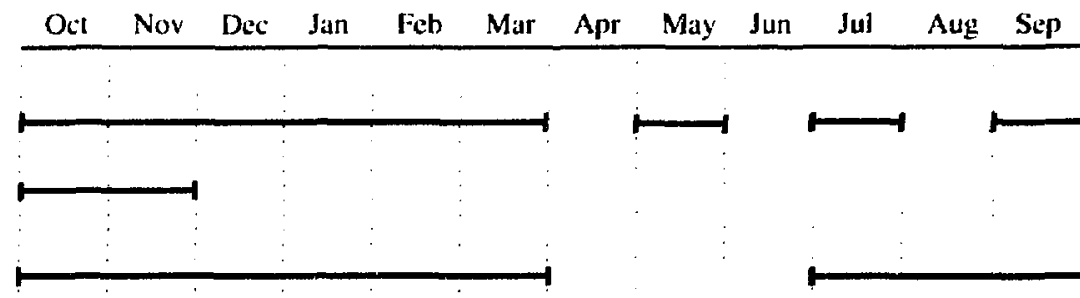

System analysis

Module protoype drawings

Optical instrument alignment verifification study

Space frame design drawings

\section{Fabrication}

Silicon wafers

Prototype cooling rings

Optical instrumentation

Protolype module

Central region space frame

\section{Testing}

Wick development

Cooling ring/ wick integration

Material stability and component radiation

Module stability

Test evaluation and report preparation

\section{Project Support}

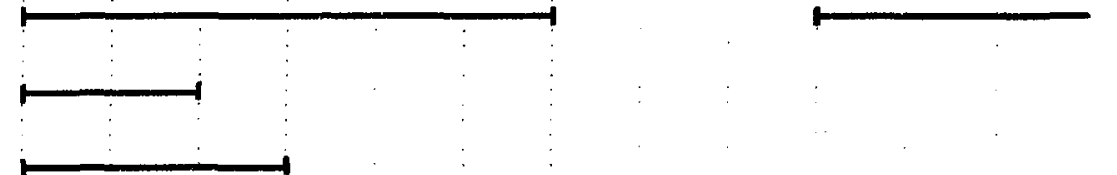

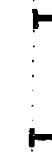
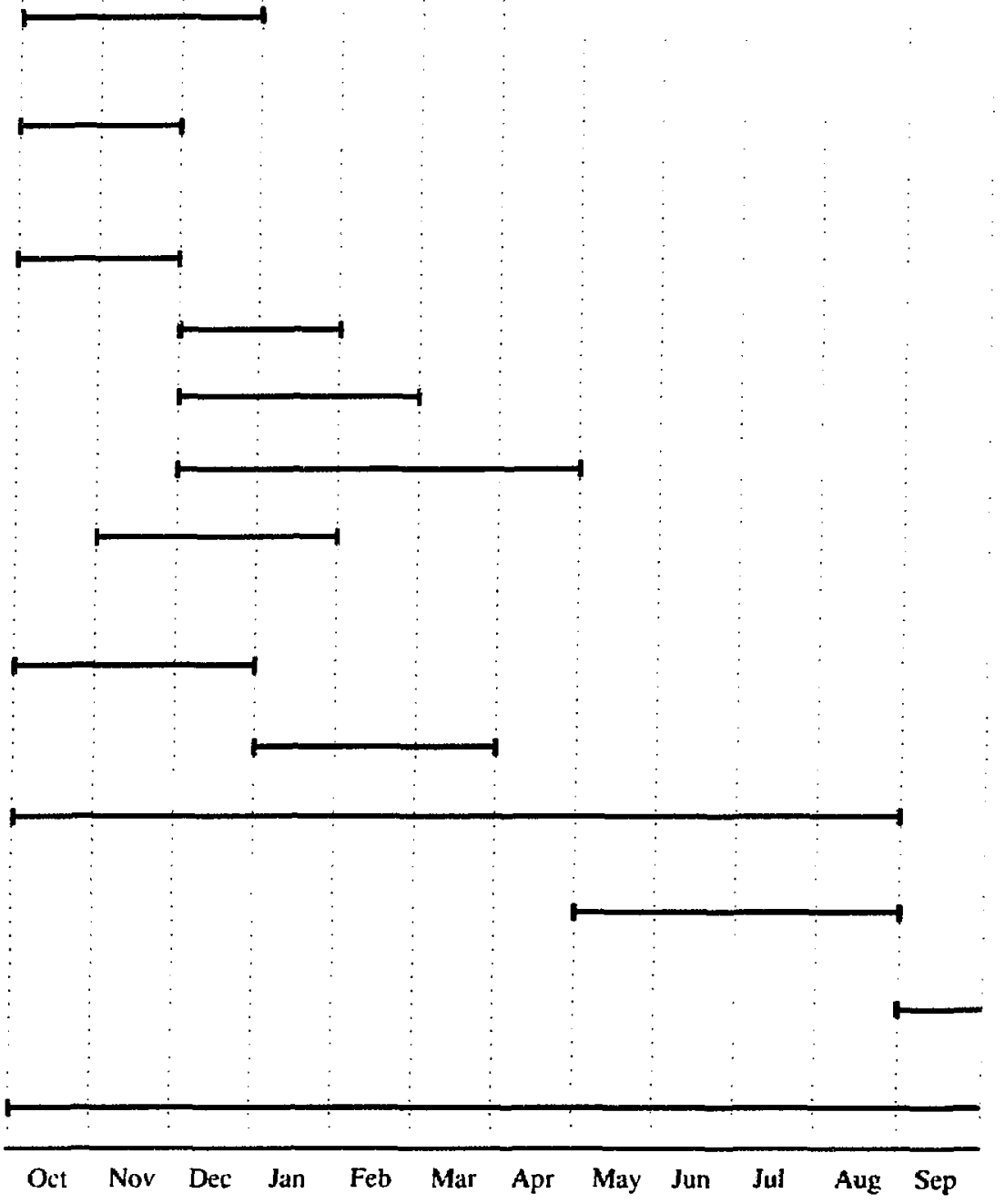

Figure 4-1. Estimated mechanical engineering program schedule for FY 1991. 


\section{Acknowledgments}

The authors wish to acknowledge the invaluable contributions of the following individuals to this research and development effort.

Jack Hanlon (MEE-12) provided an optical scheme for measuring detector shape and deformation, while Cunis Baker (MEE-12) contributed space frame finite element analyses. Geoffrey Dranstield (MEE-12) prepared numerous engineering drawings for the project, thereby adding clarity and color to the presentation. Robert Reid (MEE-13) and Keith Woloshun (MEE-13) contributed heat pipe cooling technology concepts, analyses, and system studies. Jeffrey Bradley (MEE-11) fabricated edge-bonded, silicon sandwich assemblies for display and testing. Program management was provided by Gary Sanders (ADR).

Abraham Seiden and Hartmuth Sadrozinski of the University of California at Santa Cruz, Institute for Particle Physics, provided overall guidance and direction for the work performed at Los Alamos. Special recognition is due Michal Turala of the Institute of Nuclear Physics, Krakow, Poland for his concept of edge-bonded silicon microstrip detectors as structural members.

Many thanks are due Lilly Shelley (MEE-DO) for her technical editing of this manuscript and to Janet Holmes and Chuckmool Calef (IS-5) for their composition and typesetting services. Graphics were skillfully executed by Kemp Beebe, Eugene McWethy, and Florence Fujita (MEEDO). 


\section{References}

1. A. Seiden, "Silicon Tracker for the SSC," in Proceedings of the International Workshop on Solenoidal Detectors for the SSC, Tsukuba, Japan (1990), p. 330.

2. M. Turala, "Tracking with Silicon Detectors," in Procecdings of she XXIV International Conference on High Energy Physics, Berlin, West Germany (1988), p. 1240.

3. W. O. Miller, T. C. Thompson, M. T. Gamble et al., "Mechanical Engineering and Design of Silicon Tracking Devices," in Proceedings of the Symposium on Detector Research and Developmen for the Superonducting Super Collider, Los Alamos National Laboratory report, LA-UR-90-4167 (1990).

4. C. Adolphsen, G. Gratta, L. Labarga et al., "An alignment method for the Mark II Silicon Strip Vertex Detector using an X-ray Beam,"Nuclear Instruments and Methods in Physics Research, A228 (1990), 257.

5. A. Litke, C. Adolphsen et al.. "A Silicon Strip Detector for the MARK II Experiment at the SLAC Linear Collider," Nuclear Instruments and Merhods in Physics Research, A265 (1988),93.

6. C. Adolphsen, G. Granta, A. Litke et al., "Status of the Silicon Strip Detector for the MARK II Experiment at the SLC." SLAC-PUB-4452 (1987).

7. A. E. Ennos and M. S. Virdee, Optical Engineering, $21: 3$ (1980), 478-482.

8. Y. S. Tsai, "Pair Production and Bremsstrahlung of Charged Leptons," Review of Modern Physics, 46:4 (1974), 828.

9. Particle Data Group, "Review of Particle Properties, Particle Detectors, Absorbers, and Ranges," Revien' of Modern Physics, 56:2 (1984).

10. R. M. Jones, Mechanics of Composite Materials (Hemisphere Publishing Corporation), 1975 , p. 196.

11. H. J. Ziock, C. Milner, W. F. Sommer et al., "Tests of the Radiation Hardness of VLSI Integrated Circuits and Silicon Strip Detectors for the SSC Under Neutron, Proton, and Gamma Irradiation," in Proceedings of the IEEE Nuclear Symposium, Los Alamos National Laboratory report, LA-UR-90-2050 (1990). 